Portland State University

PDXScholar

\title{
Metaphoric extension as a basis for vocabulary teaching in English as a second language
}

Dennis L. Bergmann

Portland State University

Follow this and additional works at: https://pdxscholar.library.pdx.edu/open_access_etds

Part of the Applied Linguistics Commons, and the Bilingual, Multilingual, and Multicultural Education Commons

Let us know how access to this document benefits you.

\section{Recommended Citation}

Bergmann, Dennis L., "Metaphoric extension as a basis for vocabulary teaching in English as a second language" (1991). Dissertations and Theses. Paper 4209.

https://doi.org/10.15760/etd.6091

This Thesis is brought to you for free and open access. It has been accepted for inclusion in Dissertations and Theses by an authorized administrator of PDXScholar. Please contact us if we can make this document more accessible: pdxscholar@pdx.edu. 
AN ABSTRACT OF THE THESIS OF Dennis L. Bergmann for the Master of Arts in Teaching English to Speakers of Other Languages presented November 8, 1991.

Title: Metaphoric Extension as a Basis for Vocabulary Teaching in English as a Second Language.

APPROVED BY THE MEMBERS OF THE THESIS COMMITTEE:

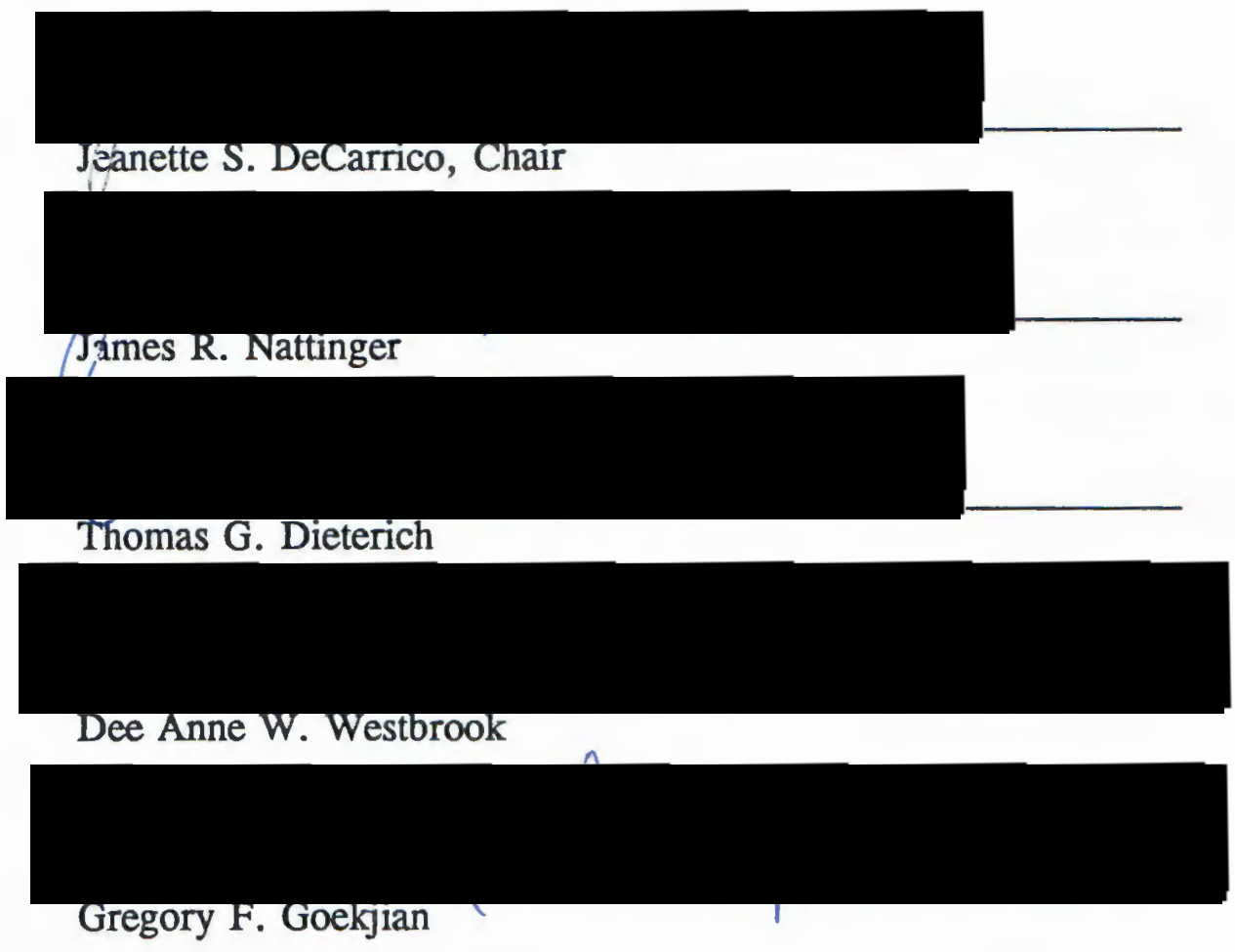

This thesis addresses the problem of teaching and learning vocabulary in English as a Second Language (ESL), and proposes that a vocabulary based on the process of metaphoric extension could be taught directly. Despite the fact that an inadequate vocabulary is one of the main obstacles for intermediate-level ESL 
students, both ESL teachers and applied linguists have emphasized other aspects of English more than the study of vocabulary teaching and learning. Consequently, ESL students have few strategies for learning vocabulary other than reliance on the dictionary, and the predominant strategy for teachers is to present words rather unsystematically in the reading curriculum. In an effort to overcome this inadequacy, current vocabulary research is identifying central patterns of word usage, including lexical phrases and other 'chunks', core words, and semantic fields. One central pattern of usage that has not yet been researched is metaphoric extension. Since the so-called 'dead' metaphors produced by that process are lexical items expressing either literal or conventional meaning, they are also candidates for direct teaching. In teaching such a vocabulary, it is necessary to have a clear understanding of what a metaphor is, and the standard definitions do not supply sufficient explanations. Therefore, some of the dominant theories about metaphor are examined in order to extrapolate more precise concepts. This analysis leads to the conclusion that it is the multi-faceted duality of sense in a metaphor that distinguishes it from any other kind of expression, which cannot be fully appreciated unless both the pragmatic and the semantic aspects of metaphor are taken into account. Essentially, metaphor is the use of an expression to refer to something in a distinctly different conceptual, phenomenal, or experiential domain in order to imply that two things may be seen as if they were similar when in fact they are substantially different. The speaker and hearer tacitly agree to see this similarity, all the while holding in mind the fact that there is no actual similarity. Consequently, the expression used metaphorically is 
given not only two referents, but also a duality of sense: its literal and conventional sense and the sense communicated by the metaphorical comparison; in Kittay's (1987) terms, a 'first-order' and a 'second-order' meaning.

It is proposed that a novel metaphor becomes established in the lexicon as a dead metaphor because we disregard the first-order meaning for pragmatic reasons; essentially, to exploit the communicative efficacy of the second-order meaning. Some metaphors are genuinely 'dead' because they express a literal and conventional sense. This is a new first-order meaning, or a new sense, established by metaphoric extension; therefore, we necessarily disregard the original first-order meaning. Others could be regarded as 'stock' metaphors because it is possible to use them to express metaphorical meaning even though they are normally used to express conventional or even literal meaning; i.e., there are degrees to which we disregard the first-order meaning, depending on communicative goals. Therefore, metaphoric extension is a systematic process that sometimes establishes new senses, which can be represented by diagrams. However, it is important to avoid erroneously attributing semantic change to metaphoric extension; therefore, other processes of semantic change are also examined, particularly literal generalization.

Since the development, selection, and organization of a vocabulary based on metaphoric extension involves projects that lie beyond the scope of this paper, the thesis concludes with some brief guidelines for the ESL teacher. If the ideas herein are found to have merit, they should serve as a basis for developing both teaching strategies and learning strategies. 


\title{
METAPHORIC EXTENSION AS A BASIS FOR
}

\section{VOCABULARY TEACHING IN ENGLISH AS A SECOND LANGUAGE}

\author{
by
}

DENNIS L. BERGMANN

A thesis submitted in partial fulfillment of the requirements for the degree of

MASTER OF ARTS

in

TEACHING ENGLISH TO SPEAKERS OF OTHER LANGUAGES

Portland State University

1991 
TO THE OFFICE OF GRADUATE STUDIES:

The members of the Committee approve the thesis of Dennis L. Bergmann presented November 8, 1991.

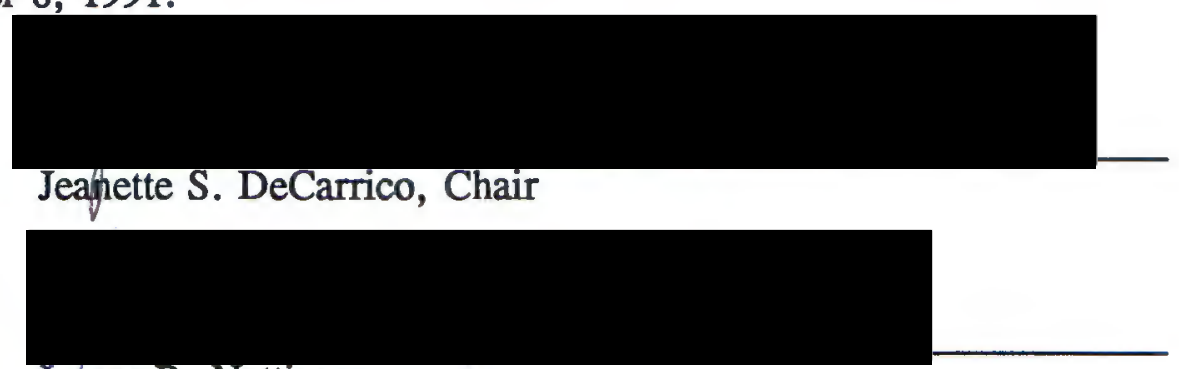

tames R. Nattinger

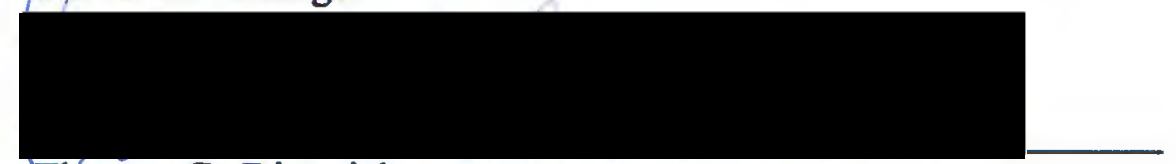

Fromas G. Dieterich

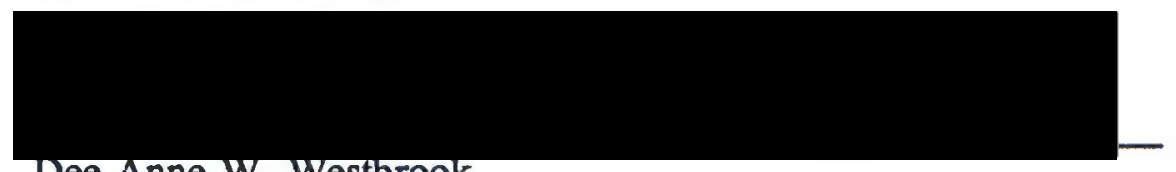

Dee Anne W. Westbrook

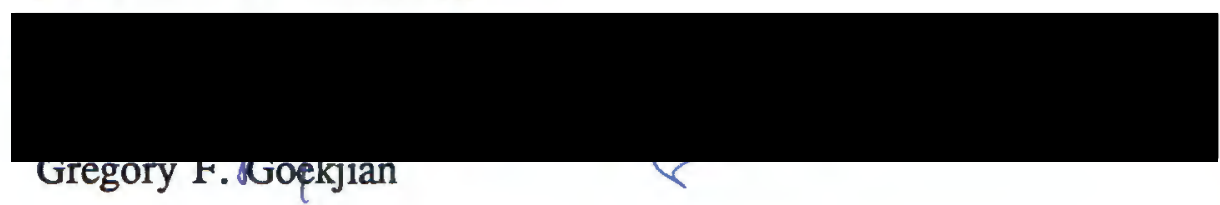

APPROVED:

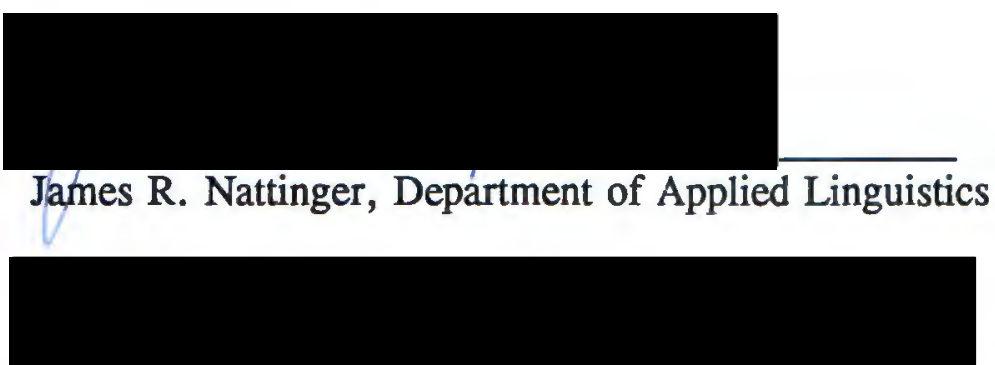

C. William Savery, Vice Provost for Graduate Studies and Research 
TABLE OF CONTENTS

PAGE

LIST OF FIGURES $\ldots \ldots \ldots \ldots \ldots \ldots \ldots \ldots \ldots \ldots$

\section{CHAPTER}

I THE PROBLEM OF VOCABULARY TEACHING IN ESL . . . . 1

Identifying the Problem $\ldots \ldots \ldots \ldots \ldots$

The Importance of Vocabulary

The Benign Neglect of Vocabulary

The Complexity of the Problem

Some Recent Work in Vocabulary Study . . . . . . . . . 11

Central Patterns of Usage

Semantic Fields

Needed: Strategies for Vocabulary Teaching and

Learning

Dead Metaphors as Vocabulary Items $\ldots \ldots \ldots \ldots 21$

Conclusion $\ldots \ldots \ldots \ldots \ldots \ldots \ldots \ldots \ldots \ldots$. . . . . . . . . .

Notes . . . . . . . . . . . . . . . . . . . . 29

II WANTED DEAD OR ALIVE: A PRECISE DEFINITION

OF METAPHOR . . . . . . . . . . . . . 32

Aristotle's Discussion of Metaphor $\ldots \ldots \ldots \ldots \ldots$

Similarity in the Traditional Framework . . . . . . . . 39

Metaphor as Substitution

Metaphor as Comparison

Paraphrasability: A Problem for Comparison Views 
Similarity in the Cognitive Framework . . . . . . . 51 Three Interaction Views

Lakoff and Johnson: Underlying Metaphors

Ortony: The Importance of Pragmatics

Kittay's Perspectival Theory

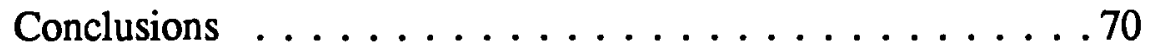

Notes $\ldots \ldots \ldots \ldots \ldots \ldots \ldots \ldots$

III DEAD METAPHORS AND METAPHORIC EXTENSION $\ldots \ldots 81$

From Novel to Dead . . . . . . . . . . . . 83

The Dilemma of 'Dead Metaphor'

Awareness and the 'Death' of a Metaphor

An Alternative: First-order/Second-order

Meaning

Patterns of Metaphoric Extension

Metaphoric Extension and Semantic Change . . . . . . 104

Conclusions $\ldots \ldots \ldots \ldots \ldots \ldots \ldots \ldots \ldots$

A Metaphor for Metaphoric Extension

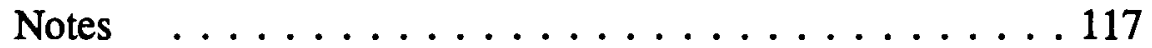

IV Implications for Teaching $\ldots \ldots \ldots \ldots \ldots \ldots \ldots \ldots$

Explaining Metaphor in the Classroom . . . . . . . . . 119

Selecting and Organizing the Vocabulary $\ldots \ldots \ldots 123$

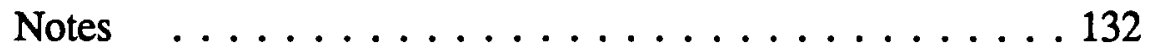

WORKS CITED $\ldots \ldots \ldots \ldots \ldots \ldots$ 


\section{LIST OF FIGURES}

1. Domains and Semantic Fields for The Man is a Wolf, According to Kittay's theory $\ldots \ldots \ldots \ldots \ldots$

2. Basic Pattern of Metaphoric Extension When New First-order Meaning is Established $\ldots \ldots \ldots \ldots . \ldots 95$

3. Original First-order Meaning (F-O.1) Either Continues or is

Replaced by New First-order Meaning (F-O.2) . . . . . . . 97

4. Different Features of Meaning Lead to Different Metaphors . . . . 98

5. A New Sense Established by Metaphoric Extension Used

Metaphorically, Leading to Another New Sense . . . . . 100

6. A Possible Pattern for the Broadening of Meaning in

Metaphoric Extension . . . . . . . . . . . . . 102

7. Mill: An example of literal generalization . . . . . . . . . 108 


\section{CHAPTER I}

\section{THE PROBLEM OF VOCABULARY TEACHING IN ESL}

"I was parlous blithe to receive your letter." The Chinese-Cambodian immigrant who wrote this sentence asked me why no one had understood what it meant and then showed me where parlous and blithe were listed in his ChineseEnglish dictionary. I improvised a lesson on appropriateness of expression, knowing the real problem ran deeper than that. This young man was among the handful of intermediate-level students of English as a Second Language (ESL) who had told me that their main problem was vocabulary, and that they were frustrated about not knowing how to learn more words. During the three terms that I taught them, I believed I had taken advantage of every opportunity to teach them new words and expressions, always striving to tie in related terms, derived forms, fixed phrases, and idioms. However, I knew the underlying problem was that vocabulary is taught only incidentally to other ESL topics. ESL teachers lack sufficient strategies for teaching vocabulary, and consequently ESL students have few strategies for learning vocabulary other than reliance on the dictionary.

A growing number of linguists and teachers are arguing that neither ESL teaching nor ESL research has given enough attention to vocabulary even though hardly anyone would deny that it is the most salient aspect of language. Linguistic theory that concentrates on syntax is often blamed for this benign neglect, but 
teaching and learning vocabulary is a complex problem compounded by the limitations of the classroom and the range of student needs. The basic questions have always been what words to teach and how to organize these words, but the more recent goal of helping students achieve communicative competence has influenced the recognition of another dimension: patterns of word usage. A current trend in vocabulary research is to describe central patterns of word usage, and the emerging methods of organizing vocabulary according to these patterns should be useful in devising strategies for both teaching and learning.

This paper proposes that one of the central patterns of word usage is metaphoric extension, which in its most prolific effect yields the open class of socalled 'dead' metaphors. This paper further proposes that we should directly teach not only the various senses of 'dead' metaphors, but also the process of metaphoric extension itself. As a strategy for teaching, it allows many related senses and words to be taught simultaneously. In turn, once the ESL students understand the process, they may be able to use it as a strategy for independent vocabulary learning.

\section{IDENTIFYING THE PROBLEM}

\section{The Importance of Vocabulary}

The importance of vocabulary in language acquisition cannot be denied. As Laufer (1986) points out, "No language acquisition, whether first, second, or foreign; child or adult, can take place without the acquisition of lexis" (p. 69). Many ESL learners who have passed through the initial stages of acquisition report that 
vocabulary learning is their greatest single problem (Crow and Quigley 1985; Meara 1980), and a few studies suggest that intermediate and advanced students may commit more lexical errors than syntactical errors (Laufer 1986; McKay 1980). Wallace (1982) describes how lexical errors typically involve the inability to retrieve vocabulary that has been taught or learned, not learning the kind of vocabulary needed for the student's purposes, and using words and expressions inappropriately.

The impairment of vocabulary knowledge and skills becomes critical in the more advanced stages of acquisition, for it is here that the student not only confronts text that is no longer simplified, but also needs to learn the standards of written English. By then the student is expected to be able to speak and write relatively fluently, and to perform more like a "good reader [who] has a sufficient command over the language so that words are recognized automatically--sight vocabulary--or recognized in context" (Nation and Coady 1988, p. 102). Teaching students how to predict and verify word meaning in context is a currently favored method of teaching reading and (incidentally) vocabulary, but with an inadequate vocabulary, "they cannot interpret surrounding context" (Nation and Coady 1988, p. 107). For the ESL student, then, an inadequate vocabulary is "one of the main obstacles to progress" (Nation 1982, p 20).

\section{The Benign Neglect of Vocabulary}

Despite the importance of vocabulary for the student, both ESL teachers and applied linguists have emphasized other aspects of English more than the study of vocabulary teaching and learning (Carter and McCarthy 1988; Richards 1976). ${ }^{1}$ 
Laufer (1986) points to hundreds of studies as well as theoretical and methodological papers, including some that promote communicative competence, which say almost nothing about vocabulary development, "as if vocabulary was not part of second language acquisition" (p. 69). In the classroom and in textbooks as well, primacy has been given to grammar (Sinclair and Renouf 1988; Summers 1988). The conventional approach is to limit vocabulary "to what is pedagogically necessary" (Wilkins 1976, p. 7), and vocabulary is often used "as a vehicle for the illustration of grammatical topics rather than a set of counters with a communicative value in themselves" (Twaddell 1980, p. 440). Typically, it is expected that vocabulary expansion will be fulfilled by the reading program, yet even here most vocabulary is taught indirectly (Richards 1976). In general, despite the recent shift away from the formal aspects of language and toward the interactively communicative use of language in naturalistic contexts, "relatively little attention has been given to vocabulary use in particular, as compared to language use in general" (Cowie 1988, p. 126).

This secondary role for vocabulary is partly attributable to foreign language teaching methods influenced by "trends in linguistic theory" (Richards 1976, p. 77). The trends in both theory and methodology in this century can be traced to Saussure's introduction, in the late nineteenth century, of the concepts langue and parole.

Langue represents the abstract system of structural relationships inherent in language...Parole, on the other hand, represents the individual act of speaking, which is never performed exactly the same way twice. (Newmeyer 1986, p. 3) 
This distinction provided a rationale for replacing the grammar-translation (or classical) method, which emphasized langue by analyzing grammar, learning and practicing grammatical rules, translating classical texts into the native language, and memorizing lists of isolated, mostly literary words. With parole as the main goal of foreign language teaching, the new 'direct' method taught vocabulary as part of a controlled progression in developing oral communication skills. However, although the direct method has survived in some private schools (e.g., the Berlitz method) and was revived in the '40s and '50s as the audiolingual method, it was difficult to implement in the public classroom, and most foreign language curricula returned to the grammar-translation method by the 1920 s. In the meantime, at least in the U.S., theoretical linguistics became dominated by followers of Bloomfield who concentrated on the empirical description of language, and the resulting 'structural linguistics' treated words primarily as components of structure rather than as communicative units. (For more complete discussions, see Brown 1987; Carter and McCarthy 1988; Newmeyer 1986; and Richards 1974.)

In reaction to both structural linguistics and the grammar-translation method, the 'vocabulary control movement' of the 1930s attempted to achieve communicative adequacy in students of English as a foreign language by teaching "a basic minimum vocabulary for the learning of English" (Carter and McCarthy 1988, p. 2). Initiated by C. K. Ogden and I. A. Richards, the aim of the movement was to simplify the teaching of English by using a 'basic English word list' of 850 words and reducing the rules of usage. In the 1950 s, this list was expanded to 2,000 words with the 
publication of Michael West's General Service List, and became useful in the audiolingual method. (See also Ogden 1934; Read 1988; I. A. Richards 1943; J. Richards 1974.)

Based on the theories of structural linguistics and behaviorist psychology, and still influential today, the audiolingual method postpones vocabulary expansion until the student has achieved mastery of the structure (Brown 1987; McKay 1980). Originally known as the Army Specialized Training Program or the 'Army method', audiolingualism grew out of the need, during and immediately after World War II, to teach basic fluency in a foreign language quickly, which obviated the grammartranslation method with its emphasis on reading and its predominantly literary vocabulary. Because the students were expected to expand their vocabulary at some later stage, usually while living in the foreign country, structure was more important than vocabulary. Consequently, for both teaching foreign languages to English speakers and teaching English as a foreign language, "the period 1945-1970 was a limbo for vocabulary as an aspect of language teaching in its own right" (Carter and McCarthy 1988, p. 41).

However, the secondary role of vocabulary in ESL teaching has extended beyond 1970, partly as a result of attempts to translate Chomky's generative model of language into teaching methodology. Two of Chomsky's ideas have had a broad appeal for teaching methodology. The first is that language is infinite and recursive: we are capable of producing an infinite set of possible sentences, and in any given sentence, an infinite number of embedded sentences is possible. Second, language is 
creative and independent: we can understand and produce novel utterances independently of any specific stimulus. According to the generative model, language has these formal properties because it is a rule-governed, structure-dependent system. These concepts suggest that the child's acquisition of language is not a product of stimulus-response mechanisms, but rather it is a process of forming hypotheses about the system and then testing, revising, or abandoning these hypotheses. Some teaching methodologists have reasoned that if second-language acquisition in any way recapitulates first-language acquisition, then we ought to focus on the rule-governed, structure-dependent system. Consequently, for a while generative linguistics "only served to reinforce the idea that lexis was somewhat peripheral" (Carter and McCarthy 1988, p. 41).

Rivers (1972) expresses this idea as follows:

In our foreign-language classrooms we have gone beyond isolated words, mere "vocabulary teaching ": We have realized that what students must possess is the ability to use syntactic structures into which they can incorporate these words to communicate their intentions. They can acquire the many new labels they will need as their interests develop. In class we ensure that they are familiar with a basic vocabulary that can be used for many purposes. This they can use to practice the syntactic operations they will need, if the rich vocabulary they will acquire later is to express their meaning appropriately. (p. 57, italics added)

Although Chomsky's principles and the principles of audiolingualism are very different from each other, the effect of this attitude on vocabulary teaching and learning is somewhat the same. The emphasis is still on the manipulation of structure, and vocabulary is a 'mere' sub-topic that students somehow are expected to learn later with little guidance or direct teaching. At best, vocabulary is used as a 
means of illustrating notions, functions, how meaning is negotiated through interaction, how communication occurs in context, etc. (See Savignon 1983.)

One reason for the continued benign neglect of vocabulary may be that grammar and phonology "are closed systems and therefore lend themselves to much more abstraction and generalization than vocabulary, which is...an open set" (Laufer 1986, p. 70). In addition, within the teaching profession there has been more interest in methodology than in content, and vocabulary lists are "reminiscent of teaching methods that are not currently in fashion" (Sinclair and Renouf 1988, p. 145).

\section{The Complexity of the Problem}

Reasons other than the influence of linguistic theory or teaching methodology have also contributed to the secondary status of vocabulary in ESL teaching. Broadening an explanation given by Twaddell (1980), both qualitative and quantitative factors are involved. The qualitative aspects of vocabulary teaching involve the complexity of word forms and meanings; the quantitative aspects are related to the limitations of the classroom.

Twaddell (1980) gives an interesting analysis of how attitude has affected the role of vocabulary in the ESL classroom. In the first place, among teachers there is the "general conviction that our students learn vocabulary control slowly and erratically" (p. 440) because there are inherent difficulties in learning a foreign vocabulary. Second, students often "exaggerate the importance of learning at once 'what the words mean'" (p. 440) and assume that there are exact correspondences of 
meaning between a native word and a foreign word. In reaction, teachers tend to "down-grade" vocabulary (p. 440).

The other main limitation in the classroom is time. The students need to learn a large amount of language in a small amount of time. Within these time constraints, it is impossible to teach students all the words they will need to know (Nation 1982; Twaddell 1980).

When considering the qualitative aspects of vocabulary teaching, it is important to keep in mind the basic question of what it means to know a word. In attempting to answer this question, Richards (1976) proposes eight assumptions. The first one is that native speakers continue to expand their vocabulary in adulthood; the implication is that ESL students should do so as well. The other seven say that knowing a word is...

...knowing whether a word is used frequently;

...knowing how to use it appropriately in discourse;

...knowing its syntactic behavior;

...knowing its "underlying form" as well as its derivations;

...knowing the "network of associations between that word and other words";

...knowing its "minimal semantic features";

...knowing a word's internal "associated" meanings (pp. 78-83).

Richards concludes, "The goals of vocabulary teaching must be more than simply covering a certain number of words on a word list" (p. 88). 
Setting goals for vocabulary teaching entails questions about what words are most needed by the students, whether to distinguish between spoken and written language, the quantity of words, the sequence of teaching, and whether any particular method of organizing vocabulary will facilitate learning. (For broad discussions, see Carter and McCarthy 1988; Richards 1974; and Sinclair and Renouf 1988.) Furthermore, among the words most needed by the students in both spoken and written contexts are those that native speakers use and understand as multi-word 'chunks' of meaning; e.g., idioms, formulaic speech patterns, and other relatively 'fixed' expressions. It is suggested by Cowie (1981; 1988), Nattinger (1988), and Yorio (1980), that these 'chunks' be treated as lexical units in ESL teaching.

The primary reason to organize the vocabulary in any particular way is to account for those aspects of word meaning that contribute to 'knowing' a word in the way Richards proposes: (a) the relatedness of meaning between and among words (synonymy, antonymy, hyponymy, metonymy, etc.); (b) relatedness of meaning within words; i.e., polysemy and the 'fuzzy' boundaries of word meaning; and (c) pragmatic aspects of vocabulary, such as how meaning is negotiated, how new senses are created, and patterns of both conversational and written discourse (Carter and McCarthy 1988; Cowie 1988; McCarthy 1988). Of course, the native speaker acquires this word knowledge by using and hearing words used in many different contexts. For the ESL student, the learning process may be accelerated by a vocabulary organization that takes these aspects of meaning into account. 
The most useful vocabulary organization would be one that helped the students remember the words and use them appropriately. If we organize words in the mind in certain ways, and use that organization to retrieve words for speaking and writing, then it would make sense to present words to ESL students in the same organization. Unfortunately, the answer is not that simple, for research on verbal learning and memory has not yet been able to describe our so-called 'mental lexicon'.2

The preceding discussion of the quantitative and qualitative issues involved in vocabulary teaching and learning is by no means complete, but it may serve Twaddell's injunction "to be clear about the complex nature of the problem itself" (Twaddell 1980, p. 443). Unfortunately, it may be this complexity that discourages the direct teaching of vocabulary. At the same time, there is a growing belief that "language practitioners need not shy away from lexis as a boundless chaos; organizational principles are available and simply wait to be more fully exploited" (Carter and McCarthy 1988, p. 38).

\section{SOME RECENT WORK IN VOCABULARY STUDY}

In the past fifteen years there has been an upsurge of interest in the study of vocabulary teaching and learning, stimulated primarily by the goals of communicative competence. The communicative approach has shifted value from sounds and structures to meaning and discourse. ESL methodology is now guided by a more holistic view of language, a recognition that both language acquisition and language use are more process than product, and a willingness to accept fluency at the expense 
of accuracy from the students. There is also more interest in learner-centered teaching, the problems of the more advanced learner, and teaching for selfmanagement. Attending these new interests is an awareness that an inadequate vocabulary may be more of an impediment to communication than syntactic inaccuracy. (For more complete discussions, see Carter and McCarthy 1988; Laufer 1986; McCarthy 1988; Savignon 1983; Sinclair and Renouf 1988; Strevens 1982; Wallace 1982; Widdowson 1979.)

\section{Central Patterns of Usage}

The trend in current research is to identify the "central patterns of usage [of words]" (Sinclair and Renouf 1988, p. 148) and "to explore the nature of their relationship as connected items in a coherent text" (Carter 1988, p. 171).

Consequently, some vocabulary is selected and organized according to the communicative purposes that it serves.

Courses in English for Specific Purposes (ESP) teach vocabulary as well as grammar and rhetoric for education (both academic disciplines and the teaching profession), sciences, and occupations (Martin 1976; Strevens 1982; Widdowson 1979). The courses are designed around the educational and occupational goals of the students, and the teaching process is more of a training than an education in that the objective is to develop a restricted competence in the practical use of English (Widdowson 1983). Strevens (1982) claims that ESP has shown excellent results and stands out as a desirable alternative to "the disappointing achievements of long-term, low-intensity, general English courses" (p. 469). 
However, Widdowson (1983) claims that the concept of ESP has often been misinterpreted as a method of teaching only the specialized words that are used in specific disciplines. He says that this vocabulary is "symbolically highly specific and...indexical in use to a narrow range of reference" (p. 92). Students also need to acquire a mediating "procedural vocabulary" consisting of words

subject to a wide range of interpretation... words of wide indexical range [that] are especially useful for negotiating conveyance of more specific concepts, for defining terms which relate to particular frames of reference. (pp. 92-93)

Procedural vocabulary defines, interprets, paraphrases, expresses register, achieves cohesion and coherence, and creates novel expressions such as metaphor. It also fulfills the four maxims of Grice's (1975) 'cooperative principle' for conversation, which may be paraphrased as follows:

1) Make your contribution as informative as required, but not more than required.

2) Be truthful, neither saying what you know to be false, nor saying something for which you lack evidence.

3) Be relevant.

4) Be brief and orderly; avoid ambiguity and obscurity of expression.

In effect, like the word lists of the 'vocabulary control movement', Widdowson's concept of procedural vocabulary is an attempt at identifying and defining a "'common-core' vocabulary" (p. 92). However, whereas the earlier word lists were based on high frequency counts, Widdowson is focusing on the communicative functions that words perform in discourse. ${ }^{3}$

Carter $(1987 \mathrm{a} ; 1987 \mathrm{~b} ; 1988)$ is also trying to identify a 'core' vocabulary and proposes some tentative tests for core words. According to Carter (1987a), a 
fundamental feature of core words is that they are "more tightly integrated into the language system" (p. 179). Therefore, a general test for a core word is whether it can be substituted for many other words with similar meaning, whether it has more 'collocations' (i.e., habitual associations) with other words, and whether it is used in more compounds, idioms, phrasal verbs, etc. It will be easier to find an antonym for a core word, and a core word will have more generic than specific properties. A second general test for core words is whether they "are more discoursely neutral than others; that is, they function in pragmatic contexts of language use as generally unmarked and non-expressive" (p. 180). Therefore, a core word is free from culturespecific uses and will not be associated with any particular field of discourse (e.g., nautical speech); it will be neither too formal nor too informal, and will be neutral with respect to judgmental associations (strong/weak, good/bad, positive/negative, etc.). Also, according to this test, core words are used more often in discourse that summarizes experience.

Another central pattern of word usage may be identified as the open set of language 'chunks'--the prefabricated expressions that we learn, use, and understand as communicative units. Such an expression is 'prefabricated' because we do not create it by combining its component words; it has been pre-packaged by our speech community. The most fixed or frozen form is commonly identified as the idiom: kick the bucket; open up a can of worms; cut to the chase. While some 'prefabs' are restricted to spoken English (you betcha; like I say; now mind you; there you go; what it is is; say what?), others are commonly used in writing, including formal registers; 
e.g., as a matter of fact; on the one/the other hand; by and large; no sooner than; in the long/short run; by virtue of; on the face of it. Less obvious are the numerous collocations that we utter with no consciousness of choosing to associate the words: flow of traffic; bitter truth; stunning victory; crushing defeat; sweeping generalizations; last-ditch effort; den of iniquity; run amuck; big mistake vs. large mistake. It might even be argued that the phrase $B E$ going to as a marker of future tense is one of these chunks. Bolinger and Spears (1981) suggest that we store these chunks of language in memory in the same way we store individual words.

Using the general term 'lexical phrase' to characterize some chunks of language, Nattinger (1986) focuses on how they function in conversation. Lexical phrases may be described as "conventionalized structures that occur more frequently and have more idiomatically determined meaning than language that is put together each time" (p. 3). Nattinger (1988) points out that natural language processing is "basically a 'compositional' process, one of 'stitching together' preassembled phrases [i.e., not just single words] into discourse" (p. 76). These phrases are relatively fixed, but can be expanded; e.g.:

this/that point at this/that point in time/history/the story prior to/before/after/since that point the point is the main/most important/central point is to the point more to the point short and to the point to come/raise/make/develop a point to drive a point home 
Stitching several together could yield this kind of sentence: On the other hand, the fact of the matter is that at about this point in time Hitler was going nuts.

Nattinger (1988) advocates teaching lexical phrases and their patterns of usage in terms of their functions as social interactions, necessary topics, and discourse devices. 'Social interactions' include greetings/closings, politeness routines, question/answer formulas, requesting, etc. 'Necessary topics' include language, weather, shopping, autobiography, etc. 'Discourse devices' include:

fluency devices: You know...

Let me think...

Well, it seems to me...

conjunctions: Which is to say that...

subordinators: In other words...

logical connectors: As a result...

temporal connectors: In that day and age...

In an empirical study of academic lectures, DeCarrico and Nattinger (1988)

describe a taxonomy of discourse devices that function as either global or local 'macro-organizers'. Global macro-organizers include topic markers (The first thing is...), topic shifters (So let's turn to...), and summarizers (What I'm saying is that...). Local macro-organizers include exemplifiers (Take something like...), relators (This ties in with...), evaluators (Look what's going on here...), qualifiers (The catch here is...), and aside markers (I guess I got off the track here...). One rationale for teaching the patterns of lexical phrase usage is that a native language is acquired in chunks, only some of which are technically words. ${ }^{4}$ (See Peters 1983.) Therefore, ESL students "already have developed this strategy in the language they bring to the classroom" (Nattinger 1980, p. 341). 


\section{$\underline{\text { Semantic Fields }}$}

An approach to organizing vocabulary that would be less concerned with either sociolinguistic or acquisition issues, and more concerned with semantic relatedness between words, is suggested by semantic field theory. The notion of semantic fields is based on two assumptions. First, "the vocabulary of a language is structured, just as the grammar and phonology are structured" (Lehrer 1974 p. 15). Second, word meaning is partly determined by "relations of sense holding within sets of lexemes" (Lyons 1977, p. 270), which can be characterized generally as systems of affinity and contrast (Kittay 1987). Therefore, it is possible to identify sets of "lexemes that share some aspect of meaning" (Lehrer 1983, p. 18).

The broadest aspect of meaning is a "conceptual field" (Lyons 1977, p. 253); e.g., perception (colors, shapes), activities (cooking, fishing, hunting, agriculture, building), culture (marriage, kinship, values, beliefs), animals, plants, health, war, etc. The lexical sets in each conceptual field are structured according to relations of affinity (synonymy and hyponymy) or contrast (antonymy and incompatibility). "Incompatibility is the most basic contrast to be found...for example, 'blue', 'green', 'yellow', 'red', etc." (Kittay 1987, p. 241); i.e., something cannot be both blue and green and still be either blue or green. Lyons (1977) divides antonyms into "gradable and ungradable opposites" (p. 271). Ungradable opposites are complementary (deadalive, married-single, male-female); "the denial of one member of the pair implies the assertion of the other" (Lehrer 1974, p. 26). Gradable opposites can be compared by their positions on a scale (hot-warm-tepid-cool-cold-icy). If something is hot, it is not 
any other degree on the scale, but to deny that something is hot does not assert it is warm, tepid, cool, cold, or, icy. Lehrer (1974) identifies two other contrasts as well: converseness (buy-sell) and rank.

There are many ways of organizing vocabulary into semantic fields because the theory lacks adequate criteria for defining fields and determining whether a lexical item belongs to a particular field (Lehrer 1983; Lyons 1977). ${ }^{5}$ Consequently, McKay (1980) assumes that semantic fields can be identified as those listed in a thesaurus as synonyms, and then recommends teaching the groups of synonyms by exposing students to examples in written contexts taken from the Stanford Computer Archive of Language Materials. Godman (1982) proposes teaching verbs in semantic fields organized hierarchically. For example, under break, are subordinate related words that represent different breaking actions on physical objects: snap, crumble, chip, and split. Under these words are others that represent the actions producing successively smaller pieces; e.g., under split is crack and tear; under tear is rip and rupture; under rip is shred; etc. Similarly, in an experiment conducted by Crow and Quigley (1985), each semantic field is built around a "keyword...that the students would probably know" (p. 502). For example, under the keyword anger, they include types of anger: "fury, ire, wrath, indignation" (p. 502). An alternative to a hierarchical organization is the presentation of words within a grid that analyzes the components of the meanings of the words; for example, chop, dice, cube, shred, slice, mince, and grate are related under the semantic field "reducing to small pieces" (Channell 1988, p. 91). Even though the concept of semantic fields invites some 
rather loose interpretations, the idea that words share aspects of meaning not only has appeal as an organizing principle, but also has "a strong psychological reality for language learners and users" (Carter and McCarthy 1988, p. 211).

\section{Needed: Strategies for Vocabulary Teaching and Learning}

Whęther based on communicative functions or semantic relatedness, organizing words according to central patterns of usage should be able to avoid some of the weaknesses of earlier word lists that were based on the erroneous assumption that there is a correlation between frequency and utility. As Richards (1974) and Twaddell (1980) point out, these lists included words of doubtful utility and excluded others that may have more utility. Also, the idea that a few 'basic' words can be used to express many notions sometimes produces language that is unlike naturally spoken English; for example, "I am able takes the place of I can" (Ogden 1934, p. 9). Furthermore, the words that occur the most frequently in everyday speech (as much as $80 \%$ ) have low information content, while the remaining less-frequent words have content that is "crucial for communication" (Richards 1974, p. 72).

Since a majority of communicatively useful words occur infrequently, and since there is a minimum of time available for classroom teaching, Twaddell (1980) concludes that it is a "sheer impossibility to teach the learner what he will need" (p. 446). At the same time, he acknowledges that "the expansion of vocabulary is the indispensible intermediate stage of FL [foreign language] acquisition" (p. 441). Therefore, students need to learn a "strategy of massive vocabulary control" (p. 443). 
Twaddell's (1980) solution is to guide the students in developing the skill of "sensible guessing...the skill of inference from context" (pp. 448-449). Like the native speaker of English, the ESL student brings to the reading process knowledge about the world, knowledge about how language expresses meaning, and some specific knowledge about English. The student can draw upon this knowledge to interpret grammatical and pragmatic clues in order to understand the meaning in a text and to learn the meanings and uses of words. Also like the native speaker, the ESL student should develop a willingness "to tolerate a considerable degree of vagueness" (pp. 448-457).

Twaddell's suggestion has become the predominant way of teaching vocabulary. (A balanced analysis of the research is presented in Nation and Coady 1988.) However, it is vulnerable to criticism on several grounds. In the first place, the ability to guess meaning in context depends on knowing the words that define that context. Second, many of the words learned will probably be the same "somewhat literary and arbitrary vocabulary" (Wilkins 1976, p. 4) for which the grammartranslation method has been criticized. In effect, the approach still treats vocabulary with benign neglect: expose the students to words in a reading context and hope for the best. Furthermore, in taking this approach, some teachers seem to have made the "faulty assumption...that words do not have meaning outside of context" (Nilson 1976, p. 100). The opposite is true: "The meaning of the word as encountered in the passage is contextually bound or limited, a particular realization of the concept that the word expresses" (Summers 1988, p. 116). Therefore, perhaps the students 
should learn the basic meanings of words before discovering how that meaning is affected by context (Nilson 1976). ${ }^{6}$

Even if there is a value to teaching words in a reading context, it "should not have the negative effect of discouraging the initial learning (or learning at some time) of words in isolation" (Nation 1982, p. 24). Current research in vocabulary is reinforcing the idea that some vocabulary should be taught directly. Good candidates for direct teaching include core words, semantic fields, procedural vocabulary as well as the more specific words in ESP courses, collocations and other lexical sets, and lexical phrases. In effect, this research is breaking down the total English lexicon into smaller, more manageable units that should be useful in devising strategies for both teaching and learning vocabulary.

\section{DEAD METAPHORS AS VOCABULARY ITEMS}

The so-called 'dead' metaphors are also good candidates for direct teaching. They are abundant in everyday speech and writing, and new ones are continuously evolving. Many of them can be integrated into other vocabulary sets such as lexical phrases and core words. Like words that are related in semantic fields, the related senses of a dead metaphor as well as related words and expressions can also be taught simultaneously. In addition, if the ESL student understands the process of metaphoric extension, which creates dead metaphors, then that knowledge can be used as a strategy for independent learning. 
A more precise definition of metaphor will be explored in Chapter II; Chapter III will describe the process of metaphoric extension and propose a possible explanation of how a novel metaphor becomes a 'dead' one. At this point, I simply want to suggest through examples that dead metaphors are part of a central pattern of word usage. ${ }^{7}$

In general terms, a word or a phrase is recognized as a dead metaphor if we use it in everyday speech with little or no consciousness of speaking metaphorically even though one or more of its senses can be traced to a metaphoric origin.

Sometimes only etymology can discover that a supposed literal sense is in fact derived from the metaphoric use of a word:

aftermath: a second mowing browse: young shoots or twigs of bushes, trees, etc. clue: a ball of yarn or thread

No metaphor could be more 'dead' than these are. (See $O E D$.

However, when a metaphorical sense is detectable, the intuitions of native speakers will vary. For example, some dead metaphors may conjure up a vaguely metaphorical sense even though the original reference is unknown to most speakers; e.g., to stonewall; springboard; benchmark; landmark; milestone. Others may convey a relatively strong metaphorical sense:

It was a blanket indictment.

The city had proposed axing the money from the budget.

He fleshed out his idea.

They set it up as a shell corporation.

There was a storm of protest.

The problems for Nixon snowballed after Watergate. 
Anechdotal evidence for a strong metaphorical sense includes puns, jokes, and qualifying phrases such as so to speak. ${ }^{8}$

However, many dead metaphors probably do not trigger any awareness of a metaphorical sense:

The house faced the mountains.

I bank at the Hilltop branch.

Has he landed a job yet?

There were three key points in the proposal.

The situation hinges on the response of the U.S.

I'm swamped with work.

Certain foods can trigger an asthmatic attack.

On the other hand, if pressed, the native speaker of English will probably explain the meaning of a dead metaphor in terms of comparison. For example, the sentence, I'm swamped with work, may be explained as follows: "It's like I'm surrounded by a swamp and don't see any way out." This is easiest to do when a metaphor is used frequently but may not be quite 'dead' yet, which seems to be the case in these examples:

The hostages say the bottom line remains the same--they are still being held against their will.

In another effort at shuttle diplomacy, Baker is on his way to Egypt.

In any case, awareness of a metaphorical sense is not necessary in order to understand the meaning of a dead metaphor, as the following examples illustrate:

East Germans are flooding into West Berlin.

People are flocking to buy guns and security hardware.

Pockets of troops were seen along the Saudi Arabian border as Hussein's troops swept across Kuwait.

The meeting between Bush and Kaifu helped to spur the settlement.

A Federal-State battle is brewing over the proposed tax increases.

The Commissioner dished out punishment to Steinbrenner.

Two Soviet cosmonauts have been stranded in space since February. 
Gorbachev is insisting that the negotiations be frozen.

More money is being pumped into into drug programs.

This is not a fringe movement... it is a mainstream movement.

The U.S. version of the trade agreement will be watered down.

...the savings and loan bailout

...a simple new test to weed out drugs that don't work

...a groundswell of public opinion

....an agreement on a ceiling for troop levels in Europe

...a cliff-hanger election

...a watershed election

...to drum up financial support

.... roadblock for the prosecution

In expressions such as these, a metaphorical sense has become conventionalized to the extent that it is used and understood as a literal sense.

Conventionalizing a metaphorical sense brings many dead metaphors into the realm of a core vocabulary, according to some of Carter's (1987a) criteria. It establishes many phrasal verbs and verb-plus-preposition units:

I was polishing off my breakfast when...

I need to polish up my writing.

It dawned on him that...

It boils down to this...

They keyed in on the enormous cost of the program.

Conventionalization also establishes collocations for many dead metaphors:

foot of a mountain/hill/page/line/bed

bed of flowers/roses/clover/hay/a river/a stream

stream of people/speech/thought/consciousness

floor of an ocean/forest/canyon

bitter truth/cold/experience/argument/opposition/resentment/ changes

winning/losing streak; streak of luck/good fortune/bad luck/ misfortune

storm of protest

heat wave

cold snap 
Numerous compounds become dead metaphors: ballpark, blackmail, brainchild, brainstorm, bulldoze, centerpiece, cherry-pick, deadlock, dead-ringer, feedback, hallmark, hotspot, ironclad, millstone, network, offshoot, nosedive, overboard, piecemeal, side-rail, side-track, showdown, standpoint, stonewall, touchstone, whirlwind, windfall, etc. Carter also says that a core word is used in many idioms, many of which could be regarded as metaphoric 'chunks'.

Some of those chunks of varying length--the lexical phrases--that Nattinger (1988) says we stitch together are formed out of dead metaphors; for example:

core/the core of/at the core of shed light: shed some/a little/more/further/more illuminating light

breaking point: up to/beyond/near the breaking point stand: as it/things (now) stand

Similarly, the organization of some words into semantic fields would have to be based on the extension of meaning achieved by the use of dead metaphors. For example, within the conceptual field of plants, words used metaphorically include blade, bloom, blossom, bear fruit, branch, bud, core, flourish, flower, fruit, fruition, germ, germinate, grassroots, kernel, leaf, mushroom, offshoot, plant, root, shoot, sprout, stem, stump and twig.

Another reason to consider dead metaphors as part of a central process of word usage is that so often they involve conversion, which is very productive in English: verbalization, nominalization, adverbialization, and adjectivialization. The most productive conversion is probably the use of a noun as a verb (verbalization); some non-metaphoric examples are: 
We need to transition the students into the mainstream curriculum.

She prefers to conference with her students about their writing.

They all choppered to Camp David.

We amnestied over 3 million aliens.

The guards shouldered their rifles.

He was benched for the rest of the game.

Everyday speech is peppered with novel metaphors that involve conversion:

That's a problem that a lot of analysts have noodled.

...as Musgrave tries to submarine to the 22-yard line.

Left-handed, he [Mickey Mantle] would golf the ball. Right-

handed, he would tomahawk the ball.

We're sort of arm-chair-quarterbacking this [Persian Gulf war].

But examples of conversion in using dead metaphors are also plentiful:

Drexel is saying, "We're being scapegoated."

Israel weathered another scud missile attack last night.

We need to mainstream the students.

Oil prices are skyrocketing.

He bootstrapped his way up to his present job.

She breezed into the room.

They spearheaded the campaign to change the name of the street.

Does this idea dovetail with your own?

Two militants barged into a farm and killed the residents.

Snow blanketed the city last night.

The competition blind-sided them.

His staff was button-holing him.

They fingered him for the crime.

She shouldered her responsibilities like a trooper.

The firm is saddled with debt.

Many adjectives with strong collocations can also be traced to metaphoric origins:

She was petrified.

I was devastated.

...naked aggression

...skyrocketing prices

...astronomical prices

...biting satire

.... shattering experience

...a knee-jerk reaction

...a thorny problem 
...a crusty old man

...a ballpark figure

.... fiery speech

... a fledgling democracy

.... a dirty/filthy trick

... filthy rich

...liquid cash

...fluid speech

...the fuzzy boundaries of word meaning

These and similar examples suggest that, in ESL teaching, it is insufficient merely to label such metaphors as idioms, slang, colloquial expressions, figurative speech, polysemous words, or even 'dead'. They are not just metaphors that have lost their metaphorical senses. On the contrary, the fact that they can be recognized or construed as metaphors suggests that the metaphorical sense lives on. Consequently, "past metaphors--now taken as literal--can generally be retrieved as metaphors" (Kittay 1987, p. 20). More important, dead metaphors become established in the lexicon through a process in which a word or a phrase is used metaphorically, and then, if the metaphorical sense continues to communicate intended meaning in various contexts, it becomes used and understood as either a literal sense or a conventional sense. The process is metaphoric extension, and it is a central pattern of word usage.

\section{CONCLUSION}

The acquisition of vocabulary by ESL students could be facilitated by more direct teaching of vocabulary as well as by more strategies for independent vocabulary learning. Research that identifies and describes central patterns of word usage may 
provide the teacher with some tools for organizing and presenting large blocks of vocabulary items, thus overcoming some of the time constraints in the classroom. In turn, teaching not only the vocabulary but also the patterns of usage may provide the student with some tools for developing strategies for independent learning. The process of metaphoric extension should be included among those central patterns of word usage that are adding "new dimensions to our view of vocabulary" (Carter and McCarthy 1988, p. 201). 


\section{NOTES}

${ }^{1}$ This is not to say that there has been no work on the direct teaching of vocabulary. Some of the more laudible approaches include Gairns and Redman (1986), Rudzka, et. al. (1981;1985), and Wallace (1982).

${ }^{2}$ Channell (1988) contradicts this idea:

For L1 [first-language], research on the nature of the mental lexicon is reasonably well developed, with research findings and resultant models available. (p. 83)

However, the multitude of conflicting theories and models of memory do not justify such optimism. Rather, it is more prudent to accept Tulving's (1985)

unassailable assumption that most, if not all, of our currently held ideas and theories about mental processes are wrong and that sooner or later in the future they will be replaced with more adequate concepts, concepts that fit nature better. (p. 386)

${ }^{3}$ A related concept proposed by Winter (reported in Carter and McCarthy

1988 ) is that inherent in the semantics of some words is a "text-structuring" function:

...these words signal the logic of a text, they link parts of texts to one another, they encapsulate chunks of text and refer back, forth and out into the world in a way comparable to how pronouns operate... acting as a half-way house between the grammar words and the lexical words of English. The list...includes achieve, addition, basis, cause, compare, differ, explanation, feature, kind, method, opposite, point, problem, result, situation, truth, way and many more. (pp. 207-208)

${ }^{4}$ For example, when my wife was in the fifth grade, she told her family that she had to bring some "kernivents" to class each week. Her brother tried to explain that the term was "current events," but she told him he was crazy; her teacher had said they were "kernivents," and she knew better than he did. 
${ }^{5}$ One cause of this inadequacy may be that the influence of sociolinguistic factors is not always taken into account. The essential question to be answered is to what extent semantic relatedness is determined by conventional usage as opposed to dictionary definition.

${ }^{6}$ Another criticism is that research has not yet shown conclusively that learning words in context facilitates learning (Carter and McCarthy 1988; Nation 1982; Nation and Coady 1988). However, this is hardly a fair criticism because the same could be said of any other method of teaching vocabulary. In fact, in one study of English-speaking eighth-graders, the authors conclude:

For any given small set of words, it is easy to show that direct vocabulary instruction is superior to learning from context...But if one asks a different question--what approach to vocabulary can more effectively lead to the acquisition of several thousand words per year-our results indicate that learning from context would be an easy winner (Nagy, Herman, and Anderson 1985, p. 251).

Of course, this is not to say that the same results would be found in ESL students.

${ }^{7}$ All the examples were taken from conversations, radio and television news broadcasts, radio talk shows, television shows, newspapers, and popular magazines such as Newsweek. I tried to select those that are topical as well as commonly heard in order to establish veracity without burdening the reader with citations for each source.

Some of these examples could be identified as involving metonymy, synechdoche, personification, hyperbole, or some other trope of similarity. However, I am using metaphor in an inclusive sense for two reasons. First, many such tropes could be either metaphoric or non-metaphoric. Second, a discussion relating 
metaphor to other figures of speech veers away from the central goal of understanding metaphoric extension as a central pattern of word usage. Why I consider these particular expressions to be metaphoric should become clearer in Chapter II.

${ }^{8}$ For example, referring to school officials who applied first-aid to a child who had cut off the tip of her finger, a radio talk-show host said, "I thought that the people on hand, so to speak, did a good job." 


\section{CHAPTER II}

\section{WANTED DEAD OR ALIVE:}

\section{A PRECISE DEFINITION OF METAPHOR}

In order to teach a vocabulary based on metaphoric extension, the ESL teacher needs a clear definition of metaphor. The standard definition found (in slightly varying versions) in any good dictionary or encyclopedia is clear, and in fact, it is the definition the teacher will have to use because it will be referred to by the students. However, it is too brief to account for either the process of metaphoric extension or the abundance of dead metaphors in everyday speech. Therefore, the teacher will need to augment this definition with a more precise explanation. To this end, the objective of this chapter is to develop a clearer understanding of what metaphor is by examining some of the dominant views on metaphor. The results of this analysis should also facilitate the selection of a vocabulary based on the process of metaphoric extension.

A convenient way of sorting out these views is to recognize that some of them . analyze metaphor essentially within the framework of more traditional concepts, while others concentrate on the cognitive significance of metaphor. Most views are neither strictly 'traditional' nor strictly 'cognitive', and there are potential problems in trying to rely exclusively on either framework. 
In the traditional framework, a precise accounting of metaphor may be limited by the tendency to treat metaphor as an artistic literary device, or verbal adornment, rather than as a central pattern of word usage. (For example, see Henle 1958; Hester 1967; Levin 1988; and Perrine 1971). This is one reason that the traditional (standard) definition of metaphor as an implied comparison is criticized for being inadequate and vague (Black 1962; Moore 1982; Ortony 1980b). Quine (1979) says that metaphor

flourishes in playful prose and high poetic art, but it is vital also at the growing edges of science and philosophy...It is a mistake...to think of linguistic usage as literalistic in its main body and metaphorical in its trimming. (pp. 159-160)

If Quine is correct, then metaphor must have a role in cognition. This aspect of metaphor is neglected by discussing only its literary role.

In contrast, proponents of cognitive views believe the study of metaphor can reveal something about how the mind conceptualizes experience (M. G. Johnson and Malgady 1980; Lakoff and M. Johnson 1980a, 1980b; Schön 1979; Verbrugge 1980). It is a belief based in part on the recognition that metaphors are pervasive in everyday speech (Harris, et. al. 1980; M. G. Johnson and Malgady 1980; Lakoff and M. Johnson 1980a, 1980b); for example: "That metaphor is pervasive in language is an aspect of its prominent place in the structure of thought itself" (Kittay 1987, p. 326).

Attempts to discover the cognitive significance of metaphor are expanding metaphor beyond the idea that it is a figure of speech; i.e., "saying one thing in terms of something else" (Barnet, et. al. 1960, p. 41). In the cognitive framework, metaphor is a "figure of thought" (Lakoff 1986, p. 215), and the concept of metaphor 
ranges from 'seeing' one thing in terms of another (Black 1962) to 'experiencing' one thing in terms of another (Johnson 1987; Lakoff and Johnson 1980a; 1980b). The resulting analyses are providing more precise theories about what metaphor is, how metaphor expresses meaning, and how we comprehend that meaning.

However, some cognitive views may be causing another vagueness by seeing underlying metaphors in almost any expression. For example, Richards (1936) asserts that "metaphor is the omnipresent principle of language" (p. 92). A stronger claim is that "metaphorical talk is temporally and logically prior to literal talk" (Cooper 1986, p. 257). Stronger still is the claim by Lakoff and Johnson (1980a):

Metaphor is pervasive in everyday life, not just in language, but in thought and action. Our ordinary conceptual system, in terms of which we both think and act, is fundamentally metaphorical in nature. (p. 454)

These kinds of statements suggest that the expanded concept of metaphor offered by some cognitive views may be tantamount to saying that there is no distinct expression known as metaphor. If we believe that all language is inherently metaphoric, then we deny literal meaning; "if we deny the literal in language, we deny the possibility of metaphor as well" (Kittay 1987, p. 20). In addition, as Booth (1979) points out, there is a problem for students of any subject when the word for that subject expands to cover everything... Metaphor has by now been defined in so many ways that there is no human expression...that could not be metaphoric in someone's definition...Surely when a word can mean everything it risks meaning nothing. (p. 48)

Yet intuitively we know that "the rules of our language determine that some expressions must count as metaphors" (Black 1962, p. 29). 
For the ESL teacher, the main problem is how to teach metaphor as a distinct kind of expression without restricting it to its literary role. A first step toward a solution is to accept the premise that the literary use of metaphor is "a refinement upon one of the commonest devices of ordinary speech" (Waldron 1967, p. 167). But there are other issues as well. We know when we have heard or read a metaphor, but how do we know that? Furthermore, how do we explain to an ESL student that one expression in English (She shouldered her responsibilities) is a metaphor, and a similar one (She shouldered her rifle) is not, or that what might seem to be a metaphor (It dawned on him) is really 'dead'?' In order to explain why something is identified as a metaphor, we need to understand (at least hypothetically and tentatively) how it communicates its meaning. Finally, since metaphor is pervasive in everyday speech, we also need to be able to explain why we use metaphor.

Therefore, although the distinction between traditional and cognitive views will serve organizational purposes, the following examination of some of the dominant views will be more concerned with how any view provides answers to these three, interdependent questions: how we identify a metaphor, how a metaphor communicates its meaning, and why we use metaphors. Since every major view is in part an effort to explain, augment, or transcend Aristotle's concept of metaphor, it is necessary to begin by looking closely at Aristotle's discussion of metaphor in Poetics and Rhetoric. 


\section{ARISTOTLE'S DISCUSSION OF METAPHOR}

Aristotle (The Revised Oxford Translation, 1984) identifies metaphor as the substitution of one term for another:

Metaphor consists in giving the thing a name that belongs to something else; the transference being either from genus to species, or from species to genus, or from species to species, or on grounds of analogy. (p. 2332)

The transference is not just of a noun (or 'name'), for Aristotle's examples include verbs, phrases, riddles, proverbs, and hyperboles. (See pp. 2238-2257.) What has since become known as synecdoche includes both 'genus to species' and 'species to genus' transference:

That from genus to species is exemplified in 'here stands my ship'; for lying at anchor is a sort of standing. [The whole is substituted for the part.] That from species to genus [part for the whole] in 'Truly ten thousand good deeds has Ulysses wrought', where 'ten thousand', which is a particular large number, is put in place of the generic 'a large number'. (p. 2332)

The 'species to species' transference is using one word where another one with a related sense could have been used:

in 'Drawing the life with the bronze,' and in 'Severing with the enduring bronze'; where the poet uses 'draw' in the sense of 'sever' and 'sever' in that of 'draw', both words meaning 'take away' something. (p. 2332)

In analogy, it is a matter of putting the fourth term "in place of the second, and the second in place of the fourth" (p. 2332).

However, not just any word can be put in place of another and still be identified as a metaphor. Aristotle believes that the use of metaphor is "a sign of 
genius, since a good metaphor implies an intuitive perception of the similarity in dissimilars" (p. 2335). Here and in other statements, he seems to be implying that metaphoric substitution is possible only when there is similarity either in the two subjects referred to or in the meanings of the words used. For example, both a man and a lion have the trait of courage:

The simile also is a metaphor; the difference is but slight. When the poet says: 'He leapt on the foe as a lion', this is a simile; when he says of him 'the lion leapt', it is a metaphor--here, since both are courageous, he has transferred to Achilles the name of 'lion'. (p. 2243))

In the preceding example of substituting the sense of sever for that of $d r a w$, and vice versa, the similarity is in the meanings of the two words.

Metaphor communicates similarity in dissimilars in two ways:

By making our hearers see things...I mean using expressions that represent things as in a state of activity... and by the further power of surprising the hearer; because the hearer expected something different, his acquisition of the new idea impresses him all the more. (pp. 22522253)

Consequently, Aristotle regards metaphor as one of the most effective ways of using language because "it is from metaphor that we can best get hold of something fresh...a new idea, a new fact" (p. 2250).

Presenting new ideas in this manner is not the only reason we use metaphors.

Some metaphors are necessary. For example, some provide names for terms that

have no name of their own...Thus to cast forth seed-corn is called 'sowing'; but to cast forth its flame, as said of the sun, has no special name. This namelass act, however, stands in just the same relation to its object, sunlight, as sowing to the seed-corn. Hence the expression in the poet, 'sowing around a god-created flame.' (p. 2333) 
In addition, metaphor belongs to that class of "unfamiliar terms" (including foreign terms, ornamental equivalents, coined words, and words that are lengthened, curtailed, or altered) which are "necessary...[because they] save language from seeming mean and prosaic, while ordinary words will secure the requisite clearness" (pp. 2333-2334).

We also use metaphor because it adds to the ordinary use of language "clearness, charm, and distinction as nothing else can" (p. 2240). Since Aristotle is primarily interested in metaphor as a rhetorical or poetic device, he frequently describes appropriate use and form; for example: "The materials of metaphor must be beautiful to the ear, to the understanding, to the eye or some other physical sense" (p. 2241). However, this is not saying that metaphor is limited to literary adornment, for Aristotle recognizes its pervasiveness in everyday speech: "These two classes of terms, the proper or regular and the metaphorical--these and no others--are used by everybody in conversation" (p. 2240).

In sum, Aristotle says that metaphor is the transference of a term to a dissimilar subject, achieved by putting one term in place of another, which expresses the speaker's perception of 'similarity in dissimilars'. It is a form of word usage that is not only rhetorically and poetically valuable but also necessary. The central concept is 'similarity in dissimilars', and this is the point of departure for traditional and cognitive views. Because Aristotle says metaphor makes the hearer 'see' the similarity, thereby grasping a new idea, some interpreters say that he is an early proponent of the cognitive significance of metaphor (Johnson 1980; Kittay 1987; 
Ricoeur 1979). Cognitive views propose that verbal metaphor reflects how the mind works; how it creates similarity as a way of understanding experiences, phenomena, and concepts. In contrast, traditional views tend to follow the interpretation that Aristotle regards metaphor as a way of making a comparison; the similarity preexists, either in physical reality or in the meanings of the words, and metaphor is a way of expressing it.

\section{SIMILARITY IN THE TRADITIONAL FRAMEWORK}

If asked to define metaphor, most of us would probably recall the traditional definition taught in high school English classes: metaphor is a figure of speech that makes an implicit comparison, as opposed to the explicit comparison made by another figure of speech, the simile. Therefore, in the following examples, (1), (2) and (3) are similes while (4) through (7) are metaphors:

1) The ship was like a ghost.

2) The man ate like a wolf.

3) The ship, a veritable ghost, loomed on the horizon.

4) The ship was a ghost.

5) The man is a wolf.

6) The man wolfed down his food.

7) The ghost [referring to a ship] loomed on the horizon.

Since both a metaphor and a simile say the same thing, a metaphor is an abbreviated, or elliptical, simile.

However, metaphor is more than simply eliminating a word such as like. For example, in (4), a ghost is substituted for another subject complement, such as enshrouded in a gray mist, vaporous and evanascent as a ghost; in (6), wolfed down 
his food is substituted for another verb phrase, such as tore at his food the way a wolf might do. In effect, there is a "substitution of a non-literal phrase for a literal phrase" (Ortony et. al. 1978, p. 921), and the result expresses "a comparison between essentially unlike things...the literal term and the figurative term" (Perrine 1971, p. 125). Consequently, the traditional way of defining metaphor is both a "comparison view' and a 'substitution view' (Black 1962).

\section{Metaphor as Substitution}

If the aspect of substitution is emphasized, there is a tendency to regard metaphor as "somehow special, deviant, anomalous, or different from normal language" (Johnson and Malgady 1980, p. 259). This idea derives from Aristotle's observation that metaphor replaces a word or phrase with another that "belongs to something else', which probably reflects the assumption of Greek rhetoricians that "every word had its true and correct meaning" (Waldron 1967, p. 44). However, defining metaphor as a substitution does not explain why some substitutions are not metaphors. For example, why are the sentences in (a) metaphoric while those in (b) are not?

a) She shouldered her responsibilities.

Tanks shouldered up to the central bank in Kuwait City.

b) She shouldered her rifle.

He shouldered his way through the crowd.

The traditional answer is that only the (a) sentences make comparisons. Therefore, even if the aspect of substitution is emphasized, it is almost never discussed without involving the issue of comparison. 
Hester (1967) points out that Aristotle's discussion is usually interpreted to mean that metaphor is "essentially a decoration or ornament to enliven [literary] style" (p. 14). In support, he expresses his own view:

Reading is the stance appropriate to metaphor...Reading... with regard to metaphor essentially involves imagery...I argue that metaphor essentially involves imagery while literal writing does not. (pp. 117133)

However, this is not true of all metaphors, for some are "nearly impossible to imagine in a perceptual manner...[e.g.,] Dreams are the judicial system of the unconscious" (Reichman and Coste 1980, p. 184). Furthermore, non-metaphoric language can also produce strong images, as Hemingway's style demonstrates so well:

Nick looked down into the clear, brown water, colored from the pebbly bottom, and watched the trout keeping themselves steady in the current with wavering fins. (Hemingway 1938, p. 209)

Therefore, perhaps Hester is only saying that metaphor is used more frequently to evoke images. In any case, Hester's view is representative of the traditional tendency to focus on the use of metaphor in writing.

Even when a traditional view recognizes the conversational use of metaphor, the emphasis is still on comparison achieved by substitution. For example, Grice (1975) says that metaphor "flouts" the maxim (in his "cooperative principle") to be truthful. Using the example You are the cream in my coffee, he says the hearer knows that

it cannot be THAT that such a speaker is trying to get across. The most likely supposition is that the speaker is attributing to his audience some feature or features in respect of which the audience resembles (more or less fancifully) the mentioned substance. (p. 53) 
The hearer draws "conversational implicatures" (p. 45) about the statement, and consequently, the substitution of a false statement for a normally expected truthful one somehow tells the hearer that some kind of similarity is being expressed. ${ }^{2}$

Searle (1979) explains the substitution by making a distinction between intended meaning and the spoken or written expression, calling "the former speaker's utterance meaning, and the latter, word, or sentence meaning" (p. 93). Searle asserts that metaphor, irony, and indirect speech acts are examples of how a speaker "is able to mean more than, or something different from, what he says" (p. 93). In each case, the speaker substitutes one statement for another that could have expressed the intended meaning directly. With irony, the hearer knows the opposite is intended. With an indirect speech act, the hearer knows something more is intended; e.g., It's hot in here means exactly that, plus Open the window. Metaphor always expresses the speaker's utterance meaning, but not the sentence meaning. The primary strategy for understanding the utterance meaning is this : "Where the utterance is defective if taken literally, look for an utterance meaning that differs from sentence meaning" (p. 114).

Matthews' (1971) anomaly view also regards metaphor as a substitution comprehended in two stages. Metaphor is an anomaly because the substitution violates certain semantic rules, resulting in an expression that is "semantically deviant" (p. 419). This view is based on the Katz-Fodor componential theory of semantics (Katz and Fodor 1963), which claims that words have several senses, each of which can be represented abstractly by semantic features or markers. For 
example, man may be represented as [+HUMAN], [+MALE], [+ADULT], etc.; wolf may be represented as [+ANIMAL], [+CANINE], [+PREDATORY], etc. Each of these features may be further defined: human includes [+PRIMATE], [+LINGUISTIC], [+GREGARIOUS]. Using these two terms in the metaphor, The man is a wolf, violates selectional restriction rules, or rules about selecting lexical items for a grammatically well-formed sentence. At the very least, man is [+HUMAN], and wolf is [+CANINE], and therefore it is patently false that the two can be equated. The hearer attempts a literal interpretation and, failing in that, seeks a non-literal interpretation (Loewenberg 1975; Matthews 1971). Quoting Chomsky (1965), Matthews (1971) explains that "these deviant sentences 'are interpreted by direct analogy to well-formed sentences that observe the selectional-restriction rules in question'" (p. 419).

The strongest criticism of the anomaly view is that some statements "could be used either literally or metaphorically" (Morgan 1979, p. 137), depending on the context. One frequently-cited example is The rock is becoming brittle with age. The words in this sentence have not violated any selectional restriction rules because the sentence may refer literally to a rock; yet when the sentence refers to an old professor, it is a metaphor (Morgan 1979; Ortony 1980a). Some metaphors can be semantically anomalous regardless of context; e.g., The crowd floated up the courthouse steps. However, it is not true that, in order to identify a metaphor, "the presence of a selectional restriction violation is a necessary and sufficient condition" (Matthews 1971, p. 424). 
The anomaly view may help identify some metaphors, and regarding metaphor as an indirect way of speaking, as a flouting of a conversational maxim, or as a literary ornament may suggest some reasons we use metaphors, but the emphasis on substitution provides little insight into how a metaphor communicates its meaning. It does not explain how the hearer knows that the statement is not a lie, an exaggeration, an ironic comment, or a mistake that merely expresses ambiguity. Furthermore, describing how a word or an expression is used in an abnormal way does not necessarily tell the hearer in what way it is being used (Ortony 1980b). Once we have recognized that someone has used a metaphor, and we know that the intended meaning is something different from what it first appears to be, how do we know what the metaphorical meaning is; i.e., what is that non-literal interpretation we are supposed to make?

\section{Metaphor as Comparison}

The emphasis on comparison in the traditional framework is an attempt to answer this question by explaining how metaphor expresses 'similarity in dissimilars'. Aristotle used metaphor to refer to the transfer of one term into a context in which another term normally would be used. Since then, the Greek roots (meta, 'over', and pherein, 'to carry') have been reinterpreted (Waldron 1967), which has resulted in a "fairly wide agreement that metaphor involves, or is, the transfer of meaning" (Ortony 1975, p. 45).

In order for meaning to be transferred, there must be two terms even though there is a substitution. For example, the word ship does not appear in the metaphor, 
The ghost loomed on the horizon, but (given the appropriate context) the hearer knows that the speaker is referring to a ship. The dissimilarity between the two referents surprises the hearer and prompts a search for similarity. Since it is assumed that a metaphor is an abbreviated simile, the similarity may be discovered by transforming the metaphor into a simile: The ship loomed on the horizon like a ghost. If the similarity is there, then somehow some of the meaning of ghost has been transferred to ship, or to the concept of ship. However, "it is an understatement to say that the mechanism of this transference is not well understood" (Miller 1979, p. 221).

One way of explicating the idea is to say that the transference is an extension of the literal meaning. Henle (1958) suggests that transfer may be too strong because some of the similarity may be "antecedent" and some of it "induced" (p. 191). The antecedent similarity already exists, either in the meanings of the words or in realworld conditions. It enables metaphor to show how one term symbolizes another through analogy; rather than transferring meaning, metaphor extends this "parallel structure" (p. 180). Metaphor may also induce similarity by

infusing the symbolized situation with the feeling belonging to the one which functions as the symbol...[i.e.,] an aura of the feeling in the one case pervades the other. (p.191)

On a more rational basis, Waldron (1967) says that in addition to the "emotive force... [and] suggestiveness" (p. 166) of some metaphors, in general metaphor enlarges the semantic range of words, momentarily or permanently changing the frontiers of our lexical categories... Metaphor is a transfer of category-names on the basis of some common criterion between the two categories. (p. 180) 
Shibles (1971) adds the idea that this is possible because "there is an intuitively grasped core meaning which every word has and which cannot be fixed to mean one thing only" (p. 90). This core meaning is extended when there is "the transference of a word or phrase from one universe of discourse to another" (p. 77).

As suggested by the phrases universe of discourse, lexical categories, and parallel structures, the problem of how metaphor expresses the comparison is broader than the idea that there is a transfer of meaning from one word to another. The two terms of a metaphor are not just two words, as might seem to be the case in The man is a wolf and The ghost loomed on the horizon. It is more precise to say that there are two different referents; i.e., "what is normally designated by the word....and what is designated by it in its metaphoric use--its actual referent" (Waldron 1967, p. 162). Therefore, wolf refers to both an animal and a man, and ghost refers to both a supposed apparition and a ship. However, to be even more precise, the meaning that emerges from the metaphoric use is distinctly different from the literal meaning of either referent: wolf is neither the animal nor the man, but something at once both more than and less than either one. This 'something' is usually called metaphorical meaning.

Perhaps this is best illustrated by a metaphor submerged in a context, such as the following cathedral metaphor in E. B. White's (1944) essay, "Once More to the Lake":

One summer, along about 1904, my father rented a camp on a lake in Maine...[Returning years later] I wondered how time would have marred this unique, this holy spot...I guess I remembered clearest of all the early mornings..I would dress softly so as not to wake the others, 
and sneak out into the sweet outdoors and start out in the canoe, keeping close along the shore in the long shadows of the pines. I remembered being very careful never to rub my paddle against the gunwale for fear of disturbing the stillness of the cathedral.

(pp. 246-247)

White is not just extending the literal meaning of cathedral, nor is he simply using a false, logically absurd, or semantically deviant sentence to say what he really intends. What he intends is a metaphorical meaning of cathedral. Since it is a 'holy spot', the reader knows that the metaphorical meaning includes everything to which cathedral refers: not just a stereotypical structure, but a whole set of experiences, values, beliefs, etc. that the reader associates with the word. At the same time, in this text, cathedral refers to the lake, or more accurately, to the narrator's experience of the lake. This experience includes his values, beliefs, hopes, dreams, memories, and recalled emotions, as well as his perception of stillness, peace, tranquility, purity, spiritual power, and certainly much more. In other words, the word used metaphorically, cathedral, has two referents: (1) the object to which the reader might expect it to refer, including a set of connotations, and (2) the lake to which it does refer, including the reader's inferences about the narrator's experience of that scene. In either case, this cathedral is more than (and less than) any particular structure that might be called cathedral; this cathedral is metaphorical.

The problem is this: how does a metaphor construct a semantic relationship between two terms so that the hearer (or reader) understands the metaphorical meaning? More specifically, how does a metaphor reveal the similarity between the 
two referents for the word used metaphorically when those referents are so different from each other?

One approach to this problem is suggested by Frye's (1967) analogy between 'pure literature' and 'pure mathematics': each is "concerned more and more with its inner integrity, and less and less with its reference to external criteria" (p. 351). Like rational and irrational numbers, the two terms of a metaphor "depend for their meaning solely on the interrelations of the subject itself" (p. 351). Metaphor is a way of naming (or renaming) something, as a decimal names a fraction. Like the equation, metaphor is a tautology and creates a "hypothetical identification" (p. 352). Turbayne (1962) makes a similar argument, but significantly incorporates the fact that people are involved--speakers/writers and hearers/readers. Consequently there is an "as if or make-believe feature" (p. 17) to metaphor. Turbayne refers to the substitution as a kind of "sort-crossing" (p. 11), and says that in using a metaphor we are creating a "duality of sense" (p. 17) by treating one thing as if it belonged to some other sort of thing. Pragmatically, "the use of metaphor involves the pretense that something is the case when it is not" (p. 13); e.g., that a man is a wolf. Furthermore, we are asking our audience to participate in this pretense.

Semantically, the term used metaphorically is given two senses; e.g., "the literal and the metaphorical senses of 'wolf'" (p. 15).

In short, the use of metaphor involves both the awareness of duality of sense and the pretense that the two different senses are one. To Dr. Johnson's remark that metaphor "gives you two ideas for one," we need to add that it gives you two ideas as one. (p. 17) 
One idea is that wolf can refer to the feral canine, and the other is that in a hypothetical, 'as if' context of agreed-upon pretense, wolf can also refer (metaphorically) to a man.

In Miller's (1979) defense of metaphor as an abbreviated simile, the dual senses converge into a set of "missing properties [that, for example,] are understood to be something attributable to both wolves and men" (p. 241). Miller draws a parallel between the reading process and the comprehension of a metaphor, saying that in both, "new things are learned by being related to things already known" (p. 202). Metaphor states something that does not fit in with our "familiar conceptual system" (p. 202); it is not true in fact. Therefore, we accept the context in which the metaphor is stated as a "semantic model" (p. 206) and look for truth in the model. In other words, readers of metaphors

assume that what the author said is true in the state of affairs he is describing, then search their general knowledge for plausible grounds for saying that in the given context. Their search, however, is guided by whatever resemblance and analogies they can find between the world of the text and the world of reality. (p. 214)

In The man is a wolf, the old information (what we know) is that man and wolf refer to two different objects, and the new information is that, in a given context, they may be seen to resemble each other. "Finding that resemblance can be viewed as a process of paraphrasing the metaphor as a comparison statement" (p. 219).

\section{Paraphrasability: A Problem for Comparison Views}

The most common assumption among traditional views is that we comprehend a metaphor by paraphrasing it as an explicit statement of comparison. However, it is 
an oversimplification to say that a metaphor can be paraphrased as a simile because similes may be either literal or metaphorical; for example:

1a) The crystal is like a block of ice.

1b) Sally is like a block of ice

2a) The dog is like a wolf.

2b) The man is like a wolf.

According to the standard definition of metaphor, the presence of like makes each of these sentences a simile, or an explicit comparison. But in (1b), any similarity between Sally and a block of ice is only metaphorical. "Even if we were to throw in the various beliefs that people have about blocks of ice, they still would not be literally true of Sally" (Searle, 1979, p. 107). The same argument could be applied to (2b); a man is not in any literal way like a wolf. In other words, "the explicit statement of comparison that is supposed to underlie the metaphor is itself metaphorical in nature" (Ortony et. al. 1978, p. 940). Therefore, some similes may be metaphors, but not all metaphors are similes.

It may be that any paraphrase only adds overt signals to a metaphoric expression, for metaphors themselves can be stated in overt terms of comparison; for example: "Patterson was a gamecock, moderate in height, wiry in build, jittery in movement and irascible in expression" (Bernstein 1989, p. 151). The comparison is not implied, and yet no matter how much the metaphor is elaborated upon, it is still a metaphor and not a literal comparison because Patterson is a gamecock only in a metaphorical sense. Also, the duality of sense is still prominent. The qualifying phrases tell us how Patterson is similar to a gamecock, but we are aware that he is 
not a gamecock. At the same time, we accept the pretense that he is a gamecock if by gamecock we mean to exhibit certain characteristics. In other words, since both writer and reader know that Patterson cannot be literally similar to a gamecock, the sentence is making a statement about Patterson as if he were similar to a gamecock. It is the duality of sense, more than the substitution or the comparison, that makes this statement a metaphor. Therefore, metaphor may be more than a substitution, more than an implied comparison, and more than an abbreviated simile.

Furthermore, if a metaphor were only a statement of similarity, then we would assume that the more similarity expressed, the better the metaphor. On the contrary, "when there is too much similarity...the metaphor becomes...a literal statement of resemblance or identity" (Tourangeau and Sternberg 1982, p. 208). "Indeed, it seems a reasonable view that a metaphor is the opposite of an equation" (Empson 1964, p. 332). Metaphorical meaning is about 'similarity in dissimilars', but as Frye, Turbayne, and Miller point out, and as White's cathedral metaphor illustrates, it is more than a simple one-thing-is-like-another-thing statement.

\section{SIMILARITY IN THE COGNITIVE FRAMEWORK}

The fact that the whole meaning of a metaphor cannot be paraphrased as a literal statement of comparison provides the main impetus for substantiating the cognitive significance of metaphor (Kittay 1987). Among cognitive views, a common theme is that metaphorical meaning is not the product of using words metaphorically; "what is created is not simply a new emphasis on some preexistent but hitherto, unnoticed aspect of meaning or similarity" (Waggoner 1990, p. 93). Rather, the verbal metaphor is the 
product of a cognitive activity that might be called "metaphorical thought" (Black 1979a, p. 3). Metaphor is a way of perceiving or understanding something; "metaphor is, at root, a problem of knowing" (Verbrugge 1980, p. 87). I have chosen six views to represent the cognitive framework, presented in this sequence: Richards (1936); Black (1979a, et. al.); Tourangeau and Sternberg (1982); Lakoff and Johnson (1980a, et. al.); Ortony (1980a, et. al.); and Kittay (1987). Kittay's theory is examined in more detail than any other theory because of the new and useful insight it offers.

\section{Three Interaction Views}

The current interest in the cognitive significance of metaphor arises from Richards' (1936) 'interaction' view. Richards identifies the two terms of a metaphor as the tenor and the vehicle, and introduces two other influential terms as well: ground and tension. The tenor is the "principle subject" (p. 97), and the vehicle is the term used metaphorically. The similarity, or set of "common characteristics" (p. 117), is the ground. The tension is the semantic incongruence caused by the "disparities" (p. 108) between the tenor and the vehicle. Hence, in The man is a wolf, the tenor is man, and the vehicle is wolf. To the extent that there is similarity in the ground, the hearer will be able to compare them, but the tension caused by their dissimilarity signifies that it is not a literal comparison.

Richards says, "If we cannot distinguish tenor from vehicle, then we may provisionally take the word [or phrase] to be literal" (p. 119). For example, The dog is a wolf would probably be taken to be a literal statement because there is a weak tension and a strong ground between $\operatorname{dog}$ and wolf. In contrast, there is a strong tension and a weak ground between man and wolf in the metaphor, The man is a wolf. 
For this reason, Richards emphasizes the role of the differences in expressing the metaphorical meaning. Rather than similarity being revealed through the transfer of meaning from the vehicle to the tenor, Richards says that there are "exchanges between the meanings" (pp. 108-109) of the tenor and the vehicle. The metaphorical meaning will derive in part from the similarities, "but the peculiar modification of the tenor which the vehicle brings about is even more the work of their unlikenesses than of their likenesses" (p. 127). Therefore, "we need the word 'metaphor' for the whole double unit" (p. 96), and not just for the term used metaphorically.

In the simplest formulation, when we use a metaphor we have two thoughts of different things active together and supported by a single word, or phrase, whose meaning is a resultant of their interaction. (p. 93)

Since metaphor is "a borrowing and intercourse between thoughts" (p. 94), and not just words, it has a cognitive role: "Thought is metaphoric, and proceeds by comparison, and the metaphors of language derive therefrom" (p. 94).

While Richards seems to be implying that we use metaphor because that is the way the mind works, Black's $(1962 ; 1979 a)$ interaction view describes metaphor as an instrument for changing, compressing, and expanding concepts. ${ }^{3}$ We use metaphor because literal language is often insufficient for expressing "our sense of the rich correspondences, interrelations, and analogies of domains conventionally separated" (1979a, p. 34). This idea is almost identical to Aristotle's 'intuitive perception of the similarity in dissimilars'. However, Aristotle could be interpreted to mean that the similarity exists prior to the metaphoric statement. Black (1962) proposes that "it would be more illuminating in some of these cases to say that the metaphor creates the similarity" (p. 37). 
According to Black (1979a), the outcome of the interaction is "of course produced in the minds of the speaker and hearer" (p. 29). In "strong metaphors" (p. 27), as opposed to 'dead' metaphors, there are "unstated implications: Their producers need the receiver's cooperation in perceiving what lies behind the words used" (p. 26). The words used identify the primary subject (the tenor) and the secondary subject (the vehicle).

The metaphorical utterance works by "projecting upon" the primary subject a set of "associated implications," comprised in the implicative complex, that are predicable of the secondary subject. (p. 28)

In White's cathedral metaphor, the implicative complex of the secondary subject, cathedral, might include :

(C1) A cathedral is a place of expansive but limited space, diffuse light, and tall columns that echo the faintest sounds

(C2) in which holy songs are sung, holy words spoken, holy thoughts contemplated, and worship undertaken,

(C3) which brings the visitor a feeling of peace, tranquility, humility, love, and an overwhelming sense of spiritual power.

Implications such as these (and not, for example, implications about architectural characteristics) would be selected by the reader because the narrator had said that the lake was a unique, holy place.

The interaction is initiated when this implicative complex is projected upon the primary subject, a lake in Maine. The implicative complex of the primary subject depends upon the interpretations that the speaker and hearer give to the implications of the secondary subject. Therefore, a lake in Maine could have these implications:

(L1) A place of...(same as C1)

(L2) the experience of which is akin to that of holy places, but not exactly the same,

(L3) which brings the visitor...(same as C3) 
The primary subject is now seen in a new way, which "reciprocally induces parallel changes in [the way we see] the secondary subject" (1979a, p. 29). By seeing the lake as a cathedral, we also begin to see a cathedral as something more than (and less than) the stereotypical structure; something rather like the lake. ${ }^{4}$

Therefore, metaphor is not 'saying-as', but 'seeing-as'. "One thing is thought of (or viewed) as another thing" (Black 1979b, p. 192). Black (1979a) says that this is a more accurate way of explaining metaphor as an elliptical simile: metaphor is an "instrument for drawing implications grounded in perceived analogies of structure between two subjects belonging to different domains" (pp. 31-32). However, he does not specify what he means by domain.

Tourangeau and Sternberg (1982) are a little more specific about the meaning of domain: "Concepts--and the features, dimensions, and semantic relations that characterize them--cluster into domains" (p.215). They "intend the notion of domains to be flexible" (p. 215) because the domain of an object may be perceived differently by different people. Furthermore, some objects may be seen as belonging to several domains, and therefore "context can determine the relevant domains" (p. 215). Finally, if a metaphor is uttered with minimal linguistic or contextual clues, we may infer the domain. In any case, a metaphor is identified when a hearer recognizes that "two domains or systems of thought are both active" (p. 217).

In their 'domains-interaction' view, the interaction involves the domains as well as the tenor and the vehicle.

We suggest that metaphors generally involve seeing something (men) in one domain in terms of something (wolves) in a second domain, with a resulting change in our view of both domains. (p. 214) 
In The man is a wolf, we not only see man in terms of wolf; we also see certain human behavior as analogous to animal behavior.

In both creating and comprehending a metaphor, we construct "correspondences" (p. 218) or parallel "systems of beliefs" (p. 225) not only about the tenor and the vehicle, but also about their domains. We "see one concept in terms of another by construing features or dimensions" (p. 215) that are parallel, and through a selective 'mapping' process, we carry them over from the tenor to the vehicle, from one domain to the other, and vice versa. Consequently, there are two sources of similarity: "within-domains similarity of tenor and vehicle...[and] between-domains similarity" (p. 225). The domains

help specify what characteristics are important...[and] place limitations on the manner by which features or dimensions applying within the domain of the vehicle can be altered so as to fit the tenor. (pp. 216-217)

Their concept of 'within-domains similarity' is rather vague, but the important point is that since the tenor and vehicle belong to different domains, much of the similarity is "at best only analogous" (p. 218).

The concept of domains is an important contribution to understanding metaphor although it is not entirely new. Bréal (1897/1964) uses domain to refer to an "order of ideas" (p. 129):

A special kind of metaphor...comes from the communication between our organs of sense, which permit us to transport the sensations of sight into the domain of hearing, or the ideas of touch into the domain of taste. (pp. 129-130)

It is similar to Shibles' 'universe of discourse' as well as other concepts: "field of association" (Waldron 1967, p. 169); "different orders" (Empson 1964, p. 336); "thoughts...[or] contexts" (Richards 1936, p. 94); and "spheres of knowledge or experience" (Miller 1979, p. 222), which is also cited by Stern (1932), although he 
rejects it as too vague, preferring "essential identity" (p. 299). All these concepts seem to be suggesting that the duality of sense in metaphor encompasses more than the idea that there are two dissimilar referents.

\section{Lakoff and Johnson: Underlying Metaphors}

The duality of sense is interpreted in a radically broad way by the use of source domain and target domain in the theory of Lakoff and Johnson (Lakoff 1986, 1987a, 1987b; Lakoff and Johnson 1980a, 1980b; Johnson 1980, 1987). On the premise that "experience is structured in a significant way prior to, and independent of, any concepts" (Lakoff 1987b, p. 271), Lakoff and Johnson claim that all metaphors are "experiential" (Lakoff and Johnson 1980b, p. 19). From our bodily experiences--movement, sensations, orientational awareness, etc.--we form pre-conceptual image schemata to "give order and connectedness to our perceptions and conceptions" (Johnson 1987). Examples include "CONTAINERS, PATHS, LINKS, FORCES, BALANCE...UP-DOWN, FRONT-BACK, PART-WHOLE, CENTER-PERIPHERY, etc." (Lakoff 1987b, p. 267).

Using balance as an example, Johnson (1987) explains that metaphor involves projections of image schemata.

The meaning of balance begins to emerge through our acts of balancing and through our experience of systematic processes and states within our bodies. (p. 75)

From this experience, we form image schemata, and then in using the word, balance, "the metaphorical projections move from the bodily sense (with its emergent schema) to the mental, epistemic, or logical domains" (p. 87). Consequently, we can perceive sounds, colors, power, personalities, etc. as either balanced or unbalanced. 
According to Lakoff and Johnson (1980a), image schemata are distributed over three domains of experience, "physical, cultural, and intellectual" (p. 461). Metaphor draws from an image schema in one domain of experience and applies the concept to a target domain (Lakoff 1987b). For example, the statement My income rose this year entails the metaphor MORE IS UP, in which UP is in the (physical) source domain, and MORE is in the (intellectual) target domain; the experience of UP is used to understand the abstract concept of MORE (Lakoff and Johnson 1980b).

In most other theories of metaphor, My income rose probably would not be regarded as metaphorical, but Lakoff and Johnson (1980a) claim that "the essence of metaphor is understanding and experiencing one kind of thing or experience in terms of another" (p. 455); "one concept is understood in terms of another" (Lakoff 1986, p. 224). In general, we understand "the less clearly delineated in terms of the more clearly delineated" (Lakoff and Johnson 1980a, p. 477); for example, we understand the abstract in terms of the concrete.

They also claim that there are patterns of metaphors, and within these patterns there is "systematicity" (Lakoff and Johnson 1980a, p. 456). For example, all the UP metaphors are coherent, and all the DOWN metaphors are coherent:

HAPPY IS UP; SAD IS DOWN...

CONCSIOUSNESS IS UP; UNCONSCIOUSNESS IS DOWN... HEALTH AND LIFE ARE UP; SICKNESS AND DEATH ARE DOWN...

MORE IS UP; LESS IS DOWN...

GOOD IS UP; BAD IS DOWN...

VIRTUE IS UP; DEPRAVITY IS DOWN...

(Lakoff and Johnson 1980b, pp. 15-17) 
However, they are looking at presumed "underlying metaphorical systems" (Johnson 1987, p. 101). Consequently, they can claim there is such a metaphor as ARGUMENT IS WAR pervading English spoken in the United States:

Your claims are indefensible.

He attacked every weak point in my argument.

His criticisms are right on target.

I demolished his argument.

I've never won an argument with him.

You disagree? Okay, shoot!

If you use that strategy, he'll wipe you out.

He shot down all my arguments.

(Lakoff and Johnson 1980a, p. 454)

They also claim that "we don't just talk about arguments in terms of war...we live by the ARGUMENT IS WAR metaphor in this country; it structures the actions we perform in arguing" (Lakoff and Johnson 1980a, p. 455).

These are fascinating ideas, but their claims are challenged by counter-examples that spring up at every turn. For example, we defend Masters theses and attack meals; we can be on target in making a guess; we can demolish someone's faith; we can win someone's love; and we can say, "You have any good ideas? Okay, shoot!" Conversely, we can criticize someone's argument with a variety of metaphors: it won't hold water; it falls flat on its face; it is full of holes (or some scatalogical material); etc. As for 'systematicity', certainly many 'DOWN' expressions have negative connotations, but not all, for at least down-to-earth is good, and so is Our expenses were down this year.

Their premise that all metaphors have an experiential basis is also rather precarious. Johnson (1987) claims that "we cannot begin to understand the various meanings of balance without focusing on the preconceptual gestalt structures within our network of meanings" (p. 74). If this is true, it may be after the fact, for balance derives 
from the Latin bilanx (bi-twice + lanx-flat plate, scale); i.e., two-scaled or two-plated, referring to a device for measuring the weight of one thing against that of another $(O E D)$. Therefore, it is possible that at one time balance may have been used metaphorically with reference to the body, as were chest (a box for valuables) and skull (a shell of an egg or nut); the word balance may have been taken from another domain because the physical experience of balance was 'nameless'.5 Regardless of the metaphoric origin, the related senses of balance are established through use, and it cannot be that every one of them is entirely dependent on the physical experience of balance. The same could be said of any other supposed underlying metaphor; otherwise, how could a metaphor such as ARGUMENT IS WAR have meaning for someone who has not experienced war?

The larger question is whether all their examples are metaphors. Lakoff and Johnson are focusing on a supposed psychological process, and when they try to explain the linguistic phenomenon of metaphor in terms of this process, they make claims about underlying metaphors that can be neither proved nor disproved. Perhaps one cause of this problem is that "schema theory is so general that it readily lends itself to ad hoc accounts of almost any phenomenon" (Ortony 1980b, p. 359). The Lakoff-Johnson view is attractive because it confirms our intuition that many metaphors are systematically related. We do use up-oriented metaphors to express happiness floating; higher than a kite; on cloud nine), and we use down-oriented metaphors to express sadness (sink to the depths of despair; down in the dumps); if we can attack an argument, then we can also shoot it full of holes, blow it apart, etc. Such patterns of usage are worthy of study. However, it does not necessarily follow that every expression with the sense of either up or down in it is a metaphor. Despite the influence that it currently enjoys, the Lakoff- 
Johnson view of metaphor does little to help identify a metaphor, for it implies that an underlying metaphor can be found in any expression.

\section{Ortony: The Importance of Pragmatics}

In a more balanced approach, Ortony $(1975 ; 1979 c ; 1980 a ; 1980 b)$ says that "it is not linguistic expressions themselves that are metaphors, but particular uses of them" (1980a, p. 73). Metaphor fulfills one or more of three communicative functions, which Ortony (1975) explains in terms of "the compactness thesis, the inexpressibility thesis, and the vividness thesis" (p. 45). Metaphor can express ideas or feelings that are inexpressible in literal language. When literal expressions are too complex or verbose, metaphor can provide a compact alternative by communicating large chunks of meaning in a few words. The 'vividness thesis' repeats Aristotle's point that metaphor is often able to evoke images more vividly than literal language can, but Ortony adds the cognitive assumption that "metaphor lies much closer to perceived experience" (p. 50). Metaphor is "a means of conveying and acquiring new knowledge and of seeing things in new ways" (1980b, p. 361). Depending on the insight derived, a metaphor may be a comparison for someone who sees pre-existing similarity, and an interaction for someone who discovers similarity through the metaphor (1980b).

According to Ortony (1980a), a necessary condition for identifying a metaphor is pragmatic, or contextual, anomaly. This premise holds even for a semantically anomalous sentence, such as The crowd floated up the courthouse steps (though Ortony does not use this example), because "there can be no normal context in which it will fit unless it is interpreted metaphorically" (1980a, p. 73). Contextual anomaly becomes both necessary and sufficient when combined with two other conditions. First, expanding 
Grice's 'cooperative principle' to include a "sincerity postulate...[and a] relevance postulate" (1980a, p. 76), Ortony says that the speaker must both intend the expression to be a metaphor and believe that the hearer will recognize this intention. The second condition is that the hearer should be able to eliminate the tension created by the contextual anomaly.

In eliminating the tension, the hearer ignores the "salient aspects or attributes ...that are perceived as being incompatible" (1980a, p. 78) between the topic and the vehicle. For example, in The man is a wolf, these attributes of wolf would be ignored: physical traits; specific behaviors of hunting, procreating, and raising young; types of food eaten; etc. The process also involves "predicating of the topic only those contextually salient features of the vehicle that are consistent with the topic" (1980b, p. 358). Depending on the context, these salient features of wolf would probably be compatible with man: general behaviors of predation; killer instinct; voracity; rapacity; dogged determination; etc. Of course, the hearer does not do this incrementally; rather, "an entire cognitive substructure is mapped onto the topic" (p. 78).

\section{Kittay's Perspectival Theory}

Kittay's (1987) 'perspectival' theory also emphasizes context but argues that a metaphor can be identified and understood independently of speaker intention because "metaphorical use of language depends on systematic semantic features" (p. 46). For our purposes, the most significant aspect of this theory is the proposition that metaphor exhibits both "first-order and second-order meaning" (p. 41). This concept depends upon two other related concepts: a 'relational' (as opposed to atomistic) theory of meaning, and Kittay's version of semantic field theory. 
In presenting a relational theory of meaning, Kittay contends that "the context of an utterance is another utterance of greater complexity" (p. 78). In addition to the explicit linguistic context, there is a non-linguistic context (e.g., the time and place of utterance), which is also explicit because it could be "rendered linguistically as an utterance of a complexity higher than that of the given expression" (p. 62). Every utterance also has an implicit context, or "default frame" (p. 59), consisting of "default assumptions" (p. 56) about physical reality, cultural values, discourse requirements, common interests, shared experiences, dialects, etc. ${ }^{6}$ Given this definition of context, all meaning in natural language can be said to be context-dependent.

While a word does have meaning that is independent of both its default frame and the time and place of utterance, the informative content of a word is specified by its linguistic context. "All information is related to other information--it both includes and is included in other information...This is a relation of nesting" (p. 128). The nesting of information establishes relations of affinity between words; relations of contrast are established by alternate possibilities of information. "When words combine [in discourse], their informative content is selectively pruned so that the resulting message is coherent and appropriately informative" (p. 137). In other words, the specific meaning of a word is partially determined by "the system in which it is embedded" (p. 123). One system is its context of utterance, but even before it is used in that context, "a word's meaning is partially determined by its position in a semantic field" (p. 34).

Kittay explains the concept of semantic fields in terms of content domains and lexical sets. 
When a set of words, a lexical set, is applied to a domain unified by some content, a content domain, we have a semantic field. The semantic fields are comprised of terms which cover some specifiable conceptual ground and which bear certain relations of affinity and contrast to one another. (Kittay 1987, p. 33)

A content domain may be "any experiential, phenomenal, or conceptual domain" (p. 34), and it is comparable to Lyon's (1977) 'conceptual field'; e.g., colors, shapes, cooking, fishing, marriage, etc. "Content domains provide the conceptual substratum underlying language, independent of any particular language" (p. 228). Until a content domain is articulated by a set of related lexical items, it has "unformed content" (p. 225).

Conversely, a content domain provides "the informative content of a term" (p. 225). The set of lexical items that articulates a content domain is a semantic field.

Metaphor uses words in one semantic field (and its content domain) to refer to something in another content domain. Since a semantic field articulates a content domain, there must be two content domains and at least one semantic field. ${ }^{7}$ This is the condition when a semantic field is used to articulate an unformed content domain, such as a new concept. For example, the phenomenon of electromagnetism is articulated metaphorically by terms expressing fluidity: flow, current, waves, juice, etc.. Only one semantic field is involved because there were no (satisfactory) terms referring to the movement of electrons until fluidity terms were used. In a metaphor that articulates an unformed content domain, there is a transference of the "relations which pertain within one semantic field to a second, distinct content domain" (p. 36).

In other metaphors, there may be two semantic fields as well as two content domains. For example, one interpretation of The man is a wolf would determine that the content domain of the vehicle is ANIMALS, and the content domain of the topic is 
HUMANS; the semantic fields, respectively, are terms referring to animals and terms referring to humans, and within these fields are terms referring to wolf behavior and terms referring to human behavior. The transference of meaning is "a transference of relations of contrast and affinity across semantic fields" (p. 138) as well as a transference from one semantic field to another distinct content domain. Therefore, "metaphor involves at least one semantic field and another distinct content domain, and often two distinct semantic fields" (p. 291). Figure (1) illustrates Kittay's idea, incorporating the terms source domain and target domain used by Lakoff and Johnson.

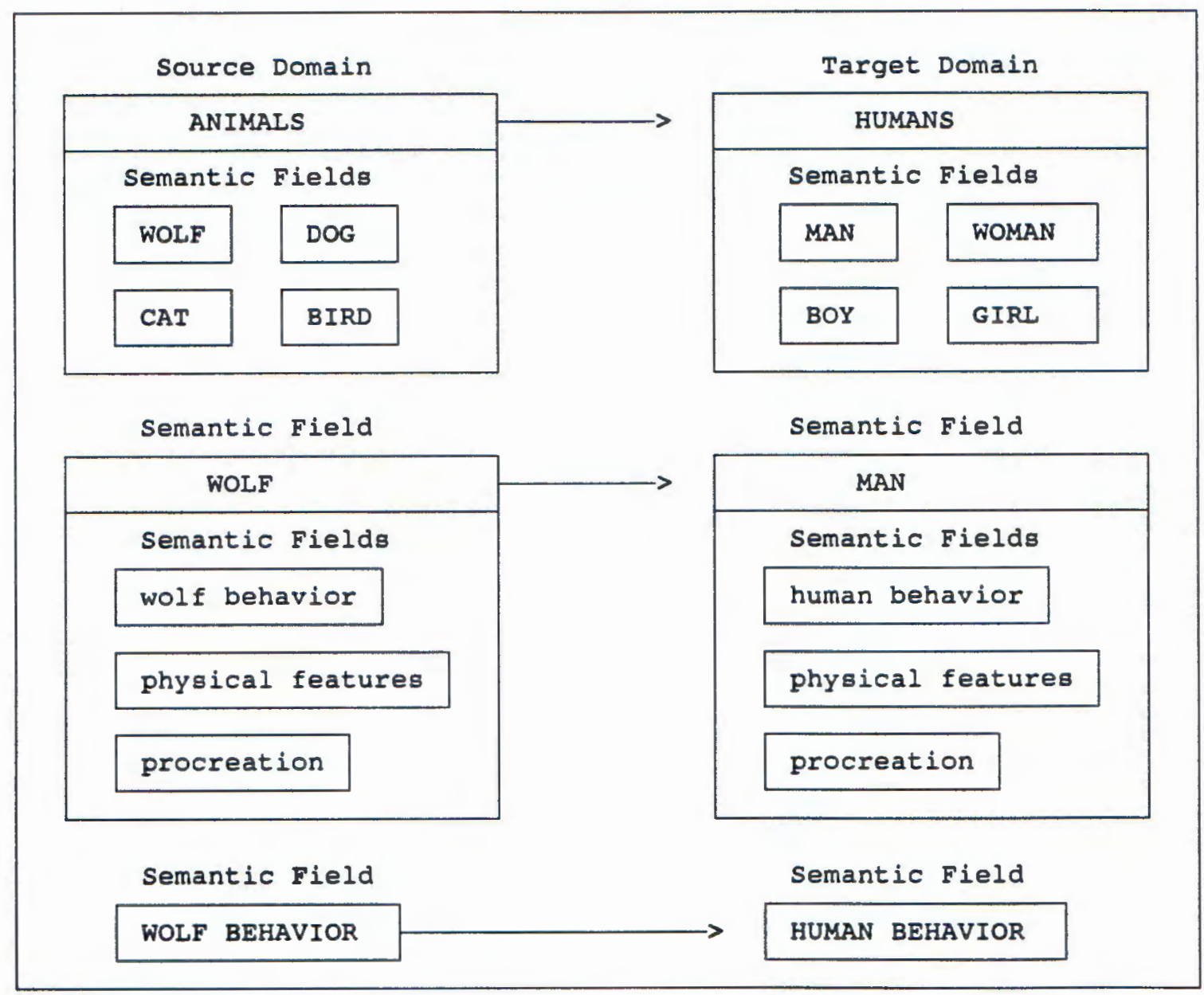

Figure 1. Domains and semantic fields for The man is a wolf, according to Kittay's theory. 
The chart also illustrates a corollary: a metaphor cannot consist of terms that belong to the same semantic field. This explains why The dog is a wolf is not metaphoric, for $d o g$ and wolf could easily be perceived as belonging to the same content domain and as co-hyponyms in the same semantic field. This also explains why to shoulder responsibilities is metaphoric, but to shoulder a rifle is not. In contrast to the semantic field for responsibility, the semantic field for rifle includes words for actions that can be taken with rifles, one of which is to place it on the shoulder. Furthermore, rifle has an affinity with other words for things that can be shouldered, such as broom, which cannot be said of responsibility. Finally, this requirement means that metonymy and synechdoche cannot be metaphors because each is comprised of terms in the same semantic field. Other figures of speech could be metaphors if their terms come from two distinct semantic fields; for example, hyperbole is often metaphoric, as in I was eaten up with jealousy.

However, stipulating the involvement of two distinct semantic fields and two distinct domains does not fully account for the duality of sense in a metaphor. It tells us how the topic and the vehicle are different from each other, but it does not explain how the metaphorical similarity is expressed. To this end, Kittay proposes that the meaning of a metaphor is "second-order meaning, which is a function of first-order meaning" (p. 24).

Consistent with advocating a relational theory of meaning, Kittay describes linguistic meaning in terms of compositionality. Just as words, phrases, sentences, texts, and discourse are "progressive combinations [that] produce increasing orders of 
grammatical complexity" (p. 51), the meanings within those constituents also combine. When we comprehend discourse, we strive to specify meaning by selecting among the possible interpretations those that seem to cohere with both contextual factors and our default assumptions. When interpretations cohere, we have secured "first order meaning, that is, the literal and conventional senses of an utterance" (p. 24). ${ }^{8}$

First-order meaning depends on two sets of semantic rules. One is " a set of conditions and restrictions on the semantic combination of utterences...known as semantic combination rules, or sc-rules" (p. 53). The other is a set of "cohesive projection rules" (p. 64) that govern "permissible linguistic combinations which are both intra- and inter-sentential" (p. 61). Metaphor creates an incongruity between the metaphorical utterance and its context by "bringing together...semantic fields that are kept distinct in first-order discourse" (p. 70). Therefore, metaphor breaks semantic rules and yields second order meaning.

Kittay's idea that second-order meaning is a function of first-order meaning adds some new insight to the duality of sense. In a metaphor, the speaker and the hearer perceive both a first-order meaning and a second-order meaning. In The man is a wolf, the first-order meaning of wolf is whatever we believe our speech community accepts as the literal and conventional sense of the word. The secondorder meaning of wolf is that, within the context of utterance, we may be able to see that the man is similar to a wolf, but in ways that are not exactly equivalent to the literal and conventional sense of wolf because a wolf and a man belong to different 
domains. The wolf that is hypothetically similar to a man is an abstraction, the features of which we can understand only if we have some first-order meaning of wolf in mind. However, the first-order meaning will vary according to individual knowledge and experience; e.g., one person may be an expert in the biology of wolves, another may have only seen wolves pacing in a zoo, and the knowledge of another may be limited to "Little Red Riding Hood" (which may be the source for the conventional sense of the metaphor). Consequently, the second-order meaning of wolf depends on, and varies with, whatever first-order meaning the speaker and the hearer have in mind; second-order meaning is a function of first-order meaning.

Kittay says that second-order meaning is as much the product of a cognitive activity as first-order meaning is, for metaphor also achieves reference. However, whereas literal meaning can refer directly, metaphor is part of an "anaphoric chain" (p. 303) in which one term from the domain of the topic has a literal referent; "metaphorical reference is always achieved through anaphora--anaphoric antecedents given in either the explicit or implicit context" (p. 310). For example, in the explicit linguistic context for White's cathedral metaphor, cathedral refers to this holy spot, which refers to a lake in Maine, which refers to the lake the author has in mind. In addition, cathedral may be regarded as a PRO-form similar to pronouns and reflexives, which replace other expressions that could refer to the antecedent, such as the repetition of the antecedent itself.

Another reason second-order meaning is a product of a cognitive activity is that seeing a man as a wolf (or a lake as a cathedral) involves a "perspectival 
shift...[i.e.,] a reordering of one content domain in accordance to the relations governing another semantic field" (p. 302). Kittay's 'perspectival theory' is named after the function of metaphor to provide a particular perspective in which both the speaker and the hearer can comprehend the topic.

Metaphor provides the linguistic realization for the cognitive activity by which a language speaker makes use of one linguistically articulated domain to gain an understanding of another experiential or conceptual [or phenomenal] domain. (p. 14)

Using Frege's distinction between sense and reference as an analogy, Kittay proposes that the vehicle and the topic of a metaphor, like Frege's 'morning star' and 'evening star,' are "two modes of presentation of the same object" (p. 30). This could be interpreted to mean that the duality of sense in metaphor involves "two conceptual contents which function as two simultaneous perspectives or categories in which some entity is viewed" (p. 29). The cognitive effect is "epistemic access to the referent through a different conceptual organization" (p. 313). Therefore, through the metaphor The man is a wolf, we have a new perspective on a man, which is achieved only because the metaphor expresses a second-order meaning of wolf that includes reference to human behavior.

Kittay's theory may be the most balanced, thorough, and precise accounting of metaphor currently available. However, there are some problems with her concept of content domain. In the first place, Kittay is not consistent in using content domain and semantic field; for example, she sometimes refers to fishing as a content domain and sometimes as a semantic field. She also uses the term "two content planes" (p. 298). A more serious problem is that often it is difficult to pinpoint the content 
domains involved, especially if they must be conceptual substrata independent of any language. In the cathedral metaphor, the possibilities for cathedral include architecture, religious architecture, places of worship, religion, and the experience of a cathedral; the possibilities for a lake in Maine include lakes, mountains, forests, camping, fishing, canoeing, vacation, and the experience of a mountain lake. Finally, as Kittay points out, the concepts of content domains and semantic fields "cannot be regarded as definitive...[because] the work in semantic field theory is still preliminary" (p. 247).

On the other hand, the concepts Kittay offers are more concrete than many other ways of explaining metaphor. Even preliminary definitions of content domain and semantic field can help identify a metaphor, for they explain why wolf can be used as a metaphor for man but not for dog, etc. It may also be easier to explain the duality of sense in terms of first-order/second-order meaning than by invoking more nebulous ideas such as implicative complex, parallel systems of beliefs, projections of image schemata, the mapping of a cognitive substructure, exchanges of meaning, or even the transfer of meaning. Finally, tracing metaphorical reference through an 'anaphoric chain' may be a concrete way of explaining Aristotle's idea that one term is 'put in place of' another.

\section{CONCLUSIONS}

Perhaps the most striking feature of metaphor is its duality of sense. A metaphor states or implies one thing and means something else, and yet the hearer (or 
reader) knows it is not a lie, an exaggeration, an ironic comment, a mistake expressing mere ambiguity, or an indirect speech act. A metaphor states or implies that two things (subjects, concepts, phenomena, experiences, actions, qualities, etc.) are similar when in fact they are substantially different. The word or phrase used as the vehicle for the meaning of the metaphor is given two referents; e.g., wolf refers to both a wolf and a man in The man is a wolf. It is also given opposing senses: a metaphorical wolf is a wolf and not a wolf; this wolf is something other than the actual wolf. The topic acquires the same duality: the man is a wolf and not a wolf; this man is a wolf only metaphorically. Consequently, the exact meaning of a metaphor is complex, ambiguous, and unparaphrasable. Paradoxically, however, the hearer has a fairly accurate idea of what the speaker means. This meaning depends upon a tacit agreement between the speaker and the hearer to see similarity between the two terms of the metaphor, all the while holding in mind the fact that they are quite different from each other. It is this multi-faceted duality of sense that distinguishes metaphor from any other kind of expression.

Faced with the task of trying to understand and explain the duality of sense, the student of metaphor may be tempted to settle for the dictionary definition and agree with Henle (1958):

There is little to be said on the subject of metaphor. It has been discussed from ancient times to the present and on the whole there has been a rough agreement. (p. 173).

The plethora of theories on metaphor currently available belie Henle's opinion.

However, they can lead to an equally dissatisfying antithesis: 
I suggest...that "Metaphors are black holes in the universe of language": We know that they are there; many prominent people have examined them; they have had enormous amounts of energy poured into them; and, sadly, no one yet knows very much about them. (Fraser 1979, p. 184)

Even if a middle ground is maintained, anyone who has studied metaphor in depth must agree with Tourangeau (1982): "To define the thing is one of the hardest problems" (p. 15).

The cause of this difficulty may be that puzzling over the duality of sense turns the spotlight on the semantic aspects of metaphor, leaving its pragmatic aspects in the shadows. Few students of metaphor would disagree with Ortony's (1979b) assessment of metaphor as a matter of both semantics and pragmatics. However, pragmatics is being overlooked when it is argued that there is a transfer of meaning from one term to another, or that there are exchanges between the meanings of words, or that systems of belief, cognitive substructures, or salient features are reciprocally 'mapped' from one term to the other.

Metaphor is, essentially, a matter of pragmatics. It is a way of using language to achieve particular communicative goals. The meaning of a metaphor depends not only on the context of utterance, but also on a "reflexivity of belief and intention" (Green 1989, p. 13) between speaker and hearer (or writer and reader). If I say, The man is a wolf, I do so with the belief that you will believe I am neither lying nor speaking irrelevant nonsense. My intention is to make some kind of comparison, and I believe that you will be able to infer my intention as well as the comparison. This belief is based partly on the fact that I will have made the 
statement in a context that not only tells you which particular man is my referent, but also should contain enough information about the man's personality and behavior to suggest in what ways I want you to see him as similar to a wolf. But I also believe that you will believe that I do not mean the man is identical to, or even actually similar to, a wolf. In fact, in order for my intended metaphorical comparison to be communicated, it is crucial that neither of us believe that my referent is in any literal way like a wolf.

This is what Grice (1975) means by saying that metaphor is a flouting of the maxim to be truthful. The obvious falsity compels my audience to draw implications, or as Grice calls them, "conversational implicatures" (p. 45), about my statement. Similarly, Black (1979a) says there are "unstated implications: Their producers need the receiver's cooperation in perceiving what lies behind the words used" (p. 27). In producing The man is a wolf, I must believe that you will be able to draw inferences from everything you know, and everything you believe I know, about this particular man as well as about certain human behavior, wolves, and wolf behavior. In order for you to make the comparison that I intend, both of us must tacitly accept "the pretense that something is the case when it is not" (Turbayne 1962, p. 13).

However, metaphor is not solely a matter of pragmatics.

The semantics will...provide a characterization of the literal meaning or conventional content of the expressions involved, and from this, together with details of the context, the pragmatics will have to provide the metaphorical interpretation... [This is because] the full meaning of most of the sentences we utter is best captured by a technical division of labor between a semantic component and a pragmatic one. (Levinson 1983, p. 156) 
Second, a word used metaphorically is not only given two different referents; it is also temporarily given an additional sense. Furthermore, semantics is apparent in the way metaphor conforms to the accepted premise that "the semantics [of any utterance] is COMPOSITIONAL and basically TRUTH-CONDITIONAL" (Green 1989 , p. 6). Even though a metaphor states or implies something that is false, it can be regarded as truth-conditional because the agreed-upon pretense gives metaphor an "as if or make believe feature" (Turbayne 1962, p. 17), which establishes conditions under which the metaphoric utterance could be considered true. According to Miller (1979), the audience assumes that "what the author said is true in the state of affairs he is describing" (p. 214); the context of a metaphor is a "semantic model" (p. 206) in which the truth conditions may be found.

"To say that the semantics is compositional means that...the meaning of the whole is a function of the meanings of the parts" (Green 1989, p. 6); that is to say, the meaning of the whole depends on, and varies with, the meanings of the parts. If we remove a metaphor such as The man is a wolf from its context, we cannot interpret it accurately; we cannot derive the intended metaphorical meaning from the meanings of its component words. However, in a sense, the meaning of the metaphor is still compositional because it is "dependent on a prior use of words which is conventional and arbitrary" (Waldron 1967, p. 18). In other words, we know what wolf means conventionally, and therefore, in the metaphor it must mean something else. Furthermore, the context of the metaphor radically alters the conventional meanings of these words, and the metaphorical meaning varies accordingly. The 
compositionality of metaphor is more precisely explained by Kittay's (1987) proposition that metaphorical meaning is second-order meaning, which is a function of first-order meaning; therefore, the only way to understand how a man can be metaphorically similar to a wolf is to have some first-order meaning of wolf in mind. In fact, Kittay claims that the distinction between first-order and second-order meaning "cuts across the semantic-pragmatic divide" (p. 42).

One advantage of a traditional approach is that it keeps our attention on metaphor as a particular use of language. Cognitive theorists may be correct in saying that metaphor is the linguistic realization of 'metaphorical thought'. Perhaps metaphor is a way of understanding one experience or concept in terms of another. However, for pedagogical purposes, it would be counter-productive to try to explain the supposed mental processes involved in 'metaphorical thought'. In contrast, we can explain in detail how a metaphor substitutes one word or phrase for another. Even if paraphrases are inadequate for expressing every nuance of meaning that a native speaker of English comprehends upon hearing a metaphor, we can explain in detail how a metaphor makes a comparison of two dissimilar subjects. It should also be easy for the student to recognize the two referents of a metaphor as well as the fact that each one includes a set of connotations that are partly dependent on context. Finally, an explanation of how metaphor expresses the comparison can be presented in concrete terms, such as Turbayne's 'as-if' feature of metaphor.

On the other hand, cognitive views offer at least three useful perspectives. First, they stress that the pervasiveness of metaphors in everyday speech is 
significant; metaphor is not just an artistic or poetic way of using language. Second, they give strong arguments against the vague idea that there is a transfer of meaning from the word used metaphorically to the word representing the topic of the metaphor. Rather, they rightly emphasize that the duality of sense involves not just two words or phrases, but two systems of thought or concepts. Third, this emphasis requires that the meaning of a metaphor be understood in terms of the different domains to which the words and concepts belong.

Since Aristotle's use of the phrase similarity in dissimilars to characterize metaphorical meaning, two general claims about metaphor have evolved. Within the traditional framework, metaphor is a way of speaking about two different things as if they were one; "it gives you two ideas as one" (Turbayne 1962, p. 17). Cognitive theorists tend to follow Black's (1979b) claim that "one thing is thought of (or viewed) as another thing" (p. 192).

These concepts really are not that far apart, and there is an interpretation that can integrate them. When we create a metaphor, we use a word that conventionally (or literally) refers to something in one conceptual, phenomenal, or experiential domain to refer to something in a different domain; i.e., the word used metaphorically is temporarily given two different referents. It is also temporarily given an additional sense. This additional sense could be regarded as a second-order meaning, in contrast to the first-order meaning, which is the literal and conventional sense of the word used metaphorically. The second-order meaning is a function of the first-order meaning because it depends on, and varies with, whatever first-order 
meaning the speaker and the hearer have in mind. This is possible only because both the speaker and the hearer tacitly agree to an 'as-if' condition; that is, both are aware that the two referents are distinctly different, but accept the pretense that they may be seen as if they were similar. Metaphor, then, is a way of using language to communicate the perception that two substantially different things may be seen as if they were similar, and this metaphorical comparison depends crucially on an awareness that they are not in fact similar. 


\section{NOTES}

${ }^{1}$ Probably any expression could be used metaphorically, given the appropriate context. For example, She shouldered her rifle could refer to a lawyer filling her briefcase with notes to be used in taking aim at her courtroom opponent. The point here is that She shouldered her rifle is an example of conversion, while She shouldered her responsibilities can only be metaphoric.

${ }^{2}$ Grice's ideas will be discussed in a little more detail in Chapter III.

3 Black's 1962 view is the one that most theorists respond to because his 1979 version has not been as widely disseminated. The older view is closer to Richards', but Black uses "principle subject" for the tenor and "subsidiary subject" for the vehicle; the ground is a "system of associated commonplaces." His 1979 view revises his earlier claim that the system of associated commonplaces transfers or projects a set of predicates pertaining to the subsidiary subject onto the principle subject. His later view also abandons the idea that a metaphor is a "filter" through which the principle subject is viewed; i.e., the idea that metaphor filters out nonsalient features of both subjects.

${ }^{4}$ Black wants to say that these two sets of implications are isomorphic to each other, but he admits that there is a "'mixed lot' of projective relations" (p. 31). In my example, C2 and L2 are not exactly isomorphic.

${ }^{5}$ It would be insightful to find out what term was used in England prior to the adoption of the French balance, but my efforts thus far have been fruitless. 
According to the $O E D$, the Old English wage referred to a pair of scales as well as its function; these senses were extended both literally and figuratively. However, apparently wage was not used to refer to the bodily experience of balance. Presumably Old English and/or Anglo-Saxon may have had a term similar to the German die Selbstbeherrschung (self-control) or das Gleichgewicht (yielding to an equal [weight]). Also, as in German, there may have been different terms to refer to the various activities and conditions currently covered in English by balance.

${ }^{6}$ It might be argued that the default frame could be articulated, just as the nonlinguistic context can be articulated. If so, there is no reason to distinguish between implicit and explicit contexts. However, the distinction is valuable because the pragmatic aspects of language require that there be non-linguistic or extra-linguistic contexts.

${ }^{7}$ That there must be two content domains is something I have had to deduce because Kittay is unclear on this point. On page 289 , she raises the question of whether it is a necessity, but never states a conclusion.

${ }^{8}$ Kittay stresses literal and conventional because some "idioms and very conventionalized metaphors, for example, 'Hold your tongue'" (p. 51), have a conventional meaning that is different from its literal meaning. There are two problems with this argument. First, Kittay is assuming "hold your tongue" metaphorically extends the literal meaning of hold, 'to take and keep with the hands or arms'. However, this meaning derived from the generalization of a literal meaning established at least since 1000 AD: 'to keep, possess, contain, detain (etc.) anything'. 
Second, if "hold your tongue" means 'do not speak', and if that is its only meaning, then that must be its literal and conventional sense. These two issues will be discussed further in Chapter III. 


\section{CHAPTER III}

\section{DEAD METAPHORS AND METAPHORIC EXTENSION}

And the bottom line is this: Iraq's reign of terror has ended. (President Bush, News Conference, March 2, 1991)

They are expressing the bottom-line feelings about the Japanese dominance in the consumer electronics market. (Dan Rather, CBS News, Feb. 17, 1989)

But when it came to the bottom line of points allowed, the Giants were the first (211) and the 49er's second. (Oregonian, Jan. 20, 1991, p. E9)

OK. That's it. That's my bottom line. That's my last offer...Wait a minute...There are bottom lines and there are bottom lines. (Murphy Brown, TV sitcom series, Nov. 5, 1990)

Anyone with experience in business knows bottom line refers to the last line on a profit-and-loss statement. Therefore, these examples must be metaphors. A term normally used in the domain of business is being used to refer to something in other domains, even the domain of emotions, to say that one thing may be seen as if it were similar to the conclusion of a balance sheet. But are they metaphors? In these examples, bottom line is synonymous with other phrases: (a) final word; (b) basic; (c) most significant factor; and (d) last offer.

Many speakers are using bottom line without consciousness of using an accounting term metaphorically. A prime example comes from a high school activities coordinator: "The bottom line is he wanted us to give him your phone 
number so that he could try to talk you into selling your skis directly to him." When asked what she meant by bottom line, she replied, "Bottom line' is 'last resort', I guess" (personal communication). Another example is pierced with irony: "But the issue is, is money the bottom line? We also have to think of morality" (Caller on a radio talk show, KXL AM, Portland, Oregon, Sept. 18, 1991). In the past decade, this expression has saturated everyday speech to the extent that, to some sensitive ears, it has become an unpleasant cliché. Indeed, there are bottom lines, and there are bottom lines.

It seems that the accounting term is becoming broader and more general. The bottom line is the result after everything that can be added in is added in, and everything that can be taken out is taken out. What was once a metaphor is no longer a metaphor, or perhaps it is a metaphor only to those with business experience. On the other hand, people in business are also using it to express this conventional sense rather than as a metaphor.

In observing the various uses of bottom line, we are witnessing the transformation of a novel metaphor to what is commonly known as a dead metaphor. Although this change may seem to be haphazard, it is actually following a systematic process of metaphoric extension. When semantic change results from this process, as seems to be the case with bottom line, it is systematically related to other forms of semantic change. However, the main objective of this chapter is not to develop an argument about the role of metaphor in semantic change, but to describe metaphoric extension in a way that will facilitate the selection and organization of a vocabulary 
based on this process. The first question to address (and the main problem) is this: How can we regard these metaphors as 'dead' if we continue to use them?

\section{FROM NOVEL TO DEAD}

\section{The Dilemma of 'Dead Metaphor'}

When a metaphor becomes established as a conventional expression, it may seem to be something less than it once was. "The metaphor may fade, so that it loses its metaphorical force" (Stern 1931, p. 309); it becomes "etoliated" (Black 1979a, p. 27) or "degenerate" (Tourangeau and Sternberg 1980, p. 208). The common pejorative is 'dead metaphor'. But if it is dead, why call it any kind of metaphor at all? The reason, apparently, is that the typical dead metaphor, "the leg of a table for example...comes to life very readily" (Richards 1936, p. 117). If that is the case, then why call it 'dead'?

This dilemma has prompted some theorists to propose alternatives to the term dead: "lexicalized" (Blank 1988, p. 21); "conventional" (Lakoff and Johnson 1980a, p. 453); "historical" (Lakoff 1987a, p. 147); "established" (Cooper 1986, p. 130); "stored" (Morgan 1979, p. 141); "hidden" (Turbayne (1962, p. 25); and "stock" (Empson 1964, p. 335). "Many words occupy a position between living and dead metaphors...[which are] sometimes called sleeping or faded metaphors" (Waldron 1967, p. 178); Leech (1974) calls these "moribund" (p. 213). Fraser (1979) suggests dead metaphors could be plotted on a continuum between 'alive' and 'dead', and Black (1979a) suggests "appropriate labels might be 'extinct', 'dormant', and 'active'" 
(p. 26). However, merely changing labels does not lead us out of the dilemma. We need to know how a novel metaphor becomes established in the lexicon as a dead metaphor.

The problem, once again, is a confounding of the semantic and pragmatic aspects of metaphor. The spotlight is kept on semantics by the assumption that a metaphor dies, fades, or diminishes in some way. The duality of sense is no longer prominent; a dead metaphor has "lost its tension of parts" (Hester 1967, p. 18). The speaker does not seem to be saying that two different things may be seen as metaphorically similar; rather, the sense being communicated seems to be literal. Consequently, the use of dead metaphor also highlights the semantic change that may have taken place; e.g., leg, once referring only to an anatomical organ, now also refers to a component of a table, a chair, a bench, etc. However, since a metaphor is a metaphor only because a word or phrase is used in a particular way, pragmatic forces must be involved in the transformation from a novel metaphor to a 'dead' one. The following discussion proposes that the process of metaphoric extension is driven primarily by pragmatics. The meaning of an expression is extended metaphorically when it is used to refer to something in a distinctly different phenomenal, conceptual, or experiential domain. This extension temporarily gives the word or phrase an additional sense, but if this additional sense continues to serve communicative goals, it can become either a conventional sense or a literal and conventional sense. Therefore, the way out of the dilemma imposed by the value- 
laden metaphor, dead metaphor, is to recognize that the metaphorical sense survives in a dead metaphor; if anything 'dies', it is the use of the expression as a metaphor.

\section{Awareness and the 'Death' of a Metaphor}

It is generally assumed that dead metaphors "are based on a conjunction of opposites which have occurred so often that the individual has become unaware of the opposites involved" (Apter 1982, p. 64). This view has little explanatory value because it says a novel metaphor becomes a dead metaphor by accident; our minds are simply stupefied by repetitive exposure to a metaphor. It does not explain why we intentionally use a word or phrase to express a metaphorical comparison, and then later (apparently unintentionally, according to this view) use it to express a literal or conventional meaning.

At first glance, an emphasis on speaker/hearer awareness may seem to be a more accurate way of characterizing these metaphors than to label them as 'dead', 'moribund', 'sleeping', etc. Speakers and hearers may be more or less aware that an expression is (or once was) a metaphor, and therefore, we could imagine a continuum of awareness rather than a dead-alive continuum. By focusing on awareness, we avoid the issue of whether leg of a table, for example, is more dead that swamped with work, or that the latter is more easily resurrected than the former. Many speakers are probably aware that swamped with work is a metaphor that has become a conventional way of saying one has too much work to do. In contrast, in normal conversation, hardly anyone is aware of the metaphoric origin of leg of a table. 
With expressions such as leg of a table, it is easy to imagine that for a time speakers were aware of the metaphor and through repetition of use lost that awareness. But consider some computer-related metaphors: shell, menu, memory, mother board, virus, clone, and mouse. As with leg of a table, these terms express literal meaning because they are the only names of specific components, processes, or conditions. However, speakers in the computer field are aware that they are using recently-introduced metaphors. This awareness is especially evident in the fact that the electrical cord attached to the mouse is humorously referred to as the tail. These metaphors reveal that it is possible to be fully aware of a metaphor and simultaneously regard it as expressing literal meaning.

Therefore, identifying degrees of awareness is no more useful than calculating some condition between alive and dead. Either approach only recognizes knowledge of the fact (or probability) that an expression at one time was a novel metaphor. Another approach is needed.

\section{An Alternative: First-order/Second-order Meaning}

Kittay's (1987) concept of first-order/second-order meaning contributes to one possible explanation of how a novel metaphor becomes a dead metaphor. Metaphor expresses both first-order and second-order meaning. First-order meaning is the literal and conventional sense of an expression. A novel metaphor temporarily creates a new, second-order meaning, which is a function of the first-order meaning. In some metaphors, that second-order meaning becomes established as a literal and conventional sense; i.e., a new first-order meaning. 
For example, clue currently refers to a fact, an idea, or an object that can help solve a problem or mystery. As early as the 9 th C., clue (or clew) referred to "A globular body; a ball (formed by coiling together or conglomeration)...A round bunch or cluster of things" $(O E D)$. One type of clue was a ball of yarn or thread, which (according to the $O E D$ ) was used to guide someone into and back out of a labyrinth, though this may have occurred only in the legend of Theseus. Consequently, clue was used metaphorically to refer to something that helped solve a problem or mystery; that is, as if similar to a thread guiding someone out of a labyrinth. For most speakers, the sense of clue as a ball of yarn or thread (the first-order meaning) ceased to be used, and the metaphorical (second-order) meaning became the literal and conventional sense of clue. ${ }^{1}$ The second-order meaning is no longer a function of the first-order meaning; we do not think, 'as if similar to a ball of thread guiding someone out of a labyrinth'. Rather, the word has acquired "as a first order meaning the sense which previously only contributed to its second-order meaning" (Kittay 1987, p. 142).

In reference to a table (chair, bench, etc.), leg has undergone the same kind of change except that its original first-order meaning continues to be used. The original first-order meaning of leg names the anatomical organ to which it refers. At one time, presumably, a second-order meaning was created by using leg metaphorically to refer to part of a table, which served as the only name for that object. The second order meaning in the metaphor has become a literal and conventional sense of leg, and therefore, another first-order meaning; it is no longer a function of the original 
first-order meaning. Since the original first-order meaning still exists, it is easy to recognize that former duality of first-order/second-order meaning, and when we do, it may seem that the metaphor 'comes to life'.

However, we are almost never conscious of the anatomical leg in leg of a table, and most speakers of English are oblivious to the original literal meaning of clue. Even if we are aware of a metaphoric origin, as is possible in swamped with work, we do not think of either of the two possible sources of the metaphor: (a) the actual conditions in a swamp or (b) a boat filling with water and sinking. In other words, it is the original first-order meaning, not the second-order meaning, that diminishes or becomes 'hidden' in a dead metaphor.

How does this happen? Is it an accident that occurs over time? Is it the result of random influences, along the lines of genetic mutation? Does a metaphor really become worn-out or sickly, or fall asleep, or die because we use it too much?

A feasible solution appears in Kittay's (1987) version of the assumption that we lose awareness of a metaphor:

No matter how 'dead' or conventionalized, metaphors are metaphors none the less. Consider the ease with which their metaphorical origins may be called forth. Few metaphors seem as dead and worn-out to us as 'leg of a table'... The conventional metaphor may, then, be viewed as falling within first-order analysis when its dormant double semantic import is either fully forgotten by the generally competent speaker (a genuinely dead metaphor) or for practical linguistic purposes safely disregarded. (p. 89, italics added)

In the claim that dead metaphors 'are metaphors nonetheless', Kittay seems to be lapsing into the common tendency to overlook the fact that an expression is a metaphor only because we use it as such. Consequently, she is undermining her 
bridge between the semantics and pragmatics of metaphor. Following her own agrument, if a metaphor expresses both first-order and second-order meaning, the latter being a function of the former, then a word or phrase expressing only firstorder meaning is not a metaphor. In normal usage, leg of a table expresses only first-order meaning; this particular sense of leg is not a function of the sense referring to the anatomical organ. We can recognize the (probable) metaphoric origin for leg of a table because the original first-order meaning is still in use, but it is not normally used metaphorically with reference to a table. It is no longer a metaphor. If it were, then we would have to say that a word such as complicated is used as a metaphor because its Latin root means 'folded together'. Rather than say these expressions are 'metaphors nonetheless', it may be more accurate to regard them as former metaphors, or expressions that at one time had been used as metaphors. However, Kittay has brought out two ideas worth pursuing.

First, we should distinguish between 'genuinely dead' metaphors and those that express a more conventional sense, such as swamped with work. For the sake of argument, I will reserve the term dead for former metaphors that now express literal and conventional meaning; e.g., leg (of a table), clue and complicated. In normal conversation, the new first-order meaning of a dead metaphor is no longer a function of a prior first-order meaning even if we are aware of its metaphoric origin. Therefore, we would have to say that even the computer mouse, which is so obviously metaphorically-derived, must be a dead metaphor. It may seem that this use of mouse cannot be regarded as a truly dead metaphor because the word also 
refers to the well-known rodent; hence the comical 'tail'. However, this only indicates a metaphoric origin. Its meaning has to be literal because it is the only name for the computer object to which it refers, and speakers do not need to think of the living mouse in order to communicate. Those metaphors that we may still intentionally use and/or construe as metaphors regardless of how conventional their meaning need another designation. For the sake of argument, I will adopt Empson's (1964) term, 'stock metaphor', because it is simple and captures the idea that they have become established as part of our lexical inventory.

The second useful idea in Kittay's statement is that when we are still aware of the 'double semantic import' in a dead metaphor, we disregard it 'for practical linguistic purposes'. Kittay does not develop this idea, but it provides a feasible solution to the problem of how a novel metaphor becomes a dead metaphor. It also helps explain how some dead metaphors seem to 'come to life'. Finally, it keeps the bridge between semantics and pragmatics intact.

I would like to propose that a novel metaphor becomes a dead metaphor because we disregard the first-order meaning for pragmatic reasons; essentially, to exploit the communicative efficacy of the second-order meaning. In a novel metaphor, the speaker and the hearer tacitly agree to accept the 'as-if' quality; they are equally aware of the presence of both first-order and second-order meaning. If the second-order meaning (e.g., 'basic issue' for bottom line) becomes communicatively more significant, the speaker and hearer disregard the first-order meaning ('net profit or loss'), which establishes that second-order meaning as a 
conventional sense. In some cases, it becomes established as a new literal and conventional sense, or first-order meaning, as it has in clue, leg, and the computer mouse. However, this does not necessarily mean that we disregard the fact that the expression is (or was) a metaphor. We may retain that awareness, and when we do, it neither contributes to nor detracts from the process of metaphoric extension because the important factor is the extent to which we disregard the original first-order meaning.

The current use of the computer terms shows that process in action. The speakers using these terms are creating metaphors, accepting them as conventional ways of speaking, and at the same time, they are establishing literal senses for those words in that context. More important, however, the speakers are aware of the metaphors, but disregard the original first-order meaning in order to achieve communication with the second-order meaning. This phenomenon suggests that the literal senses of terms such as leg of a table and electric current were established in the same way, and did not necessarily require either the passage of time or overexposure to the metaphors.

Therefore, perhaps we can characterize stock metaphors on a continuum of conventional and literal sense:

STOCK METAPHORS

literal and
conventional


We push a stock metaphor closer to 'literal-conventional' the more we disregard the first-order meaning. The less first-order meaning is disregarded, the greater is the possibility that it can be identified, construed, or intended as a metaphor. The majority of stock metaphors will drift back and forth along the continuum, influenced by a wide range of variables, such as context of utterance, verbal signals, and speaker/hearer background (experience, education, cultural values, dialect, etc.). It is not a matter of whether an expression is more or less metaphorical; i.e., more or less 'alive' as a metaphor. Rather, it is a matter of whether the speaker intends and/or the hearer construes the expression as a metaphor, and this depends upon the degree to which they either attend to or disregard the original first-order meaning.

In other words, it is a matter of pragmatics because it involves not only contextual factors, speaker/hearer background, etc., but also the reflexivity of intention and belief. When we disregard the first-order meaning, we intend to let the second-order meaning express a relatively literal or conventional sense. Furthermore, we believe that our audience will recognize that intention and not believe we are using an expression metaphorically. Even though we know our audience may be aware (as we are) that the expression was used metaphorically at one time and may still be construed as a metaphor, we believe that our audience will believe that communication of intended meaning will be facilitated more by construing the expression as literal (or conventional) rather than metaphorical. Consequently, the tacit, agreed-upon pretense of a metaphor becomes a tacit agreement to disregard the first-order meaning in favor of the second-order meaning. 
When the original first-order meaning has ceased to be used, as with clue, it is impossible not to disregard it. It is a dead metaphor and outside the continuum. Of course, it would be possible to pay attention to the original first-order meaning if someone discovers its etymological connection with the new first-order meaning. However, this would only contribute to an awareness of two senses, one of which is obsolete.

If a second-order meaning has been established as an additional first-order meaning, the original first-order meaning is necessarily disregarded; e.g., leg of a table; head of a compay; and face a problem. In these expressions, it is possible to pay attention to the original first-order meaning, but there is no need to do so because it would not facilitate communication. For example, to understand head of a company, there is no need to perceive a person occupying that position as metaphorically similar to the uppermost organ on the human body. In fact, there is a greater need to disregard the comparison because the sense of head of a company/ family/class/group; etc. has already been established as a literal and conventional sense. It is the most efficient way of communicating the idea, and therefore, not disregarding the original first-order meaning may interfere with or at least complicate communication. ${ }^{2}$

In many collocations, such as forge a plan and flow of traffic, there is no need to disregard first-order meaning, but we habitually do so. The same is true of idioms such as Cut me some slack, on the flip side and a can of worms. A strong bit 
of evidence is the often-heard It sounds fishy instead of It smells fishy, for if we were attending to the first-order meaning, we would not use the verb sound.

On the other hand, with many of these kinds of expressions, communication may be facilitated by attending to the duality of sense if it makes the statement more vivid. This may be one reason that many metaphors are 'stock' rather than 'dead'. There may be a pragmatic need to be able to disregard the first-order meaning to a greater or lesser degree according to the goals of the communication.

The exact first-order meaning of some stock metaphors may be either unknown or incorrectly identified. For example, benchmark can easily be interpreted as referring to a mark on a bench that a tailor or some other craftsman might use for measuring; in fact, it is a surveying term $(O E D)$. Similarly, folk etymology has spread the rumor that kick the bucket is derived from a method of hanging someone by having the victim kick a supporting bucket. According to the $O E D$, bucket originally referred to the beam on which a pig was suspended by its hind legs for slaughtering; when its throat was slit, it kicked the bucket. In cases such as these, the significant factor is that there is (or was) a distinct first-order meaning, and it is this fact that is either attended to or disregarded. To know the exact original first-order meaning is unnecessary.

\section{Patterns of Metaphoric Extension}

In order to illustrate how the second-order meaning of a metaphor becomes established as a new first-order meaning, the literal-conventional continuum needs to be expanded. Figure (2) shows a basic pattern that can be used for this purpose. 


\section{(1) FIRST-ORDER MEANING}

(2) NOVEL METAPHOR

(3) FIRST-ORDER $\|$ SECOND-ORDER

(4) SECOND-ORDER

FIRST-ORDER

(7) SECOND-ORDER

(6) SECOND-ORDER

(5) SECOND-ORDER

fiter Hot order

first-order

(8) STOCK METAPHOR

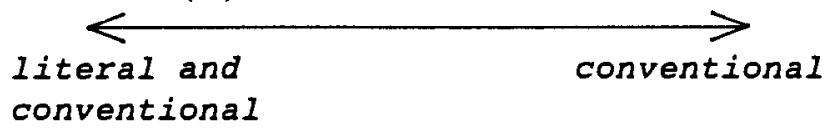

$\vee$

(9) NEW FIRST-ORDER MEANING

(10) DEAD METAPHOR

Figure 2. Basic pattern of metaphoric extension when new first-order meaning is established.

The reason for calling a literal and conventional sense 'first-order meaning' (1) is to distinguish it from the meaning that the metaphorical use of a word or phrase expresses. In a novel metaphor (2), both first-order and second-order meaning are perceived; they are parallel (3), with neither one attended to more than the other. If this usage continues to be an effective way of communicating intended meaning, there is an increasing pragmatic need to disregard the first-order meaning. As we increasingly disregard the first-order meaning (4-7), it becomes less prominent and is eventually almost obscured by the second-order meaning. There is always the possibility that the speaker and/or the hearer may be prompted to attend to the duality of first-order/second-order meaning; the second-order meaning may still be regarded 
as a function of the first-order meaning to some degree. Therefore, the continuum under STOCK METAPHOR (8) is represented by a double arrow. However, if a new first-order meaning is established (9), the second-order meaning is no longer a function of the first-order meaning, and the first-order meaning is necessarily disregarded. We could call this new sense a 'dead metaphor' (10) in order to distinguish it from a stock metaphor. (Subsequent diagrams omit 'dead metaphor' in the interest of space.)

Figure (3) illustrates the preceding analyses of clue and leg. For both words, the new first-order meaning (F-O.2) is a new sense. The main difference between them is that the original first-order meaning (F-O.1) of clue has become obsolete (at least for most speakers), while the original first-order meaning of leg has survived. ${ }^{3}$ It also illustrates that the original first-order meaning can generate other novel metaphors, which can become established first as stock metaphors and then as dead metaphors expressing a new sense of the word. However, as indicated by the question marks under leg of a journey, it is not always clear whether a new sense has been established or whether the expression is normally used as a stock metaphor.

Figure (4) shows how different metaphors can be derived from different features of a word's meaning (here, F.1 and F.2). ${ }^{4}$ Originally aftermath referred to the second mowing of grass or hay, which implies an additional benefit (F.1). However, the second mowing is never as good as the first (F.2); as quoted in the $O E D$, "No aftermath has the fragrance and the sweetness of the first crop." Consequently, the $O E D$ cites two kinds of metaphors: (1) "I am one that hath lived long and gathered in Life's aftermath"; (2) "Rash Lover, speak what Pleasure hath Thy Spring in such and Aftermath!" In most dialects, aftermath no longer refers to an agricultural event, and its current literal and conventional meaning derives from F.2: "a result or consequence, esp. an unpleasant one" (Webster's 1984). 


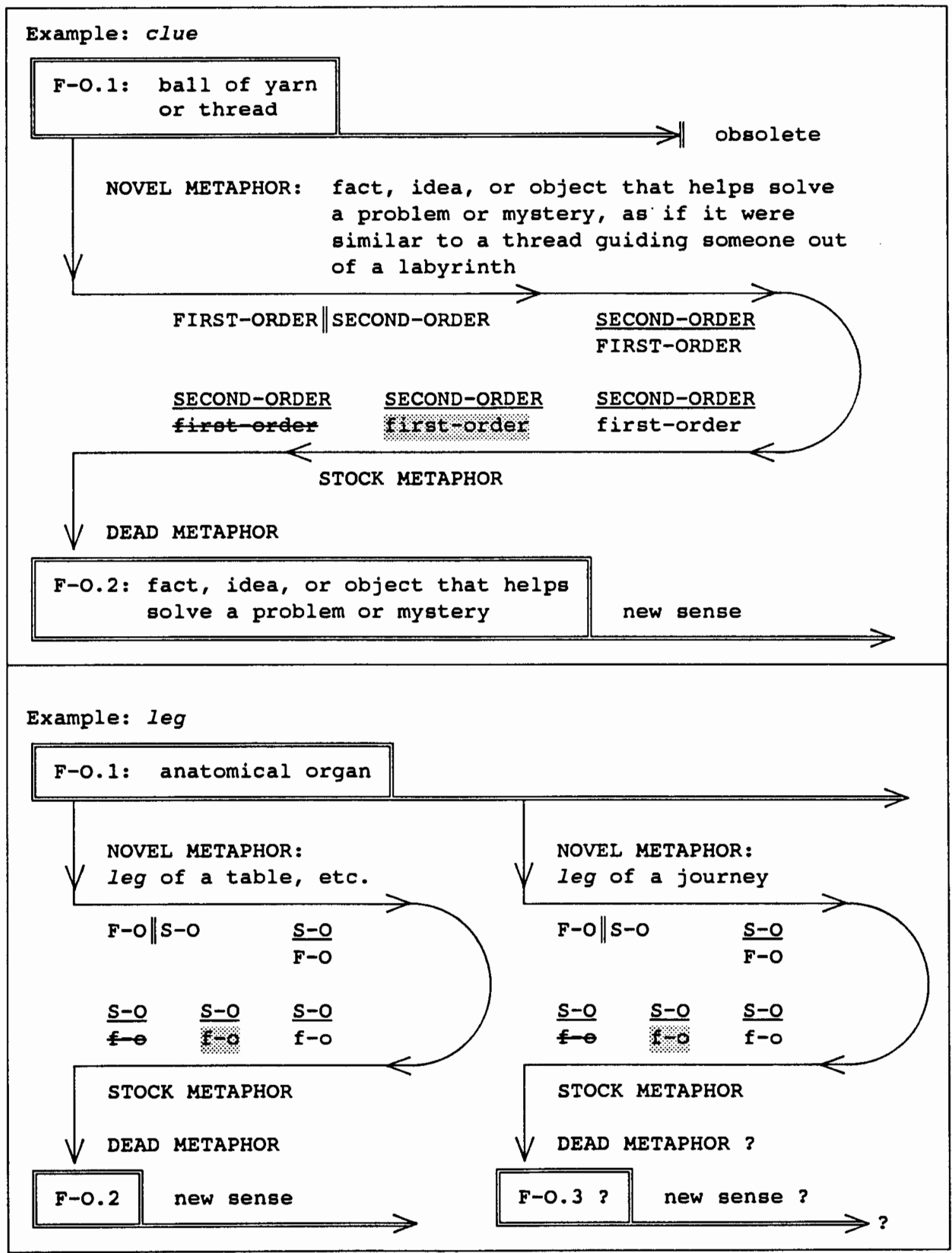

Figure 3. Original first-order meaning (F-O.1) either continues or is replaced by new first-order meaning (F-O.2). 


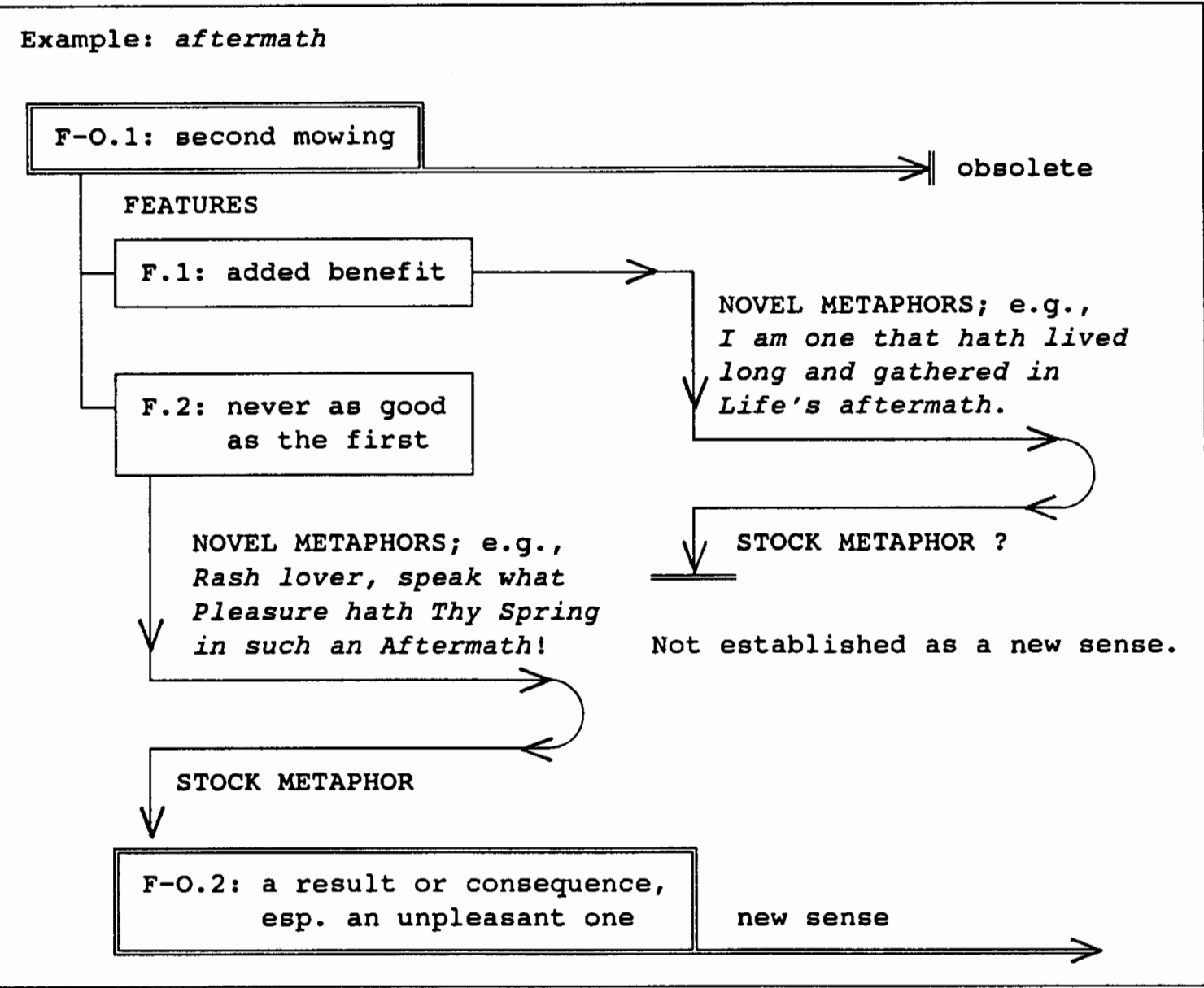

Figure 4. Different features of meaning lead to different metaphors.

The pattern illustrated in Figure (5) reveals two other characteristics of metaphoric extension. First, once a new sense is established, it can be used metaphorically, which in turn can lead to another stock metaphor and, possibly, another new sense. Second, conversion of a noun to a verb is often involved. This is apparent in so many other stock or dead metaphors, as the examples in Chapter I reveal. The example here is browse, which is commonly used (in the U.S.) as a verb meaning 'to examine anything casually, particularly articles for sale'. Figure (5) shows how this sense derives from the noun browse, which in the 16th $C$. referred to young shoots and twigs of shrubs, trees, etc. Two features of this meaning can be 
identified. The first (F.1) is that browse was eaten by goats and cattle in the field, and by deer in the wild. Consequently (F.1.a), browse was gathered by farmers as fodder for livestock: "If thou have any trees to croppe for the fyre-wodde, croppe them in wynter that thy beastes maye eate the brouse and the mosse of the bowes" $(O E D)$. The reference to fodder may have become obsolete because more efficient ways of providing winter feed have been devised. The first feature has survived, though, through the conversion of the noun to a verb, meaning "to feed on the leaves and shoots of shrubs, trees, etc., said of goats, deer and cattle" (OED). Today we still speak of animals browsing, though it may be used most often with reference to certain animals such as deer. Shakespeare used this meaning metaphorically in Cymbelline: "There is cold meat i' th' cave, we'l brouz on that" (qtd. in $O E D$ ). Whether this kind of metaphor became a stock metaphor is uncertain, but it does seem feasible. However, the metaphor to browse in a library has become not only a stock metaphor but also a new sense of the verb browse; e.g., "We get a glimpse of him browsing--for... he was always a random reader--in his father's library" (qtd. in $O E D)$. It is not uncommon today to hear browse refer to the casual sampling of books in a library, and in the U.S. we also speak of browsing in a department store, at a magazine rack, a garage sale, a crafts fair, a bake sale, etc. This sense would not have been established if the original noun had not been converted to a verb.

Using lock as an example, Figure (6) also illustrates how a new sense can be used metaphorically, but in this case the subsequent new sense seems to be what is commonly known as an idiom. Again, conversion from a noun to a verb was a necessary phase. As a noun, lock originally referred to

an appliance for fastening a door, lid, etc., consisting of a bolt (or system of bolts) with mechanism by which it can be propelled and withdrawn by means of a key or similar instrument. (In OE app. used with wider meaning, applied, e.g. to a bar, bolt, latch, or the like.) $(O E D)$ 
Example: browse

$$
\begin{aligned}
\text { F-0.1: } & (n .) \text { young shoots \& twigs } \\
& \text { of shrubs, trees, etc. }
\end{aligned}
$$

FEATURE: uge of browse

F.1: eaten by goats, deer, cattle, etc. in the

subsequent use

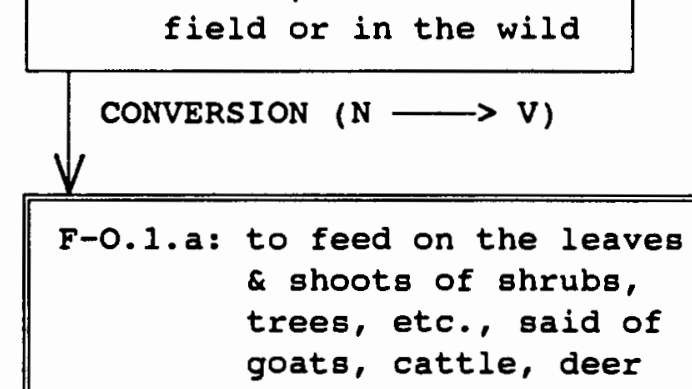

NOVEL METAPHOR:

to read parts of books

as if similar to animals

$\checkmark$

browsing (i.e., casually

sampling)

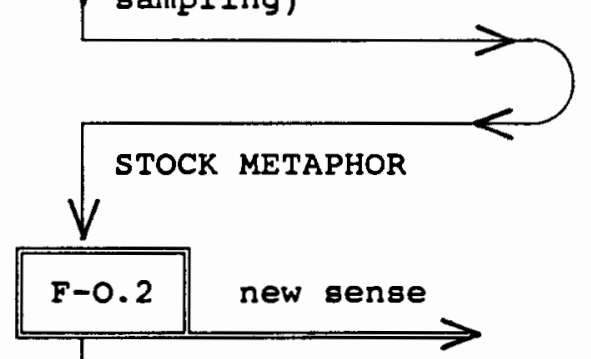

NOVEL METAPHOR:

to look casually over

$\bigvee$ articles for sale.

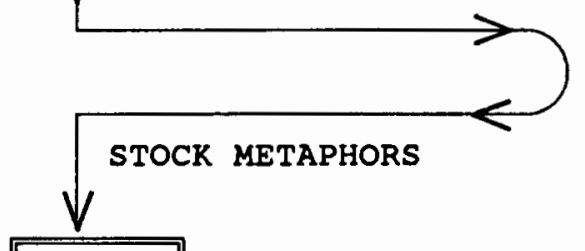

NOVEL METAPHOR:

to nibble food as if similar

to animals browsing (e.g.,

Shakespeare: There is cold

meat $i^{\prime} t^{\prime}$ ' cave, we'I brouz

on that.)

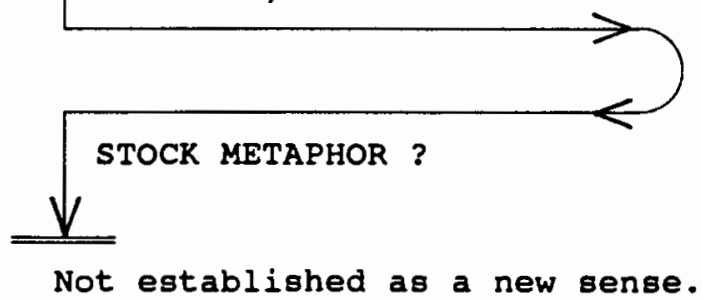

$\mathbf{F}-0.3$

to examine anything casually

Figure 5. A new sense established by metaphoric extension used metaphorically, leading to another new sense. 
The verb lock, then, means to fasten a door, etc. with a lock. One metaphor, to lock horns, has extended this meaning into the domain of animals; specifically male animals with horns, such as cattle, sheep, elk, and deer. The metaphor, of course, is saying that when the horns of these animals become stuck together during battle, the situation may be seen as if it were similar to the closure of a mechanical lock. Today the expression is at least a stock metaphor, and probably a new sense of lock.

One reason it can be considered a new sense is that the whole phrase, to lock horns, has been used metaphorically to compare human combat, whether physical or intellectual, to that of these animals; it does not compare human conflict to a mechanical lock. In other words, with reference to these animals, to lock horns expresses a first-order meaning, and when the phrase is used metaphorically with reference to humans, it also expresses a second-order meaning. However, in normal conversation, there is some degree to which we disregard the reference to animals in combat, and therefore it is at least a stock metaphor. If a new sense has been established, it is probably an idiomatic sense.

On the other hand, it may be that, once a novel metaphor acquires currency in everyday speech as a stock metaphor, its conventional sense can be extended without necessarily first becoming established as a new, literal and conventional sense. For example, if we can lock in on a military target by using radar, then we can also lock in on someone's ideas, an argument, a job, a contract, a business deal, etc., as if similar to using radar. There are many other examples of this extension. If the meaning of user-friendly becomes commonly understood, then it can be extended to include customer-friendly, viewer-friendly, family-friendly, etc. Once we appreciate the function of a computer-program menu, then we know what is meant by investment menu. In effect, this extension broadens the metaphorical meaning. 


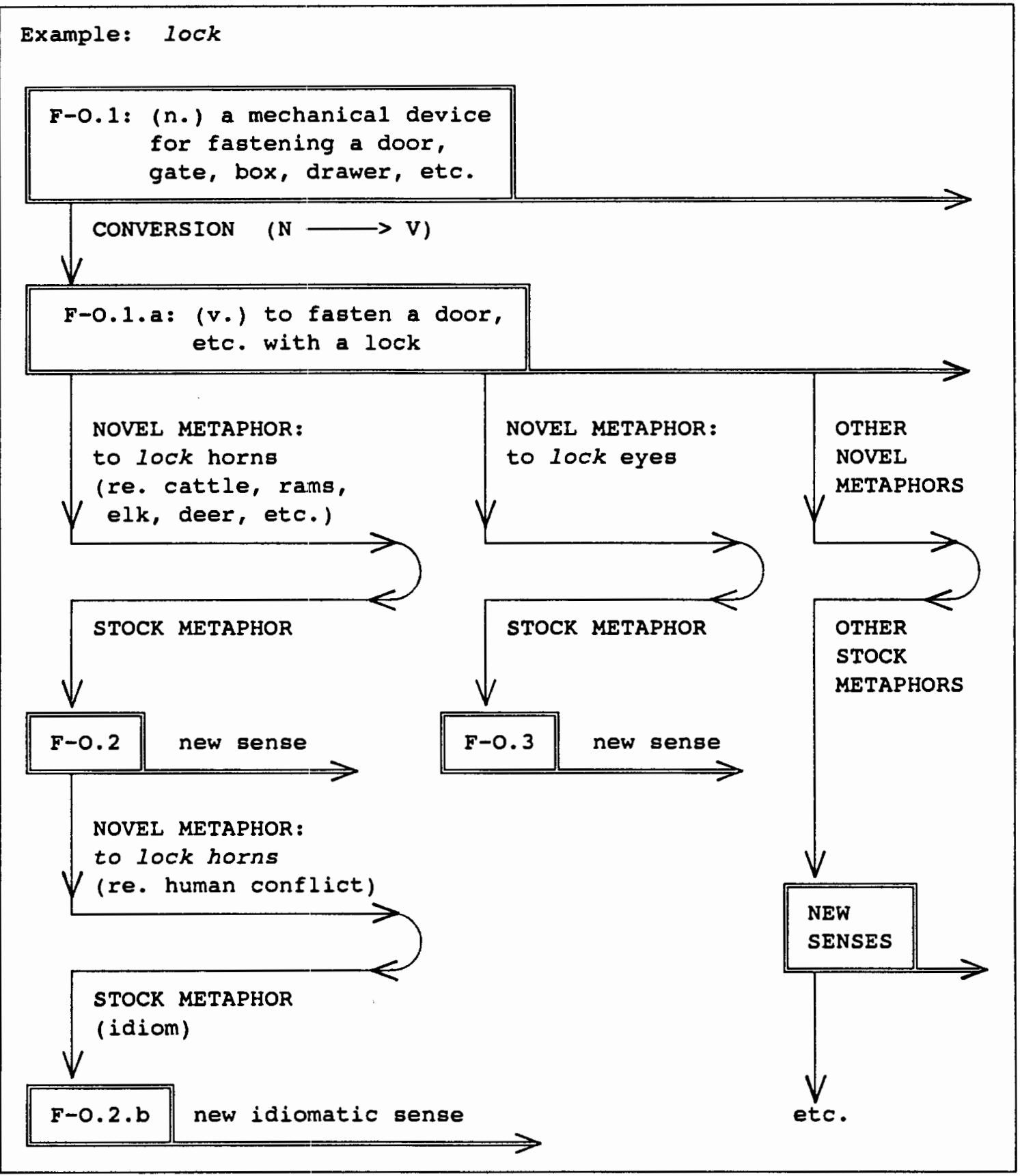

Figure 6. A possible pattern for the broadening of meaning in metaphoric extension.

Figure (6) suggests as well that metaphorical meaning is also broadened when it is used in many different contexts. As with to lock eyes, many expressions seem to 
convey the sense of fastening or securing something as if similar to the action of a lock:

to lock arms, fingers, etc.

locked away in one's head, heart, etc.

to have a lock on something

to be locked into something

to lock up a contract, a business deal, etc.

headlock/armlock/necklock (wrestling terms)

deadlock

locked in an embrace

lockstep

There are at least three idioms involving lock: to lock horns (referring to humans), under lock and key and lock, stock and barrel. Some obsolete uses of lock include reference to a hobble for horses, an enclosure for goats, and a lift on a railway. Of course, a lock on a river or canal is still a passagway for boats. Other uses include:

oarlock or rowlock

vaporlock, airlock

land-locked

flintlock, wheel-lock, percussion-lock, and matchlock

lock-nut, lock-piece, lock-band, lock-chain, etc.

Joints (ankles, knees, jaws, etc.) as well as brakes and gears can lock or lock $u p$, and lock can be used to refer to anything that fastens one thing to another or stops parts of a mechanism from moving. Indeed, many things, both abstract and concrete, can be locked or interlocked. However, with such a broad meaning, how do we know which of these examples of lock express senses derived from its metaphoric use, and which derive from its literal use? Many other patterns of metaphoric extension can probably be identified, but the various uses of lock suggest that we need to be cautious in identifying such patterns and attributing semantic change to that process. The key is to have some understanding of how semantic change resulting from metaphoric extension relates to other processes of semantic change. 


\section{METAPHORIC EXTENSION AND SEMANTIC CHANGE}

Philologists in the 19th Century described three basic processes of semantic change which are still generally accepted: generalization (or extension), specialization (or restriction), and shift (or transfer).

A sense may expand to include more referents than it formerly had (generalization), contract to include fewer referents (specialization), or shift to include quite a different set of referents (transfer of meaning) ...When we increase the scope of a word, we reduce the number of features in its definition that restrict its application. For instance... a mill was earlier a place for making things by the process of grinding ...A mill is now simply a place for making things; the grinding has been eliminated...The opposite of generalization is specialization, a process in which, by adding to the features of meaning, the referential scope of a word is reduced. Deer, for instance, used to mean simply 'animal'. (Pyles and Algeo 1982, pp. 242-244)

Meaning may be transferred in many ways. For example, the meanings of long and short have been transferred from spatial to temporal concepts. Meaning may also be transferred from concrete to abstract, from subjective to objective and vice versa, and from one sensory faculty to another. Metonymy involves the transfer of meaning from one thing to something it suggests or is closely related to, as when hand is used to refer to someone's writing. Metaphor is probably the most productive type of semantic transfer, as "when we extend the word foot 'lowest extremity of an animal' to all sorts of things" (Pyles and Algeo 1982, pp. 244-245). (See also Bréal 1897/ 1964; Leech 1974; Lyons 1977; Müller 1874; Stern 1931; and Waldron 1967.)

Sometimes it is difficult to attribute semantic change to any of these processes. For example, rather has neither become narrower nor broader, nor has it transferred meaning to 'all sorts of things'. Rather, it seems to have shifted from denoting 'precedence in time' to denoting (a) contrast or opposition, as it does in introducing this sentence; (b) degree, as in I rather enjoy etymology; (c) preference, as in I would rather do it myself; and (d) 'more truly, accurately, precisely, or properly speaking'. 
These related senses may have resulted from the kind of shift that Waldron (1967) calls "a marginal change among the criteria of a lexical category" (p. 142). Other examples include bargain (from 'agreement' to 'a good deal'), literally (from 'nonfiguratively' to 'actually'), and kick the bucket (from 'to be killed' to 'to die').

As presented here, this scheme oversimplifies the topic, but even in more detailed analyses there are many questions lurking in the background. For example, what is the difference between saying that generalized literal meaning 'includes more referents' and saying that metaphoric transfer extends meaning 'to all sorts of things'? Waldron (1967) points out that the terms generalization and specialization "describe what happens in nearly all shifts" (p. 149). Therefore, perhaps any 'transfer' is not a separate process of semantic change, but part of either generalization or specialization, or both.

More pertinent to our purposes is the issue of distinguishing between metaphoric extension and literal generalization. 5 When metaphoric extension results in semantic change, is it the result of using an expression metaphorically in many contexts, or is the fact that it can be used in many contexts an indication that the meaning has already been broadened? Perhaps metaphor itself broadens the meaning of the expression. For example, when we use a metaphor such as to lock eyes, we are eliminating all the features of the meaning of the verb lock (referring to the mechanical device) except the feature of fastening two things together; therefore, we are expanding the scope of the word to include reference to eyes, arms, horns, etc. The conclusion has to be that either metaphor generalizes literal meaning or it broadens metaphorical meaning in a way that is very similar to the way generalization broadens meaning. Perhaps literal generalization occurs in metaphoric extension after a new sense is established. On the other hand, for example, perhaps the literal meaning of lock $(v$.) had been generalized to mean 'to fasten or secure anything, 
whether concrete or abstract' long before it was ever used with reference to eyes, arms, or horns. Would it not be the case, then, that once literal meaning is generalized to that extent, an expression cannot be used metaphorically because there is no context in which it would not have literal reference?

These issues cannot be resolved here, and yet we need to be fairly certain of when semantic change results from metaphoric extension as opposed to literal generalization. Tentatively we could utilize the concept of domains as a basic criterion since metaphor involves the use of an expression to refer to something in a distinctly different experiential, conceptual, or phenomenal domain. Perhaps this is what is meant by the idea that metaphor extends meaning to 'all sorts of things'. In contrast, generalization may involve the extension of literal meaning to many referents in the same domain.

This distinction can be seen in another example of generalization given by Pyles and Algeo (1982):

For instance, tail (from OE tagl) in earlier times seems to have meant 'hairy caudel appendage, as of a horse.' When we eliminated the hairiness (or the horsiness) from the meaning, we increased its scope, so that in Modern English the word means simply 'caudal appendage.' (p. 243)

There is a metaphorical meaning that has also been broadened, and consequently we use tail to refer to the end of almost anything non-animal; for example, tail of a tale/a story/a shirt/a comet/a plane/an eddy of water; tail-wind; tail-off; tailings; etc. Apparently the broad meaning established by metaphoric extension can make reference in almost any domain as long as it is not an animal-with-a-tail domain. Conversely, in order for the literal meaning to be generalized, the domain must be broad enough to include all animals with tails.

However, it may be necessary to include the stipulation that generalization extends meaning into closely related domains as well. This is suggested by a more 
detailed analysis of the literal generalization of mill, Figure (7), which reveals that it is not quite accurate to say mill now refers to any 'place for making things'. A machine shop is not called a mill; nor do we use mill to refer to a place in which metal is stamped or pressed, plastic is extruded, electronic components are assembled, etc. The broad domain in which mill has been generalized could be identified as MANUFACTURING, but mill more specifically refers to certain kinds of machinery doing 0 certain kinds of work in certain kinds of buildings.

Originally mill referred to both the machinery used for grinding grain (or corn, as it was called) and the building fitted with such machinery. (The OED points out that, even though mill apparently was used to refer separately to machinery in the 16th C., earlier usage did not distinguish between the machinery and the building "which was necessarily connected with it.") The first general feature of this definition, the machinery (F.1), is characterized by three other features: (F.1.a) a revolving wheel or cylinder; (F.1.b) the action of reducing grain to powder or pulp by grinding or crushing; and (F.1.c) powered by either wind or water. Since the work of the wheel or cylinder is to grind and crush, then any wheel that grinds, crushes, or cuts solid material in a similar fashion could be called a mill; e.g., a drillbit used in mining ore, a (metal) milling machine, and a wood-saw. This feature was further generalized to include any machine doing work by rotary motion; e.g., rolling (metal), spinning (fibers), fulling (cloth), coin fluting, etc. The second feature of the machinery (F.1.b) has been generalized from specifically grinding grain into flour to grinding or crushing any solid substance such as wood-chips and chocolate. It is also used to refer to the reduction of ore into fragments, hulling seeds, and expressing juice in a cider-mill or a cane-mill. With the broader meaning of milling machinery as well as concommitant technological changes, the feature (F.1.c) of being powered by wind or water is no longer a relevent distinction. The second general feature, the 


\section{Example: mill}

(n). A mechanical apparatus for grinding grain

a the building fitted with this machinery

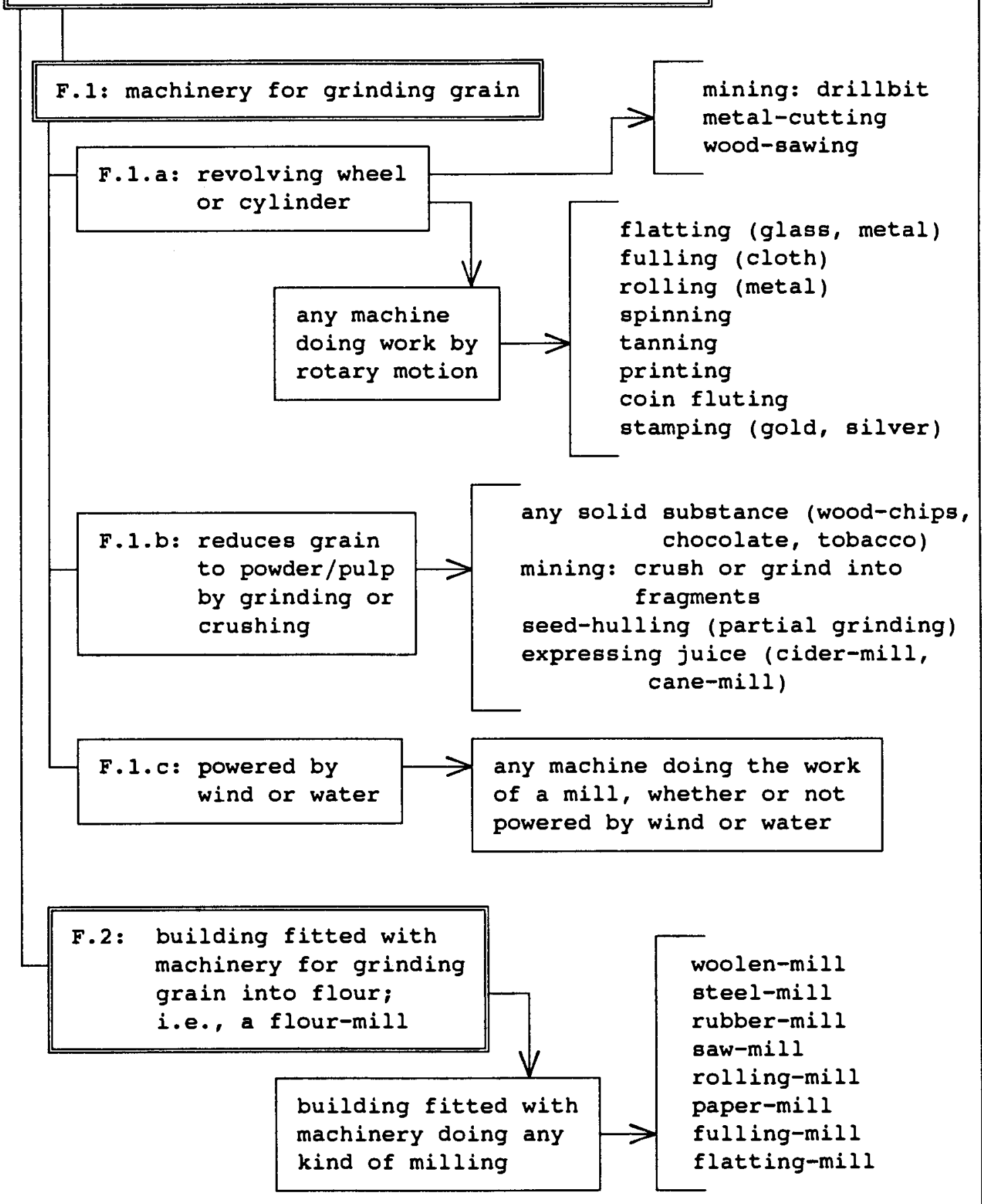

Figure 7. Mill: an example of literal generalization. 
building (F.2), now refers to any building fitted with machinery for doing any kind of milling; e.g., woolen-mill, saw-mill, paper-mill, rubber-mill, etc.

Even though it is difficult to define precisely the domain to which mill belongs, it seems to be characterized by manufacturing processes utilizing machines that do their work by rotary motion. Some mills turn material in order to process it, and others grind, crush, or cut solid material through the use of cylinders or wheels. Therefore, we could either use a detailed description to identify a broad domain, or we could identify several narrower, closely-related domains such as flour-milling, mining, cloth manfacturing, and lumber-production. In either case, when mill is used to make reference in those domains, the sense expressed is the result of literal generalization.

Apparently mill has not been used metaphorically very often, but one metaphor provides a reason to choose narrower, closely-related domains over a broad domain: to mill about (or around). This expression describes people or animals moving around in a cluster, as if similar to the slow turning of (specifically) a flour-mill. Incidentally, if we consider the degree to which we disregard the reference to a flourmill, we would probably conclude that it is either a stock metaphor or a dead metaphor and, therefore, a new sense of mill.

It is fairly obvious that to mill about is metaphorical because it makes reference in two distinctly different domains, animals and humans. But the criterion of domains can also help determine whether the meaning of an expression that sounds metaphorical actual derives from metaphoric usage or not. For example, to overhaul an engine sounds metaphorical because haul means to pull or draw something, but it is actually a product of literal generalization. Overhaul has a nautical origin: "To slacken (a rope) by pulling in the opposite direction to that in which it is drawn in hoisting; to release and separate the blocks of (a tackle) in this way" (OED). This 
meaning was generalized as follows: [slacken a rope, etc.] $\longrightarrow$ [pull any piece of nautical machinery apart in order to examine in detail and make repairs] $\longrightarrow$ [pull any machinery apart, etc., nautical or not] $\longrightarrow$ [take apart and repair engines, cars, boats, milling machines, punch presses, etc.]. Either the generalization broadened the domain of overhaul from (perhaps) NAUTICAL MACHINERY to MACHINERY, or it allowed overhaul to be used in many closely-related domains. When overhaul is used in a completely different domain, such as EDUCATION, then it is metaphorical; e.g., to overhaul the educational system. In fact, the metaphoric use of overhaul has established a new sense, which has been broadened to make reference in many non-machinery domains. Consequently it is possible to overhaul a policy manual, a set of beliefs, a wardrobe, etc.

In the same way, the criterion of domains should help identify the metaphorically-derived senses of lock. Since lock was originally a mechanical device, literal generalization occurs in any domain involving mechanical devices; e.g., oarlock; airlock; flintlock; lock-nut; locked brakes; and a lock on a river. In contrast, semantic change resulting from metaphoric extension makes reference to humans, animals, abstract concepts, or anything in a non-mechanical domain; e.g., to lock eyes, arms, etc.; to lock in on something; headlock; locked knees; etc.

In opposition to this claim, it might be argued that expressions such as locked brakes and a lock on a river could be metaphorical because they suggest similarity to the locking device. However, both a river lock and the locking of brakes may be seen as literally similar to the mechanical lock, whereas the comparison in to lock eyes is metaphorically similar, but not similar in fact. Furthermore, it seems feasible to trace the generalization from the mechanical lock to locked brakes as follows: [mechanism that locks] $\longrightarrow$ [a device for keeping any set of movable parts fixed, fast, or rigid] $\longrightarrow$ [an action or condition that causes movable parts to 
become fixed, etc.; e.g., to cause brakes to lock]. The reference to a river lock was probably generalized as follows: [mechanism that locks] $>$ [a place secured by a lock] $\longrightarrow$ [a barrier or enclosure; e.g., for goats (now obsolete); a jail] $>$ [a barrier on a river (now obsolete) $] \longrightarrow$ [a system of gates and sluices on a river or canal to lift or lower boats from one level to another]. (See OED.)

By utilizing the concept of domains as a criterion, we are merely extending one of the basic criteria for identifying a metaphor. However, this approach still does not resolve two problems. First, it is impossible to know with certainty whether an expression such as to lock eyes was ever used metaphorically, or whether it expresses a literal generalization, meaning 'to fasten anything, whether concrete or abstract'. Second, in and of itself, the criterion of domains does not always stipulate the domains involved. For example, if to overhaul the educational system is metaphorical, is it derived from the nautical usage of overhaul or from the reference to overhauling an automobile engine? Similarly, is swamped with work derived from the reference to a swamp or the reference to the sinking of a boat?

Questions such as these may only be answered by considering pragmatic factors. One speaker may have knowledge of 'to cause a boat to sink' as a sense of swamp (v.), while another may only think of the conditions in a swamp and, therefore, interpret swamped with work to mean 'as if stuck in a swamp with no way out'. If to overhaul the educational system is construed as a metaphor, recent cultural experience would probably compel the interpretation that it makes a comparison to overhauling an automobile engine, rather than overhauling a block and tackle. As for to lock eyes, the historical fact of whether or not it was ever used as a metaphor is irrelevant. All that matters is that it can be intended or construed as a metaphor and, therefore, at one time it probably was a novel metaphor. Even if the meaning of lock 
had been generalized to refer to anything abstract or concrete, this use of lock refers to something in a distinctly different domain than that of the mechanical lock; therefore, it is at least a stock metaphor, and probably a dead metaphor.

A re-examination of clue can summarize how metaphoric extension relates to other processes of semantic change. By the 9th C., it had the broad meaning of 'a ball or conglomeration, usually formed by rolling or coiling something'. That sense became obsolete as it was replaced by more specialized senses, two of which are still in use today. First, as a verb, it means ' to roll up the lower ends of sails'; hence, 'the lower ends of sails'; hence, 'a metal loop fastened to those ends'. The second sense also has a nautical origin, referring to the cluster of lines on which a hammock is hung. (See OED and Webster's.) The specialized sense of 'ball of yarn or thread' became obsolete, replaced by its metaphoric use, which has since become established as a new literal sense. This sense has become broadened in two directions. First, it includes many referents: an idea, an object, a fact, a theory, etc. Second, it expresses a broad sense, which can be represented by terms that would be synonymous in certain contexts: hint, suggestion, answer, solution, indication, symptom, guess, etc.

Generalization and specialization are systematic processes of semantic change, and whether metaphoric extension should be regarded as a transfer of meaning or a mode of generalization, it does seem to be systematically related to these processes. However, in order to avoid erroneously attributing all sorts of senses to presumed metaphors, it is important to distinguish between literal generalization and the broadening of meaning produced by metaphoric extension. The concept of domains seems to be a useful criterion for making this distinction. 


\section{CONCLUSIONS}

Metaphoric extension can result in semantic change, but it does not necessarily follow that "today's metaphor is tomorrow's literal sense" (Moore 1982, p. 23). Not every novel metaphor is retained for its communicative value in everyday speech. Among those that are retained, not all become established as dead metaphors expressing a literal and conventional sense. Many should be regarded as stock metaphors (or by some similar designation) because they express some degree of conventional sense and yet may easily be intended or construed as metaphors. However, even though stock metaphors may not have undergone permanent semantic change, both stock metaphors and dead metaphors are components of our lexical inventory and, therefore, eligible to be taught as vocabulary items.

In identifying dead metaphors and stock metaphors as vocabulary items, it is important to keep in mind that we would be teaching senses of words. They are senses that have survived the prior metaphoric use of words. Furthermore, these senses often depend upon collocation with other words, and therefore whole expressions as well as sets of related words and senses need to be taught as well. Since these expressions have the potential to exhibit the peculiar characteristics of metaphor--that is, the multi-faceted duality of sense--we also need to teach the process of metaphoric extension. In other words, we need to be able to explain not only why these expressions are regarded by native speakers as some kind of metaphor, but also how they changed from novel metaphors to the lexical items that they are.

I have suggested one possible dynamic for this process: speakers and hearers tacitly agree to disregard the original literal meaning (or first-order meaning) in order to achieve communicative goals with the meaning established by the metaphor (or the second-order meaning). This is not a haphazard, accidental occurrence, but a 
systematic process of metaphoric extension that is driven by pragmatic factors. We intentionally use a word or phrase to express a metaphorical comparison. If that metaphorical meaning continues to express intended meaning, we intentionally use it as a conventional sense (i.e., as a stock metaphor); in some cases, we use it as a literal and conventional sense (i.e., as a dead metaphor). This process can be represented by diagrams which trace the various patterns that metaphoric extension can follow.

Since we are dealing with a process that sometimes results in permanent semantic change, we also need to be able to relate metaphoric extension to other processes of semantic change. The most important process is probably literal generalization because metaphoric extension also broadens meaning. Although we may never be absolutely certain whether a sense has derived from metaphoric extension or literal generalization, we need to be fairly clear about the distinction between the two. If the concept of domains is taught as one of the criteria for identifying a metaphor, then it should also be useful in explaining this distinction to the students.

In selecting and organizing a vocabulary based on metaphoric extension, we need to begin with a clear idea of what a metaphor is; that is, what the criteria are for identifying a metaphor. Then we need to ask three basic questions about the candidate expressions: (1) Is it possible for a speaker to intend and/or a hearer to construe the expression as a metaphor? If the answer to this question is 'yes', then it must have the potential to express both first-order and second-order meaning. Therefore, (2) what are those meanings, and how is the second-order meaning a function of the first-order meaning? We are not looking for novel metaphors, but expressions that probably have been used as novel metaphors and are now normally used without intending them as metaphors. Therefore, (3) in normal conversation, is 
there any degree to which the speaker and the hearer disregard the first-order meaning in favor of the second-order meaning? In answering these and related questions, we are taking the intuition that native speakers have about these expressions and putting it into objective terms for the ESL student. The bottom line is, it is not sufficient merely to label these expressions as 'dead metaphors'.

\section{A Metaphor for Metaphoric Extension}

Kittay (1987) draws an analogy between metaphoric use of language and archaeology.

Language, similarly, has an archaeological, layered quality...there is language that we now understand as literal but whose origins are metaphorical, whose meaning still carries some of the import of its metaphorical beginnings. The originating metaphorical sense has not been destroyed. Instead it subsists in the new sense just as the ruins of former cities persist in the foundations of the new city. (p. 21)

However, the patterns of metaphoric extension suggest an alternative metaphor: the bushes and branching metaphor used by S. J. Gould (1987b; 1988) to represent his view of evolution.

Evolution, at least at geological scales, is fundamentally about bushes and branching. Modern Homo sapiens and the extinct Neanderthals are two distinct branches, two contemporaneous species for most of their existence... Evolutionary trends... arise within a forest of distinct branches. Most of these branches die; a few are successful and produce more branches like themselves to fuel the transition. Neanderthals became extinct; Homo sapiens survived. (1988, p. 21)

An expression may be used metaphorically, and if it continues to express intended meaning, the metaphorical sense becomes established as either a conventional sense or a new literal and conventional sense; a new 'branch' has grown. If it is a new literal and conventional sense, it can be used metaphorically, which in turn can branch out to another new sense, and so on. Of course, not every metaphoric use becomes established in the lexicon, and some new senses also 'die out'. In some cases, such as aftermath and harrowing, the main trunk--the original literal meaning--dies out 
except where the metaphoric senses have branched out. But often the main trunk survives and grows more branches; that is, the literal meaning may become generalized and therefore used in more contexts, which may give rise to new metaphors. The bushes and branching metaphor is not exactly parallel to the process of metaphoric extension in all respects, but at least it may remind us that the senses established by that process are not dead and buried. 


\section{NOTES}

${ }^{1}$ We cannot say with absolute certainty that any sense has become obsolete. There is always the possibility that someone, speaking some dialect of English, uses clue to refer to a ball of yarn or thread.

2 This idea seems to be supported by current pragmatic theory regarding 'processing effort'. For example, Sperber and Wilson (1988) state that "processing effort is a negative factor: other things being equal, the greater the processing effort, the lower the relevance" (p. 124).

${ }^{3}$ A more accurate term would be prior because we can never know with certainty the first meaning of any word. However, I am using original in this sense: "That from which anything arises, springs, or is derived; source" (OED).

${ }^{4}$ The aspects of meaning I am calling features could be identified as connotations, implications, or semantic features; others might be categorized according to Nunberg's (1978) referring functions, such as 'type of', 'source of', 'location of', 'part of', etc. My use of features follows Pyles and Algeo (1982), and my intention is to avoid lengthy justifications of alternative terms.

${ }^{5}$ The distinction between metaphoric extension and specialization seems to be clearer. Perhaps this is because metaphor involves the reduction of features. For example, if there is any kind of semantic 'transfer' in the man is a wolf, it involves only one small aspect of wolf; namely, certain wolf behavior, and only wolf behavior in an abstract sense. Therefore, the scope of the meaning of wolf is broadened to include reference to man. I cannot think of a metaphor that narrows the meaning of the word used metaphorically. 


\section{CHAPTER IV}

\section{IMPLICATIONS FOR TEACHING}

Chapter I argued that there is a need to teach some vocabulary directly and reviewed some of the recent research striving to identify central patterns of word usage. It also introduced the idea that one of those central patterns is metaphoric extension and proposed that, therefore, the so-called 'dead' metaphors produced by that process are candidates for direct teaching. Chapter II attempted to develop a clearer understanding of what metaphor is in order to help the teacher explain metaphor to ESL students in more precise terms than those in which standard definitions are stated. This explanation of metaphor can also serve as the basis for describing the process of metaphoric extension in a way that facilitates the selection, organization, and teaching of a vocabulary based on that process, which was the objective of Chapter III. In describing metaphoric extension, it was necessary to develop a plausible explanation of how a novel metaphor becomes established in the lexicon as that expression known as a dead metaphor.

If the ideas presented herein are found to have some merit, the next step is to select and organize the vocabulary. However, that involves projects that lie beyond the scope of this paper. In preparation for that work, this paper concludes with two brief guidelines for the teacher: (1) suggestions on explaining metaphor in the classroom; (2) ideas on selecting and organizing vocabulary items. 


\section{EXPLAINING METAPHOR IN THE CLASSROOM}

Fortunately, the definitions of metaphor available to ESL students are sufficiently vague to allow for a supplementary, more precise explanation. ${ }^{1}$ This can be accomplished by discussing metaphor in terms of the main features identified in Chapter II: comparison; substitution; an 'as-if' quality; two referents in different domains; first-order/second-order meaning; and encompassing all of these, a duality of sense. In order to augment standard definitions, the following points need to be emphasized.

The first point is that, indeed, a metaphor does make an implicit comparison of two unlike things, but it does not imply that these two things are in fact similar. The comparison that a metaphor makes expresses the idea that two substantially different things may be seen as if they were similar. A typical example the students are probably familiar with is My love is a rose, and here it should be clear that a person and a flower can only be similar in some metaphorical way.

Second, although a metaphor does seem to imply a comparison rather than state it directly, the standard method of contrasting a metaphor with a simile is an inadequate explanation. Most definitions of metaphor claim the only difference between the two is that a simile uses a term such as like or as, while a metaphor does not. However, the mere omission of like or as does not necessarily make a simile into a metaphor, and vice versa. I can compare a dahlia to a rose by saying The dahlia is like a rose, but if I say The dahlia is a rose, I have not created a metaphor; I have only uttered an absurdity. In contrast, I can compare my wife to a rose with 
My love is like a rose, and the comparison is still a metaphor because a woman is not like a rose in any way except metaphorically. The comparison in a simile may be either literal or metaphorical. A literal simile can express how two things are in fact similar, but a metaphor can never do so.

Furthermore, the comparison in a metaphor can be relatively explicit, as in Patterson was a gamecock, moderate in height, wiry in build, jittery in movement and irascible in expression. This metaphor demonstrates that no matter how a metaphor is elaborated upon, it still expresses a metaphorical comparison. Therefore, it is more important to focus on how metaphor makes a metaphorical comparison than on formal aspects.

One formal aspect that is sometimes included in definitions of metaphor is the idea that metaphor makes a substitution. The Patterson metaphor suggests that this is not always the case. The term used metaphorically, a gamecock, is not put in place of anything else; rather, it is combined with all the adjective phrases in the subject complement. On the other hand, the entire subject complement could be regarded as a figurative phrase that is used instead of some other literal phrase describing Patterson. Therefore, if the teacher is trying to augment a definition that regards metaphor as a substitution, it would be safe to say that, in general, metaphor substitutes a figurative phrase for a literal phrase.

As might be inferred from the conclusions in Chapter II, focusing on the pragmatic aspects of metaphor could help explain what is meant by 'figurative phrase' and 'metaphorical comparison'. It needs to be stressed that metaphor is a particular 
use of language that depends upon not only contextual factors, speaker/hearer background, etc., but also a tacit agreement between speaker and hearer to accept the 'as-if' conditions. That is, the speaker is asking the hearer to see two substantially different things as if they were similar, all the while knowing that they are not in fact similar. Without this agreement, the utterance could be interpreted as a lie, a mistake expressing mere ambiguity, an absurdity, etc. Therefore, whether or not the intended metaphorical comparison is communicated depends crucially on the mutual acceptance of the 'as-if' conditions.

This is the basis of the duality of sense in metaphor, for it is only within the 'as-if' conditions that a word or phrase can refer meaningfully to two substantially different things. In effect, the expression used metaphorically is temporarily given an additional referent as well as an additional sense. One concrete way of explaining this is to use the concept of domains, which could be presented as a domain of use, a domain of reference, a conceptual field, a semantic field, or some other broad concept. Regardless of the terms used, the concept can serve as a litmus test for identifying a metaphor. For example, The dahlia is a rose cannot be a metaphor because both terms belong to the domain of (perhaps) FLOWERS; they are, in fact, quite similar. In contrast, rose and its referent belong to FLOWERS, while my love and its referent belong to the HUMAN domain.

One way to explain the additional sense is to regard it as 'second-order meaning', which is a function of the first-order meaning. There is a duality of sense in a metaphor not only because there are two different referents, but also because the 
speaker and the hearer attend equally to both the first-order meaning and the secondorder meaning. Explaining the duality of sense in terms of first-order/second-order meaning may be more effective than standing at a chalkboard and drawing an arc from the 'vehicle' to the 'tenor' in an effort to illustrate the vague idea that meaning is 'carried over'.

In doing so, the teacher will probably have to contend with the terms tenor (or topic), vehicle, ground and tension because they are used in most standard explications of metaphor. The tenor is simply what the metaphor is about--the subject or topic of the metaphor; e.g., my love. The vehicle is the word or phrase used metaphorically; e.g., rose. The vehicle is so-called because it 'carries' the metaphorical meaning; the term reflects the traditional idea that there is a 'transfer' of meaning. With a little re-interpretation, ground can be understood as referring to the 'as-if' similarity which the speaker and hearer agree to see, and tension can be understood as referring to their awareness that the two terms of the metaphor are not actually similar. However, it is not necessary to use these labels if metaphor is explained in terms of first-order/second-order meaning, two referents in two distinct domains, and the necessity of a pragmatic agreement to see one thing as if it were similar to another.

Focusing on the pragmatic aspects of metaphor can also help ESL students understand why an expression that could be recognized and construed as a metaphor is used in everyday conversation apparently without the speakers intending to express a metaphorical comparison. This is a problem for students of any foreign language. 
A simple explanation could be that an expression that at one time was intentionally used to express a metaphorical comparison is now intentionally used by the majority of speakers to express a relatively conventional or even literal sense. This explanation could be reinforced with diagrams as well as the description of metaphoric extension as a process in which speakers, for communicative purposes, may disregard the first-order meaning in favor of the second-order meaning. If the students understand the process, then it should be easier for them to comprehend, for example, why so many things can be jump-started, such as a career, a job, a political campaign, the Soviet economy; why so many things can be regarded as a shuttle or a bottom line; why so many things can be mainstream, fringe, held hostage, shuttled, leveraged, or bailed out. In other words, understanding metaphoric extension as a process can serve not only as an etymological framework for relating the metaphorically-derived senses of an expression, but also as a guide in learning many expressions that have (or are gaining) currency in contemporary English. Consequently, understanding the process of metaphoric extension can serve as a springboard for developing strategies for both teaching and learning vocabulary.

\section{SELECTING AND ORGANIZING THE VOCABULARY}

For teaching purposes, the main advantage of identifying a central pattern of word usage is that it breaks down the total lexicon into smaller, more manageable units. Consequently, it can help simplify an otherwise overwhelming task. Therefore, two guidelines should be followed in developing a vocabulary based on 
metaphoric extension. First, the scope of words to be selected must be controlled. Second, both the sets of words and the sets of senses related to each word must be organized in as simple a manner as possible.

The project would be far too broad and cumbersome if it included all words with senses that have been metaphorically derived. It would be filled with scores of words such as complicated, comprehend, spirit, skull, manage, and courage. To narrow the list down, the first determining factor could be whether an original literal meaning is still in use. Therefore, most of the vocabulary would consist of stock metaphors. It would exclude genuinely dead metaphors such as clue, aftermath, and complicated. On the other hand, some of these metaphors could be included in the list of words associated with a selected vocabulary item. For example, if grasp is selected, then comprehend should probably be listed along with take in and catch; and courage may be included as associated with core. Also, sometimes it will be necessary to explain an expression by recalling the metaphoric origin of an associated word; for example, to thread one's way through the plot (of a story) is probably derived from the metaphoric use of clue (OED).

The scope of the vocabulary may also be controlled by the goals of the course. For example, an ESP course addressing the needs of students of manufacturing management might require expressions such as tramp metal, memory (plastic), fatigue (metal), and to cannibalize parts. In a notional-functional approach, a lesson focusing on shopping may include browse, scour, dig, and cornered (by a salesperson). If cross-cultural factors are stressed, then dead metaphors that reflect the U.S. culture 
could be selected and compared with those of other cultures. For example, in the U.S. the value of individuality may be seen in the description of a relationship as closely-knit; i.e., two individuals coming together. In contrast, Malays describe a close relationship by "a phrase...[referring to] the pinan (a perfectly round fruit) halved" (Deetz 1984, p. 224).

Approaches to teaching other vocabulary may also be used to limit the selection of stock/dead metaphors. As pointed out in Chapter I, stock/dead metaphors are represented in other central patterns of word usage, such as lexical phrases, core words, and semantic fields. Incorporating stock/dead metaphors into these sets not only helps selection decisions, but also provides a method of organization.

Despite its theoretical weaknesses, a semantic field approach can easily accomodate stock/dead metaphors; for example:

\section{architecture/construction}

architecture, box in, bridge, build, bulldoze, ceiling, construct, construction, to corner, deck, demolish, floor, foundation, framework, overarching, scaffolding, span, stack up, stonewall, structure, threshhold, wall, window

body (human)

back, body, brow, butt, eye, face, finger, flesh out, foot, footing, foothold, hand, head, heading, headland, headline, headquarters, head-on, heart, joint, leg, nose, nosedive, rib, shoulder, teeth, tongue, toe

\section{clothing and related materials}

belt out, bonnet, bootstrap, clothe, clue, collar, fabric, fabricate, fringe, hood, skirt, strand, sew up, stitch (together), tear, thread, unravel, weave, yarn

The advantage of this approach is that it provides a communicative purpose for the organization. 
The advantage of this approach is that it provides a communicative purpose for the organization.

With stock/dead metaphors, we also need to organize the the senses established by metaphoric extension as well as other expressions that are related to those senses. Furthermore, since the metaphorical sense of an expression is a function of a prior literal and conventional sense, the metaphorically-derived senses need to be related to the literal senses. For example, spark (n.) has two literal senses (or two features of a single literal sense): (1) a small, glowing particle discharged from a fire, an electric arc, a spark-plug, etc.; (2) the brief flash of light accompanying such a discharge. The verb spark means (1) to cause such a discharge and consequently produce flashes of light; and (2) to ignite a fire by discharging sparks. These senses have been extended metaphorically: a spark of interest/life/ vitality/enthusiasm; to spark public interest/a debate/a furor/an outcry/a battle. Furthermore, we can not only spark a debate, but also kindle, ignite or touch off a debate; if there can be a spark of interest, there can also be a particle or a trace of interest. Similarly, a related word, sparkle, has also been extended metaphorically, as in sparkling personality, which can also be described as glowing, glittering and brilliant.

The following examples suggest some ways in which related senses and related expressions can be organized. In each case, there are four basic parts. First, the literal sense is stated without going into too much detail. Second, the general sense established by metaphoric extension is presented. Third, examples of the 
metaphorical sense are given (whether stock or dead), using as many parts of speech as possible. Fourth, other expressions are related to the metaphorical sense.

\section{skyrocket}

Literal sense (n.): a fireworks rocket that explodes in mid-air.

Metaphorical sense (v.):

to rise suddenly, resulting in a sudden and significant impact, as if similar to a skyrocket

Examples:

The Dow Jones average skyrocketed today.

The price of oranges has skyrocketed since the freeze.

Skyrocketing costs have forced an increase in tuition.

Related expressions:

Fuel prices are astronomical.

The price of oranges has soared.

Operating costs this month are sky-high.

Related idioms:

to go through the roof (referring to costs or prices)

to be out-of-this-world (referring to costs or prices)

flow

Literal sense (v.): to move as a liquid does, particularly a stream or river.

feature (1): to move smoothly, incessantly

feature (2): to pour forth suddenly, strongly

Literal sense (n.): the movement of liquid 
Metaphorical sense:

to move as if similar to the way liquid does, particularly as a river moves, either (a) smoothly, gently, and easily, or (b) suddenly pouring out.

By metaphoric extension, these things flow:

speech, writing style, music

thoughts, ideas, feelings

air, electricity, electrons, light, sound

groups: people, animals, insects

money, goods, products, traffic

Related words:

nouns: current, fluidity, outpouring, stream, trickle, influence, confluence, effluence

verbs: pour out/forth, flood, inundate, stream out/forth, swamp, trickle

adjectives: fluent, fluid, flowing, streaming, flooding, trickling

Examples:

He is respected for his fluid speech.

She is fluent in three languages.

There was an outpouring of sympathy for them.

I'm swamped with work.

The police department was flooded (or inundated) with calls.

The audience gave out a steady stream of hisses and boos.

The stream of people on the street slowed to a trickle.

electric current

the flow of electrons

foot (n.)

Literal sense: the end part of a leg, on which a person or animal stands or moves.

Core sense established by metaphoric use: lowest part of anything 
Examples:

foot of a mountain

foot of a bed/sofa

foot of a page/a column of figures

foot of a line (of people)

\section{$\underline{\text { Idioms }}$}

to foot the bill: add up the figures on a meal ticket in preparation to pay; hence, to pay the bill.

Idioms not associated with the metaphoric sense:

to hot-foot it (from or to someplace): to move quickly

to put one's best foot forward: to make a favorable appearance

to put one's foot in it (or in one's mouth): to commit an embarrassing blunder.

to be underfoot: to interfere

to have one foot in the grave: to be near death

\section{bottom line}

Literal meaning (n.):

the last line on a financial statement showing the net profit or loss of a business.

Core sense established by metaphoric use:

That which is left after everything that can be added in is added in, and everything that can be taken out is taken out.

Synonymous expressions:

net/net result

upshot

basic/fundamental issue

gist/ the gist of it

crux/ the crux of the matter

heart

truth "

main idea/issue/problem, etc 
most important point

most significant factor

conclusion

final result

last offer

the long-and-the-short-of-it

the nitty gritty

real issue

central issue

in the final analysis

last word

What this all boils down to...

What I'm trying to say...

What I'm really saying...

\section{Related uses of bottom:}

bottom out

rock bottom

at bottom

bottom dollar

hit bottom

scraping the bottom of the barrel

\section{Examples:}

The bottom line is that they broke up.

The bottom line is diversity and sustainability of wild trout habitat.

Bottom line: do you think we should bring an NFL team here?

The bottom line of what I'm saying is that we shouldn't let it [the Iraq conflict] get like Vietnam.

You need to know this when you enter a negotiation: what is your bottom line, or what is the next best thing you will accept.

Somewhere we have failed--that's the bottom line.

He [Sadam Hussein] will not be allowed to stay in power [since he has attacked Israel]...that's the bottom line.

Blood's thicker than water--that's the bottom line.

These examples are only rough ideas, and more thorough analysis

accompanied by empirical research should be able to devise more appropriate formats. 
Any format will have to be flexible, open-ended, and supportive of other teaching goals.

Prior to studying any such set of words, of course, the student must understand that native speakers of English use these expressions as stock metaphors or dead metaphors in normal conversation. That is, they are used to express either a conventional or a literal and conventional sense even though the speakers may be aware that at one time they were used as novel metaphors. Therefore, it is important to teach not just the words and their senses, but also the process of metaphoric extension. 


\section{NOTES}

${ }^{1}$ Some typical examples are:

A metaphor acts like an equal sign: it implies a comparison by omitting like or as. (Tucker and Costello 1985, p. 170)

A simile makes an explicit comparison between essentially unlike things, introduced by a connective...If the speaker omits "like," or "as," or "than," making the literally impossible assertion "My heart is a singing bird," he uses a metaphor" (Barnet, et. al. 1960, p. 42).

A figure of speech containing an implied comparison, in which a word or phrase ordinarily and primarily used of one thing is applied to another. (Webster's New World Dictionary, Second College Edition 1984)

Metaphor, figure of speech that implies comparison between two unlike entities, as distinguished from simile, an explicit comparison signalled by the words "like" or "as." (Encyclopedia Britannica, 15th Edition 1988)

Metaphor: an implied comparison between two dissimilar things--an analogy that imaginatively identifies one object with another and either ascribes to the first qualities of the second or invests the first with connotations inherent in the other. The metaphor is the fundamental poetic figure of speech. (Encyclopedia Americana, International Edition 1989) 


\section{WORKS CITED}

Anderson, R. (1985). Learning Words From Context. Reading Research Quarterly, XX(2), pp. 233-252.

Apter, Michael J. (1982). Metaphor as synergy. In D. Maille (pp. 55-69).

Aristotle (1984). The Complete Works of Aristotle, Volume Two (The Revised Oxford Translation), Jonathan Barnes (Ed.). Princeton: Princeton University Press.

Barnet, S., Berman, M., \& Burto, W. (1960). A Dictionary of Literary Terms. Boston: Little, Brown and Company.

Bernstein, M. (1989). John Patterson rang up success with the incorruptible cash register. Smithsonian 20 (3), pp. 150-154.

Black, M. (1962). Models and Metaphor. Ithaca, New York: Cornell University Press.

Black, M. (1979a). More about metaphor. In A. Ortony (pp. 19-43).

Black, M. (1979b). How metaphors work: a reply to Donald Davidson. In S. Sacks (pp. 181-192).

Blank, G. D. (1988). Metaphors in the lexicon. Metaphor and Symbolic Activity; 3(1), pp. 21-36.

Bolinger, D. \& Sears, D. (1981). Aspects of Meaning. New York: Harcourt, Brace, Jovanovich, Inc.

Booth, W. C. (1979). Metaphor as rhetoric: the problem of evaluation. In S. Sacks (pp. 47-70).

Bréal, M. (1964). Semantics: Studies in the Science of Meaning. (H. Cust, Trans.). New York: Dover Publications. (Original work published 1897.)

Brown, H. D. (1987). Principles of Language Learning and Teaching. Englewood Cliffs, NJ: Prentice-Hall. 
Carter, R. (1986). Core vocabulary and discourse in the curriculum: a question of the subject. RELC Journal, 17(1), pp. 52-70.

Carter, R. (1987a). Is there a core vocabulary? Applied Linguistics, 8(2), pp. 178193.

Carter, R. (1987b). Vocabulary: Applied Linguistic Perspectives. London: Allen \& Unwin.

Carter, R. (1988). Vocabulary, cloze and discourse. In R. Carter and M. McCarthy (pp. 161-180).

Carter, R. \& McCarthy, M. (Eds.) (1988). Vocabulary and Language Teaching. New York: Longman Inc.

Channell, J. (1988). Psycholinguistic considerations in the study of L2 vocabulary acquisition. In R. Carter \& M. McCarthy (pp. 83-96).

Chomsky, N. (1965). Aspects of the Theory of Syntax. Cambridge, MA: MIT Press.

Cole, P. \& Morgan, J. (Eds.) (1975). Syntax and Semantics, Vol. 3: Speech Acts. New York: Academic Press.

Cooper, D. E. (1986). Metaphor. Aristotelian Society Series Volume 5. Oxford: Basil Blackwell.

Cowie, A. P. (1988). Stable and creative aspects of vocabulary use. In R. Carter and M. McCarthy (pp. 126-139).

Croft, K. (Ed.). (1980). Readings in English as a Second Language. Boston: Little, Brown \& Co.

Crow, J. T. \& Quigley, J. R. (1985). A semantic field approach to passive vocabulary acquisition for reading comprehension. TESOL Quarterly, 19(3), pp. 497-514.

Davidson, D. (1979). What metaphors mean. In S. Sacks (pp. 29-45).

Deane, P. D. (1988). Polysemy and cognition. Lingua, 75, pp. 325-361.

Deetz, S. (1984). Metaphor Analysis. in W. Gudykunst and Y. Kim (pp. (pp. 215228).

Empson, W. (1964). The Complex Structure of Words. London: Chatto \& Windus. 
Fisak, J. (Ed.) (1985). Historical Semantics: Historical Word Formation. New York: Mouton Publishers.

Fraser, B. (1979). The interpretation of novel metaphors. In A. Ortony (pp. 172185).

Frye, N. (1967). Anatomy of Criticism, New York: Atheneum Press.

Gairns, R. \& Redman, S. (1986). Working With Words: A Guide to Teaching and Learning Vocabulary. Cambridge: Cambridge University Press.

Godman, Arthur. (1982). Teaching verbs using a hierarchical system. RELC Journal 13(1):37-49.

Gould, S. J. (1987). Bushes all the way down. Natural History, 96(6), pp. 16-21.

Gould, S. J. (1988). A novel notion of Neanderthal. Natural History, 97(6), pp. 1621.

Green, G. M. (1989). Pragmatics and Natural Language Understanding. Hillsdale, New Jersey: Lawrence Erlbaum Associates, Publishers.

Grice, H.P. (1975). Logic and Conversation. In P. Cole \& J. Morgan (pp. 41-58).

Gudykunst, W. and Kim, Y. (Eds.) (1984). Methods for Intercultural Research. Beverly Hills: Sage Publications.

Harris, R. J., Lahey. M. A., \& Marsalek, F. (1980). Metaphors and Images. In R. Honek \& R. Hoffman (pp. 163-181).

Hemingway, E. (1938). The Short Stories of Ernest Hemingway. New York: Charles Scribner's Sons.

Henle, P. (Ed.) (1958). Language, Thought, \& Culture. Ann Arbor: The University of Michigan Press.

Henle, P. (1958). Metaphor. In P. Henle (pp. 173-195).

Hester, M. B. (1967). The Meaning of Poetic Metaphor. The Hague: Mouton \& Co.

Honek, R. \& Hoffman, R. (Eds.). (1980). Cognition and Figurative Language.

Hillsdale, New Jersey: Lawrence Erlbaum and Associates. 
Johnson, M. (1980). A philosophical perspective on the problems of metaphor. In R. P. Honek \& R. R. Hoffman (pp. 47-67).

Johnson, M. (1987). The Body in the Mind. Chicago: The University of Chicago Press.

Johnson, M. G. \& Malgady, R. (1980). Toward a perceptual theory of metaphoric comprehension. In R. P. Honek \& R. R. Hoffman (pp. 259-282).

Katz, J. \& Fodor, J. A. (1963). The structure of a semantic theory. Language, 39, pp. 170-210.

Kittay, E. F. (1987). Metaphor: Its Cognitive Force and Linguistic Structure. Oxford: Clarendon Press.

Lakoff, G. (1986). A Figure of Thought. Metaphor and Symbolic Activity, 1(3), pp. 215-225).

Lakoff, G. (1987a). The death of dead metaphor. Metaphor and Symbolic Activity, 2(2), pp. 143-147.

Lakoff, G. (1987b). Women, Fire, and Dangerous Things: What Categories Reveal About the Mind. Chicago: The University of Chicago Press.

Lakoff, G. \& Johnson, M. (1980a). Conceptual metaphor in everyday language. The Journal of Philosophy, 77(8), pp. 453-486.

Lakoff, G. \& Johnson, M. (1980b). Metaphors We Live By. Chicago: University of Chicago Press.

Laufer, Batia. (1986). Possible changes in attitude towards vocabulary acquisition research. International Review of Applied Linguistics, 24(1), pp. 69-75.

Leech, G. (1974). Semantics. Harmondsworth, England: Penguin.

Lehrer, A. (1974). Semantic Fields and Lexical Structure. Amsterdam/London: North-Holland Publishing Company.

Lehrer, A. (1978). Structures of the lexicon and transfer of meaning. Lingua, 45, pp. 95-123.

Lehrer, A. (1983). Wine and Conversation. Bloomington: Indiana University Press. 
Lehrer, A. (1985). The influence of semantic fields on semantic change. In J. Fisak (pp.283-296).

Levin, S. (1979). Standard approaches to metaphor and a proposal for literary metaphor. In A. Ortony (pp. 124-135).

Levin, S. (1988). Metaphoric Worlds: Conceptions of a Romantic Nature. New Haven: Yale University Press.

Levinson, S. (1983). Pragmatics. Cambridge, England: Cambridge University Press.

Lowenberg, I. (1975). Identifying metaphors. Foundations of Language, 12, pp. 315-338.

Lyons, J. (1977). Semantics (Vols. 1-2). Cambridge: Cambridge University Press.

Lyons, J. (1981). Language, Meaning and Context. Bungay, England: Fontana Paperbacks.

Maille, D. (Ed.) (1982). Metaphor: Problems and Perspectives. Atlantic Heights, New Jersey: The Harvester Press Limited.

Martin, A. (1976). Teaching academic vocabulary to foreign graduate students. TESOL Quarterly, 10(1), pp. 91-97.

Matthews, R. (1971). Concerning a linguistic theory of language. Foundations of Language, 7, pp. 413-425.

McCarthy, M. (1988). Some vocabulary patterns in conversation. In R. Carter \& M. McCarthy (pp. 181-200).

McKay, S. L. (1980). Developing vocabulary materials with a computer corpus. RELC Journal, 11(1), pp. 77-87.

Meara, P. (1980). Vocabulary: a neglected aspect of language learning. Language Teaching and Linguistics Abstracts, 13(4), pp. 221-246.

Miller, G. (1979). Images and models, similes and metaphors. In A. Ortony (pp. 202-250).

Mitchell, T. (1971). Linguistic 'goings on': collocations and other lexical matters arising on the syntagmatic record. Archivum Linguisticum, II, pp. 35-69. 
Moore, F. (1982). On taking metaphors literally. In D. S. Maille (Ed.) (pp. 1-13).

Morgan, J. (1979). Observations on the pragmatics of metaphor. In A. Ortony (pp. 136-147).

Müller, M. (1874). Lectures on the Science of Language. New York: Scribner, Armstrong, and Co.

Nation, I. (1980). Strategies for receptive vocabulary learning. RELC Journal Supplement: Guidelines for Vocabulary Teaching, 3, pp. 18-23.

Nation, I. (1982). Beginning to learn a foreign vocabulary: a review of the research. RELC Journal, 13(1), pp. 14-36.

Nation, I. and Coady, J. (1988). Vocabulary and reading. In R. Carter \& M. McCarthy (pp. 97-110).

Nattinger, J. (1986). Lexical phrases, functions and vocabulary acquisition. The ORTESOL Journal, 7, pp. 1-14.

Nattinger, J. (1988). Some current trends in vocabulary teaching. In R. Carter \& M. McCarthy (pp. 62-82).

Nattinger, J. and DeCarrico, J. (1988). Lexical phrases for the comprehension of academic lectures. English for Specific Purposes, 7, pp. 91-102.

Newmeyer, F. (1986). Linguistic Theory in America. Orlando: Academic Press.

Nilson, D. (1976). Contrastive semantics in vocabulary instruction. TESOL Quarterly, 10(1), pp. 99-103.

Nunberg, G. (1978). The Pragmatics of Reference. Bloomington: Indiana University Linguistics Club.

Ogden, C. K. (1934). The System of Basic English. New York: Harcourt, Brace and Company.

Ortony, A. (1975a). Why metaphors are necessary and not just nice. Educational Theory, 25(1), pp. 45-53.

Ortony, A. (1975b). On the nature and value of metaphor: a reply to my critics. Educational Theory, 26(4), pp. 395-398. 
Ortony, A. (1979b). Metaphor: a multidimensional problem. In A. Ortony (pp. 116).

Ortony, A. (1979c). The role of similarity in similes and metaphors. In A. Ortony (pp. 186-201).

Ortony, A. (1980a). Some psycholinguistic aspects of metaphor. In R. P. Honek \& R.R. Hoffman (pp. 69-83).

Ortony, A. (1980b). Metaphor. In R. Spiro, et. al. (pp. 349-365).

Ortony, A., Reynolds, R. E., and Arter, J. A. (1978). Metaphor: theoretical and empirical research. Psychological Bulletin, 85(5), pp. 919-943.

Ortony, A., Vondruska, R. J., Foss, M. A. and Jones, L. E. (1985). Salience, similes, and the asymmetry of similarity. Journal of Memory and Language, 24, pp. 569-594.

The Oxford English Dictionary. (1989). (2nd Edition). Oxford: Oxford University Press.

Perrine, L. (1971). Four forms of metaphor. College English, 33(2), pp. 125-138.

Peters, A. (1983). The Units of Language Acquisition. Cambtidge: Cambridge University Press.

Pyles, T. and Algeo, J. (1982). The Origins and Development of the English Language. New York: Harcourt Brace Jovanovich, Publishers.

Quine, W. V. (1979). Afterthoughts on metaphor. In S. Sacks (pp. 159-160).

Read, J. (1988). Measuring the Vocabulary Knowledge of Second Language Learners. RELC Journal, 19(2), pp. 12-25.

Richards, I. A. (1936). The Philosophy of Rhetoric. New York: Oxford University Press.

Richards, I. A. (1943). Basic English and Its Uses. New York: W. W. Norton \& Company, Inc.

Richards, J. (1974). Word lists: problems and prospects. RELC Journal, V(2), pp. 69-84. 
Richards, J. (1976). The role of vocabulary teaching. TESOL Quarterly, 10(1), pp. 77-89.

Ricoeur, P. (1979). The metaphoric process as cognition, imagination, and feeling. In S. Sacks (pp. 141-157).

Reichmann, P. and Coste, E. (1980). Mental imagery and the comnprehension of figurative language: is there a relationship? In R. P. Honek \& R. R. Hoffmann (pp. 183-200).

Rivers, W. (1972). Speaking in Many Tongues. New York: Cambridge University Press.

Rudzka, B. , Channell, J., Ostyn, O. and Putseys, Y. (1981). The Words You Need. New York: Macmillan Publishing Company.

Rudzka, B. , Channell, J., Ostyn, O. and Putseys, Y. (1985). More Words You Need. New York: Macmillan Publishing Company.Nagy, W., Herman, P. and

Rummelhart, D. (1979). Some problems with the notion of literal meanings. In A. Ortony (pp. 78-90).

Sacks, S. (Ed.) (1979). On Metaphor. Chicago: The University of Chicago Press.

Savignon, S. (1983). Communicative Competence: Theory and Classroom Practice. Reading, MA: Addison-Wesley.

Schön, D. (1979). Generative metaphor: a perspective on problem-setting in social policy. In A. Ortony (pp. 254-283).

Searle, J. R. (1979). Metaphor. In A. Ortony (pp. 92-123).

Shibles, W. (1971a). An Analysis of Metaphor in the Light of W. M. Urban's Theories. The Hague: Mouton \& Co.

Sinclair, J. and Renouf, A. (1988). A lexical syllabus for language learning. In R. Carter \& M. McArthy (pp. 140-160).

Sperber, D. and Wilsom, D. (1988). Relevance: Communication and Cognition. Cambridge, Mass.: Harvard University Press.

Spiro, R., Bruce, B., and Brewer, W. (1980). Theoretical Issues in Reading Comprehension. Hillsdale, N. J.: Lawrence Erlbaum Associates. 
Stern, G. (1931). Meaning and Change of Meaning with Special Reference to the English Language. Göteborg: Elanders Boktryckeri Aktiebolag.

Strevens, P. (1982). English for special purposes, In K. Croft (pp. 459-472).

Summers, D. (1988). The role of dictionaries in language learning. In R. Carter \& \& M. McCarthy (pp. 111-125).

Tourangeau, R. (1982). Metaphor and cognitive structure. In D. S. Maille (pp. 1435).

Tourangeau, R. \& Sternberg, R. (1982). Understanding and appreciating metaphors. Cognition, 11, pp. 203-244.

Tucker, A. and Costello, J. (1985). The Random House Writing Course for ESL Students. New York: Random House.

Tulving, E. (1985). How many memory systems are there? American Psychologist, 40(4), pp. 385-398.

Turbayne, C. M. (1962). The Myth of Metaphor. New Haven: Yale University Press.

Twaddell, F. (1980). Vocabulary expansion in the TESOL classroom. In K. Croft (pp. 439-457).

Verbrugge, R. (1980). Transformations of Knowing: A Realist View of Metaphor. In Honek, R. P. \& Hoffman, R. R. (Eds.), pp. 87-124.

Waggoner, J. (1990). Interaction theories of metaphor: psychological perspectives. Metaphor and Symbolic Activity, 5(2), pp. 91-108.

Wallace, M. (1982). Teaching Vocabulary. London: Heinemman Educational Books.

Waldron, R. (1967). Sense and Sense Development. London: Andre Deutsch.

Webster's New World Dictionary of the American Language: Second College Edition . (1984). New York: New World Dictionaries/Simon and Schuster.

White, E. B. (1944). "Once More to the Lake." One Man's Meat. (pp. 246-253). New York: Harper \& Brothers Publishers.

Widdowson, H. (1978). Teaching Language as Communication. Oxford: Oxford University Press. 
Widdowson, H. (1979). Explorations in Applied Linguistics. Oxford: Oxford University Press.

Widdowson, H. (1983). Learning Purpose and Language Use. Oxford: Oxford University Press.

Wilkins, D. (1976). Notional Syllabuses. Oxford, England: Oxford University Press.

Yorio, C. (1980). Conventionalized language forms and the development of communicative competence. TESOL Quarterly, 14, pp. 433-442. 